\title{
Constraints to human capital investment in developing countries : using the Asian financial crisis in Indonesia as a natural experiment
}

Citation for published version (APA):

Wu, T. (2011). Constraints to human capital investment in developing countries : using the Asian financial crisis in Indonesia as a natural experiment. [Doctoral Thesis, Maastricht University]. Uitgeverij Boekenplan. https://doi.org/10.26481/dis.20110126tw

Document status and date:

Published: 01/01/2011

DOI:

10.26481/dis.20110126tw

Document Version:

Publisher's PDF, also known as Version of record

Please check the document version of this publication:

- A submitted manuscript is the version of the article upon submission and before peer-review. There can be important differences between the submitted version and the official published version of record.

People interested in the research are advised to contact the author for the final version of the publication, or visit the DOI to the publisher's website.

- The final author version and the galley proof are versions of the publication after peer review.

- The final published version features the final layout of the paper including the volume, issue and page numbers.

Link to publication

\footnotetext{
General rights rights.

- You may freely distribute the URL identifying the publication in the public portal. please follow below link for the End User Agreement:

www.umlib.nl/taverne-license

Take down policy

If you believe that this document breaches copyright please contact us at:

repository@maastrichtuniversity.nl

providing details and we will investigate your claim.
}

Copyright and moral rights for the publications made accessible in the public portal are retained by the authors and/or other copyright owners and it is a condition of accessing publications that users recognise and abide by the legal requirements associated with these

- Users may download and print one copy of any publication from the public portal for the purpose of private study or research.

- You may not further distribute the material or use it for any profit-making activity or commercial gain

If the publication is distributed under the terms of Article $25 \mathrm{fa}$ of the Dutch Copyright Act, indicated by the "Taverne" license above, 
Constraints to Human Capital Investment in Developing Countries: Using the Asian Financial Crisis in Indonesia as a Natural Experiment

\section{Dissertation}

to obtain the degree of Doctor at Maastricht University, on the authority of Rector Magnificus, Prof. mr. G.P.M.F. Mols, in accordance with the decision of the Board of Deans, to be defended in public on Wednesday, 26 January 2011, at 10:00h.

\section{By}

Treena $\mathrm{Wu}$ 
Supervisors

Prof. dr. L. Borghans

Dr. A. Dupuy

\section{Committee}

Prof. dr. A. De Grip (Chairman)

Prof. dr. A. Bedi (Erasmus University Rotterdam)

Prof. dr. N. Datta-Gupta (Aarhus University, Denmark)

Dr. B. Golsteyn

Prof. dr. D. Hamermesh 


\section{Acknowledgements}

Throughout the course of this dissertation, Lex Borghans has provided invaluable support. He has generously shared with me his brilliant, logical way of thinking on how to approach the world using economic science. He has been very generous with his time having many insightful conversations with me as I went through each step of the PhD. I will always be grateful for this. I would also like to thank Arnaud Dupuy for his very useful guidance and support as I wrote each paper.

Several people have given their views on the ideas in this dissertation and how to improve on them as contributions to the literature. Those who merit special attention are Edward (Ted) Miguel, Nabanita Datta-Gupta, Daniel Hamermesh, Adam (Eddy) Szirmai and Eric Edmonds. In this respect, I also thank the members of the assessment committee.

A person who stands out for me academically and personally is Rebecca Blank. I first met her when she was visiting at Maastricht University. Since then, she has become my mentor where she has read my research; she advises me on career choices; and more importantly she inspires me to make sound linkages between research in economics and public policy. Because of her, I remain committed to public service.

I would like to thank the school of governance for providing me with generous European Commission Marie Curie funding to write this dissertation and to travel to various conferences to present my papers. I appreciate the intellectual support provided by Henk Schulte Nordholt, Roger Tol and Rosemarijn Hoefte of KITLV / Royal Netherlands Institute of Southeast Asian and Caribbean Studies in order for me to better appreciate the different aspects of Indonesian life then and now. I would also like to thank David Levine and Edward Miguel for inviting me to stay at the Department of Economics, UC Berkeley in the last phase of completing my dissertation. In addition, I would like to acknowledge the RAND Corporation and Kathleen Beegle for assistance with the Indonesia Family Life Surveys data. Appreciation goes out to Sander Dijksman, Lex Borghans and Jan Sauermann for summarizing this dissertation in Dutch and for proofreading.

During the process of writing the dissertation, I appreciate the support and wonderful company of Henry Espinoza Pena, Marina Petrovic, Bart Golsteyn, Jan Sauermann, Sander Dijksman, Silvana de Sanctis, Celine Duijsens-Rondagh and Susan Roggen.

Finally and most importantly, I am eternally grateful to my husband Ron for always listening to me about my research and discussing with me all new ideas and endless possibilities during the $\mathrm{PhD}$ and now for my Post-Doctoral research agenda. He moves with me not just between countries but between continents for research and he's always with me through thick and thin. I wouldn't have been able to start and complete this journey for the PhD without him.

Singapore

December 2010

Treena $\mathrm{Wu}$ 


\section{Table of Contents}

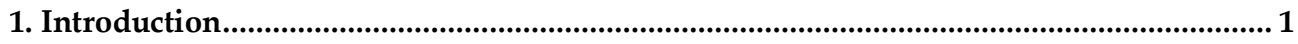

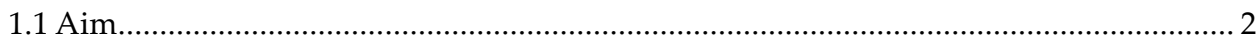

1.2 Human Capital Accumulation, School Resources, Outputs and Outcomes ................... 5

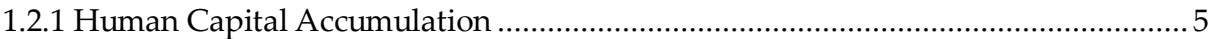

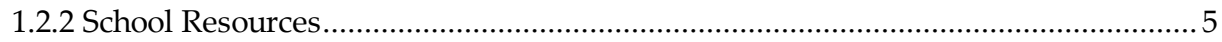

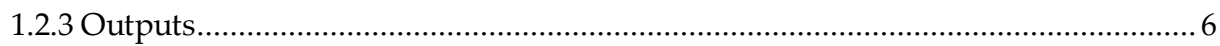

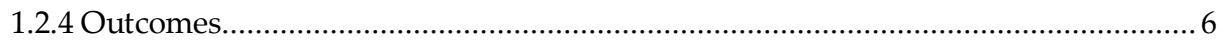

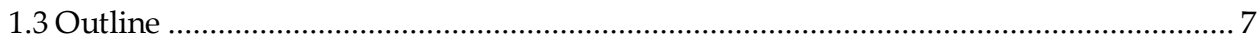

1.3.1 Family Educational Spending when Income Falls ............................................ 8

1.3.2 Electricity Access, Use and Children's Educational Performance ............................ 8

1.3.3 Family Income, Simultaneous Work-Schooling and Human Capital ...................... 9

1.3.4 Dynamic Complementarity of Investment in Education ....................................... 9

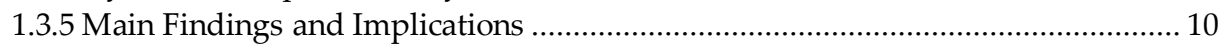

2. Family Educational Spending when Income Falls ...................................................... 11

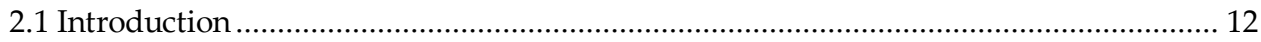

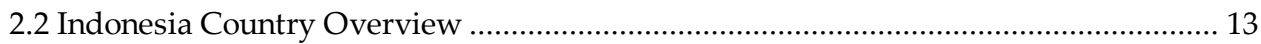

2.3 Institutional Context - Asian Financial Crisis and National Educational System ........ 14

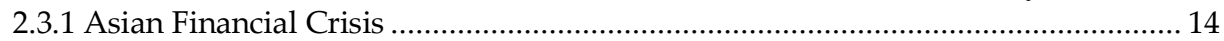

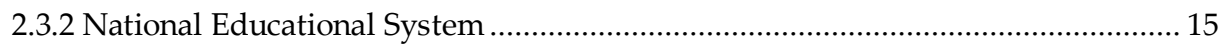

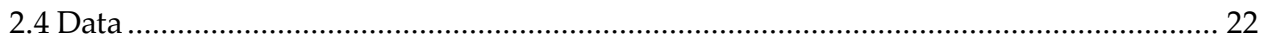

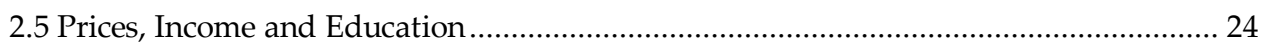

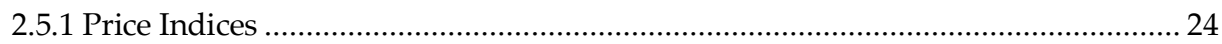

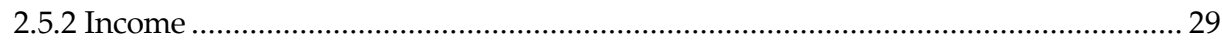

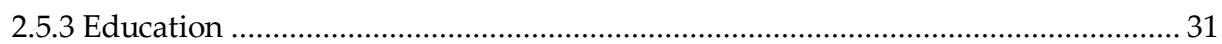

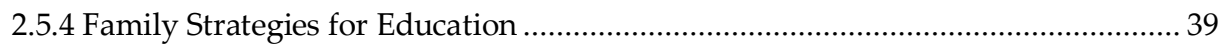

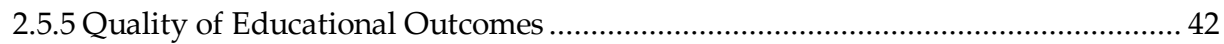

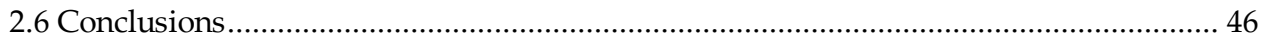

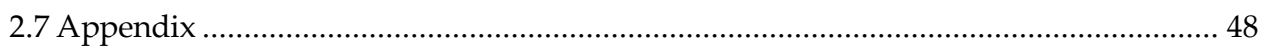

3. Electricity Access, Use and Children's Educational Performance ..................................... 49

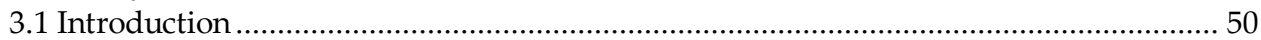

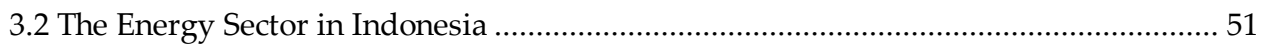

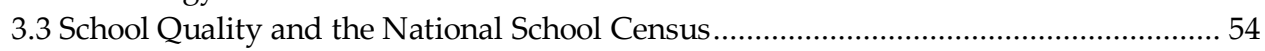

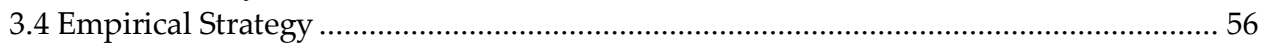

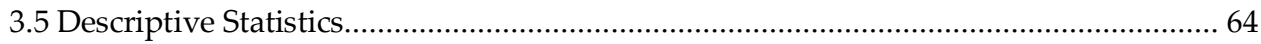

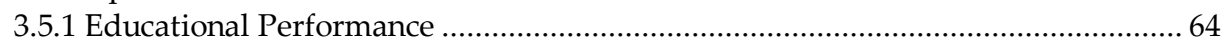

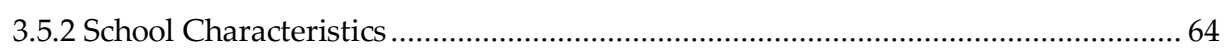

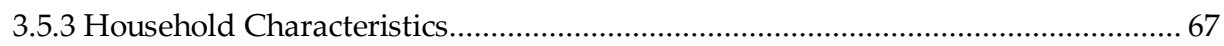

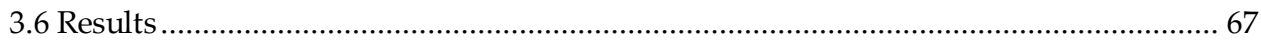

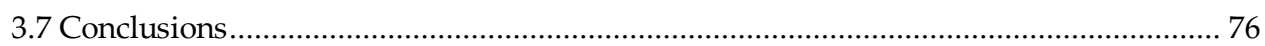

4. Household Income, Simultaneous Work-Schooling and Human Capital........................ 78

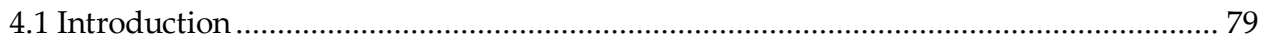

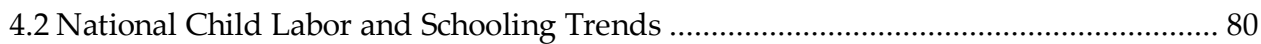




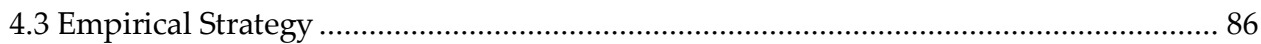

4.4 Child and Household Characteristics in Simultaneous Work-Schooling Behavior ...... 88

4.4.1 Distribution of Time for Work and Schooling ...................................................... 89

4.4.2 Relationship between Household Income and Simultaneous Work-Schooling .... 93

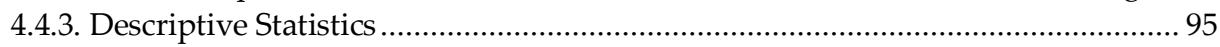

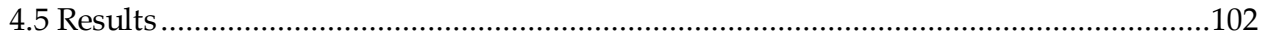

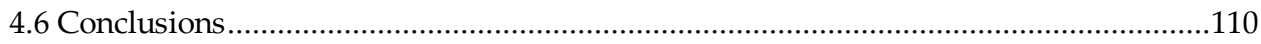

5. Dynamic Complementarity of Investment in Education ..................................................113

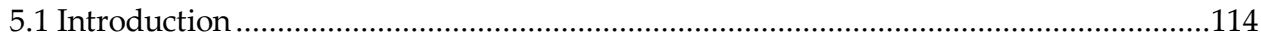

5.2 A Model of the Distribution of Investments over the Child's Life Cycle ....................117

5.3 Operational Definitions and Empirical Strategy.....................................................120

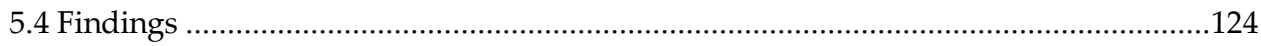

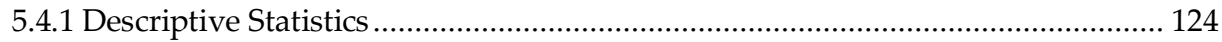

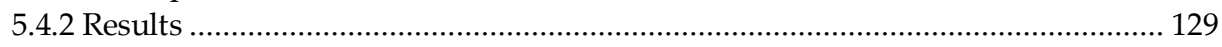

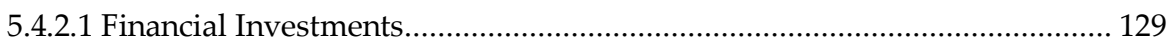

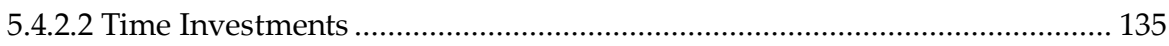

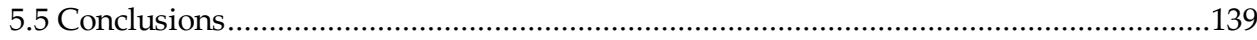

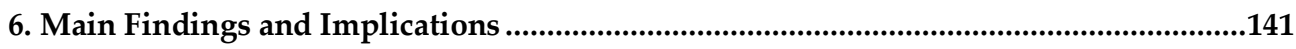

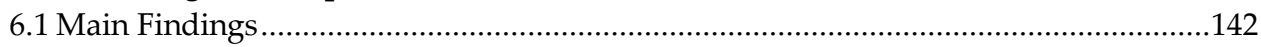

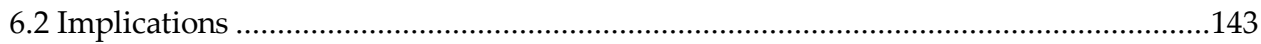

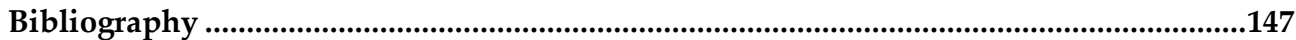

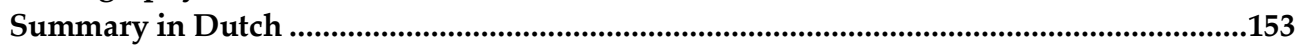

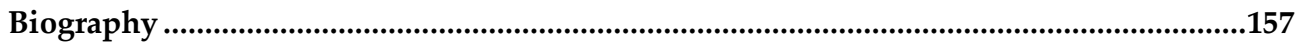




\section{List of Figures}

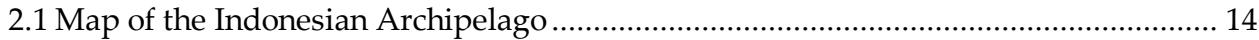

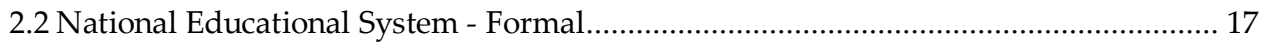

2.3 National Educational System - Formal and Informal .............................................. 18

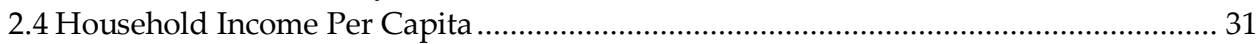

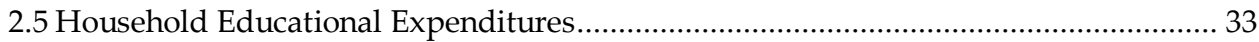

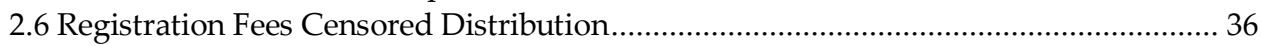

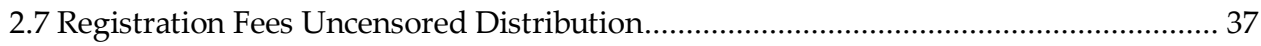

2.8 Monthly Scheduled Fees Censored Distribution ..................................................... 38

2.9 Monthly Scheduled Fees Uncensored Distribution .................................................... 39

2.10 Children in the Income Distribution and their EBTANAS Test Scores........................ 45

3.1 Indonesia Main Power Plants and Transmission Lines............................................. 52

4.1 National Level Trend of Average Hours Worked Per Week, Ages 10 - 17.................. 82

4.2 National Level Trend of Simultaneous Work-Schooling Behavior, Ages 10 - 17 ......... 83

4.3 Kernel Density for Number of Hours Worked Per Week outside the Household \&

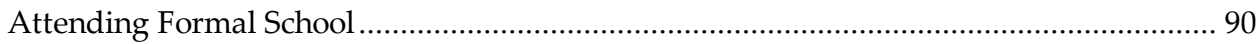

4.4 Kernel Density for Number of Hours Worked Per Week outside the Household \& Attending Non-Formal School ......................................................................................... 91

4.5 Kernel Density for Number of Hours Worked Per Week outside the Household \&

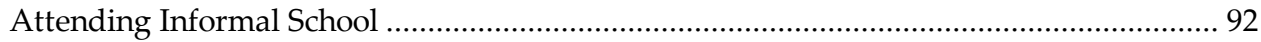

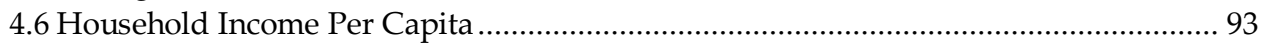

4.7 Relationship between Household Income and Child Labor ....................................... 94

5.1 Model of the Distribution of Investments over the Child's Life Cycle .........................117

5.2 School Age when Exposed to the Financial Crisis .......................................................122

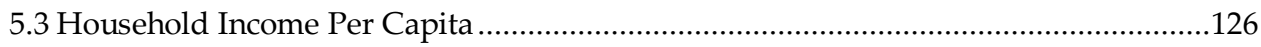

5.4 Kernel Regressions of Financial Investments given Household Income Per Capita....128

5.5 Kernel Regressions of Financial Investments in Junior High given Prior EBTANAS

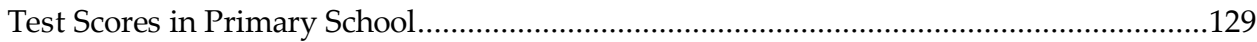




\section{List of Tables}

2.1 Indonesian Macroeconomic Variables Time Series 1997 - 2000.

2.2 Structure of Academic Hours per Week for the National Curriculum by the Primary

School Level and Junior High....

2.3 Proportion of Grade 1 Cohorts Completing 9 Year of Education Time Series ............. 20

2.4 Price Changes by Product Groups January 1997 to October 1998 ................................. 25

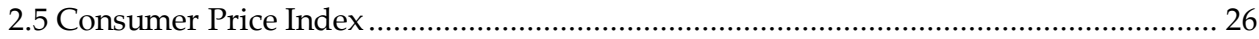

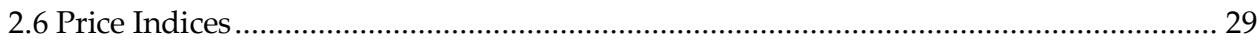

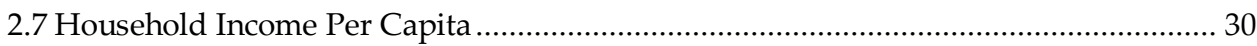

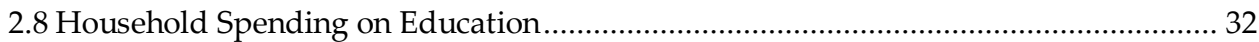

2.9 Expenditure Type as Share of Total Educational Expenditures .................................. 34

2.10 Households Reporting Zero Spent by Educational Expenditure Type........................ 35

2.11 Children Attending Different School Types................................................................. 40

2.12 Characteristics of Children who Transition and Do Not Transition to Junior High ... 43

3.1 Indonesia Total Installed Capacity and Electricity Consumption 1997 - 2000 ............. 53

3.2 Distribution of Final Energy Use by Sector in Indonesia............................................. 54

3.3 MONE / MORA School Census Data - School Conditions Checklist............................ 55

3.4 Measures of Association between Educational Performance, Electricity in School and

Electricity at Home in 1997

3.5 Measures of Association between Educational Performance, Electricity in School and

Electricity at Home in 2000 .

3.6 Measures of Association between Educational Performance, Electricity in School and

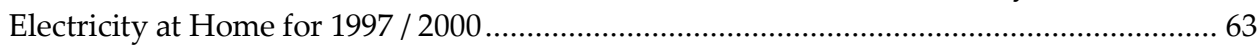

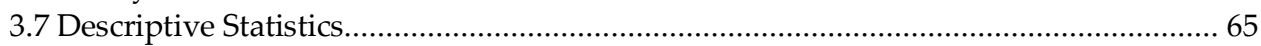

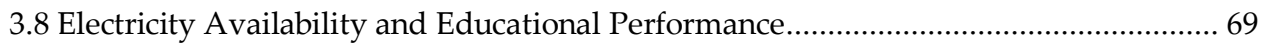

3.9 Electricity Availability, Use and Educational Performance ........................................ 73

4.1 Working Status of Children by Urban / Rural and Gender......................................... 85

4.2 Children Working and Different Sources of Skill Formation ....................................... 95

4.3 Children Working outside the Household and Different Sources of Skill Formation . 95

4.4 Children Working in the Household and Different Sources of Skill Formation ........... 96

4.5 Characteristics of Children Working outside the Household ..................................... 97

4.6 Characteristics of Children Working in the Household ................................................100

4.7 Household Income, Joint Work Outside-Schooling and Fulltime Schooling ..............103

4.8 Household Income, Joint Work Outside-Schooling and Joint Work in Household-

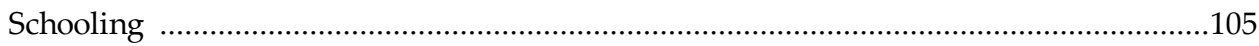

4.9 Household Income and Hours Worked by Child outside the Household while

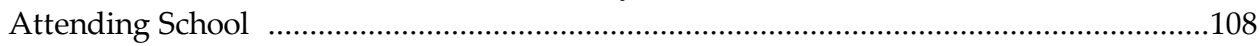

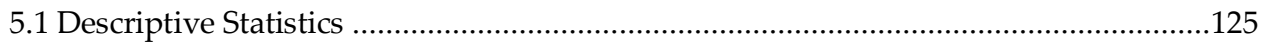

5.2 OLS \& IV-2SLS Complementarity of Financial Investments in Junior High ...............131

5.3 OLS \& IV-2SLS Complementarity of Financial Investments in Junior High ...............133

5.4 OLS \& IV-2SLS Complementarity of Time Investments in Junior High .....................136

5.5 OLS \& IV-2SLS Complementarity of Time Investments in Junior High......................138 

1. Introduction 


\subsection{Aim}

Education is considered to be very important for economic growth. But family investments in education are much lower in developing countries compared to developed countries. This leads to the question whether families in developing countries are less inclined to invest and whether the market rates of return are very low; or that there are actually constraints to investment. Potential constraints are basic facilities for schooling and low incomes. These constraints might not only affect whether or not investments are made, but might also affect the extent and quality of investments made. Spending a full day in school with limited basic facilities might be less productive than going to school part of the day and rushing home to help in the family enterprise and learn the trade. Families in developing countries tend to face such constraints or "stumbling blocks" due to a multitude of factors and unexpected events which might result in sub-optimal human capital investments. In this dissertation we study two main constraints faced in the Indonesian developing country context: resource constraints in basic facilities - we use the access to and use of electricity for learning; and monetary constraints as captured by family income.

The aim of this dissertation is to investigate the effects of inadequate basic facilities on learning; and the effects of low income on educational investment. We consider how these resource and income constraints affect the different dimensions of school quality and educational outcomes. This investigation is carried out using data for Indonesia over the period 1997 - 2000. To carry out this empirical analysis, we adopt theoretical models of human capital from Becker (1964, 1993 updated), and Cunha and Heckman (2007) and apply them within the context of Indonesian children's primary school and junior high education. The dataset that we use throughout this dissertation is the RAND Corporation Indonesian Family Life Surveys (IFLS) Wave 2 from 1997 and Wave 3 from 2000. Because of this dataset that captures family strategic behavior in education, we are able to determine a non-income resource constraint and income constraint for the following reasons. First, as Indonesia is a large country there is sufficient geographic variation in infrastructure to study the constraint of electricity access and use on schooling. Parental investments in education differ in Indonesia because of huge variations in regional development across the country with an estimated population of 237 million, land mass of 1.3 million $\mathrm{km}^{2}$ and over 13,000 islands. The main Java and Bali islands have more advanced levels of economic development, more waged labor opportunities and more schooling choice ${ }^{1}$. This is as opposed to the Outer Islands that consist more of subsistence economies, agricultural economies and

${ }^{1}$ Center for Studies in Higher Education, University of California at Berkeley 1991 
have lower levels of economic development. In terms of electricity infrastructure, Java and Bali have $77 \%$ of total capacity and the Outer Islands have the remaining $23 \%$. Also because the Outer Islands are located further away from the central government in Java and more difficult to access geographically there are fewer quality schools available. Second, Indonesia faced the Asian Financial Crisis (AFC) in end 1997 that lowered family incomes exogenously which provides us with an instrument for income to study the effects of family income on child labor and educational investments. Over the period of 1998 and 1999, the reduction in household incomes produced a variety of observable behavioral responses towards investment in education which makes this period ripe for a natural experiment ${ }^{2}$. The differences observed in family strategic behavior provide us with the opportunity to investigate various behavioral dimensions towards education.

In Indonesia investment in education is a goal shared by the family and the state. This is highlighted in the opening chapter of the 1945 Republic of Indonesia Constitution which explicitly states that one major goal of the state is to ensure the intellectual development of all citizens of the country. While there is no compulsory schooling age, the family and the state attempt to invest in at least 9 years of basic education for children aged 6 - 15. However, families face direct costs and opportunity costs for schooling. Hence having 9 years of schooling is considered an educational achievement in the country where only in recent memory, achieving full adult literacy was still a long overdue goal. With economic growth in Indonesia, there has been the expansion of schooling attainment. In the country's thirty year growth trajectory 1967 - 1997 universal primary education was on target to be achieved and to be followed by an increase in junior high. By 1997, a peak of $80 \%$ of all school children who enrolled in school had attained 9 years of education in primary school and junior high while the remaining 20\% dropped out. But after 1997 coinciding with the crisis, the percentage of children who attained 9 years of schooling fell to $75 \%$ and the trend has since deteriorated to $52.6 \%$ in 2001 ; and this negative trend continues to hold after $2001^{3}$.

\footnotetext{
${ }^{2}$ Why is the financial crisis as a natural experiment an opportunity? First and foremost this is an opportunity because it is not possible to create a randomized controlled trial using the whole Indonesian population as treatment and control subjects. Second and lyrically, we cite the econometrics forefather Trygve Haavelmo (1944) and his thoughts on natural experiments: "the stream of experiments that Nature is steadily turning out from her own enormous laboratory, and which we merely watch as passive observers. The aim of the theory (behind experimental designs) is to become master of the happenings of real life." Also more recently, Jared Diamond and James A. Robinson (2010) write about "Natural Experiments of History" on the basis that some central questions in the natural and social sciences can't be answered by controlled laboratory experiments. One has to then devise other methods of observing, devising and explaining the world.

${ }^{3}$ Indonesia Ministry of National Education (MONE)
} 
In the literature on education in developing countries, children tend not to receive a full basic education mainly because of credit constraints where there is limited scope for borrowing in order to invest in education (Galor and Moav, 1999; Foster and Rosenzweig, 2000; Glewwe and Jacoby, 2000, Glewwe and Kremer, 2005). Most of the financial investment in education therefore has to be funded by the family. In Indonesia, up to $60 \%$ of total financing for education is funded by the family (World Bank, 2007). Hence how the family makes it decisions for educational investment is a crucial issue. This is as argued by Rosen (1989) and Glewwe and Kremer (2005) where it is not just credit constraints but the nature of family decision making as well that will provide a better understanding of how much education children attain. The parental decision to finance more or fewer years of schooling is influenced by the private rate of return to additional years of schooling (Psacharopoulos, 1994 and Psacharopoulos and Patrinos, 2004). Parental decision making is also influenced by the value added to cognitive skills from each additional year of schooling (Harbison and Hanushek, 1992; Hanushek and Wößmann, 2010). Also Harbison and Hanushek (1992) find that some parents in developing countries are predisposed to education for their children simply when a minimum standard of school resources are available i.e. the school has a permanent physical structure as opposed to temporary arrangements. Because of the various considerations that parents make when deciding to finance their children's education, it is no longer simply a question of having the financing to attend or not to attend school. The calculus of decision making involves how much schooling to attain, whether the school has sufficient resources, the quality of knowledge and skills accumulated; and parents' perceived private and social returns to education.

While studying the empirics of family income and human capital is interesting in its own right, these dissertation findings provide new information for development policymaking. National development planners in Indonesia and foreign aid donors have put much focus on improving school resources for the formal education system in order to achieve the country's educational goals. The government builds more schools for formal education, buys more computers, trains more teachers and tinkers more with the academic curriculum. To complement this would be more understanding of the nature of decision making by parents for their children's future - the environment in which they live and not just the school specific environment for education, what they do each day, what difficulties they face each day and the multitudes of decisions they take for investing in their children. The findings in this dissertation provide some policy implications concerning how these two constraints affect educational investment decision making from a monetary and non-monetary perspective. These findings may perhaps be of useful application to the geographically large and socio-economically diverse developing countries of Brazil, China and India that are faced with varying school quality. 


\subsection{Human Capital Accumulation, School Resources, Outputs $\mathcal{E}$ Outcomes}

To carry out our empirical investigation, we review human capital concepts and introduce the ways in which we measure them as educational inputs, outputs and outcomes. These concepts and measures are derived from Becker (1964, 1993 updated), Hanushek (2006), Hanushek and Wößmann (2008), Cunha, Heckman, Lochner and Masterov (2006) and Cunha and Heckman (2007).

\subsubsection{Human Capital Accumulation}

Following Becker, we view human capital as a stock of knowledge or skills that are directly useful in the production process. Becker also recognizes that knowledge and skills can be gained not just from school but from various sources and these sources are elaborated upon by the Coleman Report (1966). To capture the knowledge and skills from each additional year of schooling as a part of a total stock, we mainly use the Indonesian national standardized achievement test scores EBTANAS at the end of a given school level. Together with the initial endowments when the child is born which are unobserved, additional knowledge and skills increase the size of this stock. But the marginal benefits decline as additional capital is accumulated. This can be due to memory capacity, a requisite skill or ability that is not present to build new skills, etc. The implication is that eventually over the child's life cycle, diminishing returns set in from producing additional capital (BenPorath, 1967). It becomes more costly to accumulate more human capital when the child is older; and at a later school level compared to an earlier school level. To then maximize the returns to human capital, parents should increase the productivity of early knowledge and skills accumulated by making further investments when the child is older. This can be related to complementary investments in human capital (Cunha, Heckman, Lochner and Masterov, 2006).

\subsubsection{School Resources}

To build a stock of knowledge and skills requires school resources or educational inputs for use in the educational production process. Using the structure of the Indonesia national education system and educational policy, we determine the characteristics of these school resources. Also we study how these school resources relate to school quality and the implications for how much or how little family income can do to acquire school quality (Glewwe, 2002 and Hanushek, 2009). Even if a family in a developing country has high income, they may reside in an area geographically that has limited schooling choice. This family for unobserved reasons may also have low mobility i.e. there might be a low inclination to migrate 
for education. As such they may be able to do very little using income to improve the quality of schooling inputs available in their residential area.

The school resources that we investigate in Indonesia are school facilities particularly electricity, teacher qualifications, the curriculum taught, the availability of textbooks and the mode of learning. Closely related to school quality, we study how these schooling inputs differ for children in the high quality formal education system and children in low quality alternative education (non-formal and informal schools).

\subsubsection{Outputs}

As the Indonesian national educational system recognizes but differentiates between formal education and alternative education (non-formal and informal schools), we use different measures of school attendance for formal education and alternative education as educational outputs. For the formal education system, we use each year of school enrollment as an output measure. For alternative education, we use registration in a non-formal or informal school as a mode of learning as an output measure. For both formal education and alternative education, available data enables us to include as an output measure, time allocated to the learning process over the period of a day and a week. This output measure of time allocation includes the dimensions of time for classroom instruction and studying in the evening after school. Time allocation for schooling also enables us to analyze the relative value of a child's time between schooling and work.

\subsubsection{Outcomes}

While many empirical studies define educational outcomes in terms of the number of years of schooling enrollment, we take a different approach by using the measure for transition between school levels as represented by the EBTANAS standardized achievement tests. The full set of tests for EBTANAS consists of the national language Bahasa Indonesia, Mathematics, Science, Social Studies and Religious Studies. By passing EBTANAS at the end of the primary school level, the child is qualified to transition to the junior high level.

Only children in the mainstream, formal education system are entitled to directly sit for EBTANAS at the end of a school level. Children who are in alternative schools such as non-formal school for child workers and informal school for children who are home schooled or are child apprentices are entitled to sit for these tests if they switch to the formal system and complete the full cycle of a school level. 
Transition from one school level to the next is both an output and outcome of the educational process because it measures the number of schooling years attained and the level of knowledge and skills attained. This measurement indicator is important from both a technical and policy perspective. From a technical perspective, a child's labor market outcomes in adulthood can be traced back to the number of schooling levels completed and qualifications attained for each level. In Indonesia's structured and hierarchical education system, the first transition is from primary school to junior high. The second transition is from junior high to senior high. The third transition is from senior high to tertiary education. Each additional schooling year completed does not matter but each additional schooling level completed matters because of the qualification received at the end of a level. From a policy perspective, transition rates matter for the achievement of national educational policy and the Indonesia UN Millennium Development Goal \#2 of 9 years of universal basic education.

We do not use enrollment as an outcome measure in any of the chapters for various reasons. Based on UNESCO technical guidelines, enrollment is recorded as registration on the first day of the school year. Or it is recorded during a census. As such this measurement indicator does not accurately capture school attendance flows throughout the school year. As pointed out by Krueger and Lindahl (2001), enrollment rates are then a flawed measure for human capital. Most importantly, Hanushek and Wößmann (2008) argue that using years of schooling enrollment as an education measure implicitly assumes that a year of schooling delivers the same increase in knowledge and skills regardless of the education system i.e. the difference between formal education and alternative education in Indonesia. The school enrollment measure also assumes that formal education is the primary source of education and variations in the quality of non-school factors affecting learning such as where children are raised and their daily learning environment i.e. family enterprise and lack of electricity have a negligible effect on human capital outcomes.

\subsection{Outline}

This dissertation consists of five chapters ${ }^{4}$. Chapter 2 provides the departure point for the dissertation with a detailed description of the Indonesian national education system and an overview of the AFC context. This is then followed by a descriptive analysis of changes to Indonesian family educational investment behavior. The changes are documented by comparing families in 1997 and families in 2000 that

${ }^{4}$ The five chapters have been revised from four individual papers. 
have similar characteristics. Also we justify using the crisis as a valid instrument for income. We show that the AFC is relevant because it is correlated with income and it is plausibly exogenous because it is not directly correlated with educational investments but through its correlation with income. As Chapter 2 maps out the role of the family in making educational investment decisions given available income and time, schooling prices and the institutional environment, we are able to then determine the two constraints for investment. We proceed to study the resource constraint in Chapter 3 and the income constraint in Chapters 4 and 5. For Chapters 4 and 5, we specifically use the AFC as an instrument for household income. From these chapters, we determine that there are two constraints to the amount and quality of educational investment: i) resources for basic facilities electricity, ii) low family income. The resource constraint is a non-income constraint as it is not easily influenced by family income and together with the income constraint, affect the quality of schooling inputs used for education, the number of schooling years attained, the completion of school levels and educational achievement. Chapter 6 provides a summary of this dissertation and implications for policy. We will now elaborate on the structure of the chapters, methods used and the line of thought.

\subsubsection{Family Educational Spending when Income Falls}

In Chapter 2, we describe the national education system and the environment when the financial crisis occurred from end of 1997 - 2000. We then map out the role of the family in making educational investment decisions for children aged 6-15. This is given available income and time, real schooling prices and the institutional environment. We document changes to family decision making by comparing families in 1997 with families in 2000 that have similar characteristics. We carry out a review of the extensive literature that was written to document the volatile changes to prices and we isolate the price of schooling, incomes, consumption and schooling behavior. We show that parents respond to an income reduction by compromising on the quantity and quality of education that their children attain. We then report on the various strategies families in different geographical areas took for their children's education. The documentation of these educational investment responses to the financial crisis then justifies the use of the crisis as a valid instrument for income. The crisis is used as an instrument in Chapters 4 and 5 .

\subsubsection{Electricity Access, Use and Children's Educational Performance}

In Chapter 3, we study whether there is a correlation between the availability of electricity in schools and households and educational performance at age 12. The 
potential relationship between the two main variables of interest is via the use of electricity in school and at home. We use pooled data from 1997 and 2000 which consist of regional variation in electricity availability. We find that there exists a positive correlational relationship between access to electricity and educational performance. We find this result in both developed and underdeveloped, left behind regions of the country. However children in underdeveloped, below-thepoverty-line areas have lower test score performance than children in developed areas. Using access to electricity, this chapter shows that the family can be confronted with overall resource constraints in basic facilities for schooling. When the educational performance of disadvantaged 12 year old children in underdeveloped areas is found to be lagging behind, resource constraints may prevent the children from progressing on to junior high.

\subsubsection{Family Income, Simultaneous Work-Schooling and Human Capital}

In Chapter 4, we investigate the relationship between family income and child labor in terms of the behavior of children who allocate time to work and attending school simultaneously. This chapter documents how child workers can choose to attend formal school, non-formal school or informal school. Using a natural experiment with IV estimation, we find that a fall in income results in a shift away from full time schooling to joint work-schooling. Within the joint work-schooling decision, an income decrease is also found to increase the propensity to shift more away from schooling and shift more towards work. Unexpectedly family income is not the main constraint that prevents full time schooling. What drives the joint work-schooling decision is the age of the child. After age 12, children are inclined to work more and attend school less which increases the risk of failing to complete a full course of 9 years of basic education.

\subsubsection{Dynamic Complementarity of Investment in Education}

In Chapter 5, we study the role of family income on financial and time investments in education. We apply the Cunha and Heckman (2007) theoretical formulation for the technology of skill formation. Using repeated cross sections from 1997 and 2000 , we find that about $80 \%$ of the cross-sectional link between income and educational expenditures is caused by differences in income. The remaining $20 \%$ is related to unobserved income related parental characteristics. But lower educational expenditures due to less income are highly compensated by time investments. This strongly implies that income related parental characteristics as well as unobserved child characteristics explain a substantial part of these compensating time investments. But this is only for higher ability children who 
have selected to complete primary school and transition to junior high. Also the reduction in educational expenditures is much lower for children who have already attained a few years of junior high education compared to children who have just begun junior high. This then suggests that optimal education investment does include accounting for the loss in returns from previous investments on the stock of human capital that has been accumulated. Put another way, parents do face a loss aversion where sunk costs do matter. Taken together these results reveal that income constraints do restrict parents in their educational expenditures, that they are concerned with future returns; and that especially parents with favorable characteristics compensate reductions in educational expenditures by letting their children spend more time in school.

\subsubsection{Main Findings and Implications}

The main findings of the dissertation are reviewed in Chapter 6 and we discuss the implications of the role of the family in increasing human capital in developing countries. By providing insight into the disadvantaged family and the resource constraints and income constraints they are confronted with, we will be able to better determine how to increase a child's schooling attainment and educational achievement 
2. Family Educational Spending when Income Falls 


\subsection{Introduction}

In this chapter we describe educational spending in Indonesia and how it was affected by the Asian Financial Crisis (AFC). The AFC reduced economic growth, increased unemployment, substantially increased inflation and severely reduced household purchasing power. Because of reduced income, households made adjustments to daily expenditures, savings and budget allocations for their children's education.

Our aims are to document how households spent on education before the crisis; how spending and schooling participation patterns changed in response to an income reduction; and how these patterns are influenced by where the household resides geographically in the Indonesian archipelago. Available data provides us with the opportunity to examine not just whether parents continued to spend on education and send their children to school when income fell but also the extent to which schooling quality changed, as well as how schooling participation was affected by the incidence of child labor.

We trace the effects of extreme increases in the general prices of goods and services on household consumption and savings down to spending decisions for the child's education. We document these responses for children in primary school and junior high. Regardless of extremely high levels of inflation and volatility in currency exchange rates, we find that the children still managed to receive an education. However the fall in household income reduced the quality of schooling purchased. We document an increase in the number of children in schools that have lower quality schooling inputs. We also find evidence that educational outcomes deteriorated. There is evidence too that a smaller proportion of children transitioned from the primary school level to the junior high level.

Sparrow (2006) who studied Indonesia state intervention during the financial crisis found that targeted subsidies maintained enrollment flows; and it seemed to relieve pressure on household spending in education. We expand on Sparrow's work on enrollment flows and study the quality of schooling inputs and outcomes at the time. We use measures that encompass different schooling inputs which includes school type (formal education and alternative education) and school provision type (publicly funded and managed and privately funded and managed). Our measures of educational outcomes are the EBTANAS national standardized achievement test scores and transition rates. The rest of the chapter is organized in the following way. Section 2.2 provides a general overview of the country. Section 
2.3 provides the context in terms of the AFC occurring at the time and a detailed description of the national educational system. In section 2.4 we describe the data and where we carry out a pair-wise matching of households and schools in the same community to enable comparison and use separate price deflators for education and non-education goods. In section 2.5 we map out the changes to the price of goods and services, household income and educational spending. Given these changes we analyze adjustments to the different parental spending strategies for their children. Section 2.6 covers the conclusions made from the documented changes and makes linkages to Chapter 3 which investigates how spending is influenced by where the household resides in the Indonesian archipelago.

\subsection{Indonesia Country Overview}

The Indonesian archipelago consists of over 13,000 islands spread across 1.3 million $\mathrm{km}^{2}$ with an estimated population of 237 million people speaking over 20 dialects and represented by highly diverse cultures. The unification language of the country is Bahasa Indonesia . With population planning over 3 decades, the total fertility rate has fallen from 5.6 in 1971 to 2.8 in 19976. Map 2.1shows the main islands of the Indonesian archipelago - Java and Bali; the Outer Islands of Sumatra, Kalimantan (in Borneo), Sulawesi and the Eastern Nusa Tenggara cluster of small islands. $60 \%$ of the total population is in the main islands of Java and Bali which only make 7\% of total land mass.

5 Unification of Indonesia is first set forth in the country's 1945 Constitution Pancasila.

${ }^{6}$ Indonesia Central Bureau of Statistics et al. (Badan Pusat Statistik, BPS) 1998 
Figure 2.1 Map of the Indonesian Archipelago

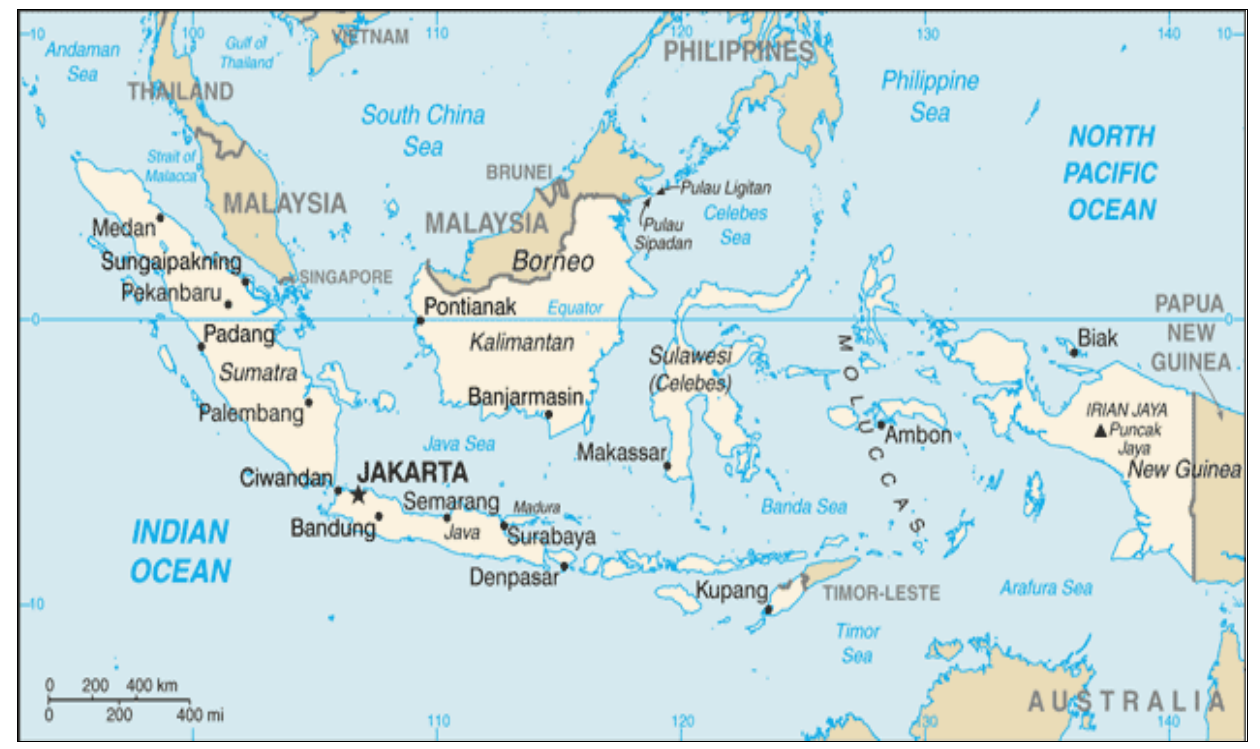

\subsection{Institutional Context - Asian Financial Crisis and National Educational System}

\subsubsection{Asian Financial Crisis}

The AFC occurred at the end of 1997 with effects in the financial markets felt until the beginning of 2000. It had interrupted a thirty year period of rapid growth in East and South East Asia. In Indonesia, real per capita GDP rose four-fold between 1965 and 1995 with an annual growth rate averaging 4.5\% until the 1990s when it rose to almost 5.5\% (World Bank, 1997). The poverty headcount rate declined from over $40 \%$ in 1976 to just under $18 \%$ by 1996 . The country's domestic savings level reached 30\% prior to 1997. Primary school enrollment rates rose from $75 \%$ in 1970 to universal enrollment by 1995 and secondary enrollment rates from $13 \%$ to $55 \%$ over the same period (World Bank, 1997).

In April 1997, the financial crisis began to be felt in the Southeast Asian region, although the major impact did not hit Indonesia until December 1997 and January 1998. With reference to the following Table 2.1, which consists of macroeconomic data, GDP growth fell from $4.70 \%$ in 1997 to $-13.13 \%$ in 1998 and then rising to $0.79 \%$ in 1999 before reaching pre-crisis growth rates in 2000. Annual inflation rates increased from $6.23 \%$ in 1997 to $58.39 \%$ in 1998 and then improving to $20.49 \%$ in 1999 before resuming a considerably lower rate of $3.72 \%$ in 2000 . The trend for 
gross domestic savings as a percentage of GDP presented a pattern of offsetting the massive spike in inflation rates. While savings were at a high of $31.48 \%$ in 1997 , there was a decreasing trend from 1998 to 2000.

Table 2.1 Indonesia Macroeconomic Variables Time Series 1997 - 2000

\begin{tabular}{|c|c|c|c|c|}
\hline & 1997 & 1998 & 1999 & 2000 \\
\hline GDP Growth (Annual \%) & 4.70 & -13.13 & 0.79 & 4.92 \\
\hline GDP Per Capita Growth & 3.27 & -14.30 & -0.55 & 3.55 \\
\hline $\begin{array}{l}\text { Inflation, Consumer Prices } \\
\text { (Annual \%) }\end{array}$ & 6.23 & 58.39 & 20.49 & 3.72 \\
\hline Real Interest Rates (\%) & 8.21 & -24.60 & 11.83 & 8.05 \\
\hline $\begin{array}{l}\text { Gross Domestic Savings } \\
(\% \text { GDP) }\end{array}$ & 31.48 & 26.53 & 19.45 & 25.56 \\
\hline Foreign Aid (\% GNI) & 0.39 & 1.41 & 1.64 & 1.19 \\
\hline
\end{tabular}

Sources: Development Research Institute, New York University; Global Development Finance, World Development Indicators

For the household, much of the impact of the aggregate shock was felt in the 52.16 percentage point or eightfold increase in inflation rates from 1997 to 1998. Inflation rates were then less substantial in 1999. The significant increases in inflation rates for the two years 1998 and 1999 compared to 1997 and 2000 would most likely have severely weakened household purchasing power of all goods including education. On this basis we focus on the relationship between price changes and household income and how this relationship affected educational spending and outcomes.

\subsubsection{National Educational System}

The following Figure 2.2 shows the organizational structure of the formal and mainstream school system in Indonesia. The formal school system is divided into two streams, namely the secular stream under the Ministry of National Education, MONE (public and private) and the Islamic stream under the Ministry of Religious Affairs, MORA (public and private). There are also Christian and Buddhist schools. The extent to which the emphasis is on skills development in language and mathematics or religion depends on whether the education provider is publicly or 
privately funded and whether the education provider is regulated by MONE or MORA.

Contrary to practices in many other countries, the public sector provides higher quality education than the private sector (Lanjouw, Pradhan, Saadah, Sayed and Sparrow, 2001; Newhouse and Beegle, 2005). The differences in quality between public and private schools are in terms of schooling inputs (Newhouse and Beegle, 2005). Based on their studies of junior high schools, in public schools textbooks are more easily available and teachers have higher educational qualifications compared to private schools.

Since the end of the Suharto regime and the introduction of regional autonomy laws, there is an increasing trend of schooling provision by religious associations and non-governmental organizations. These private providers of education retain the option to adjust the curriculum to a greater extent to meet local indigenous needs. These include a curriculum covering local agricultural farming methods, environmental education and local culture - traditional arts and languages / dialects. 
Figure 2.2 National Educational System - Formal

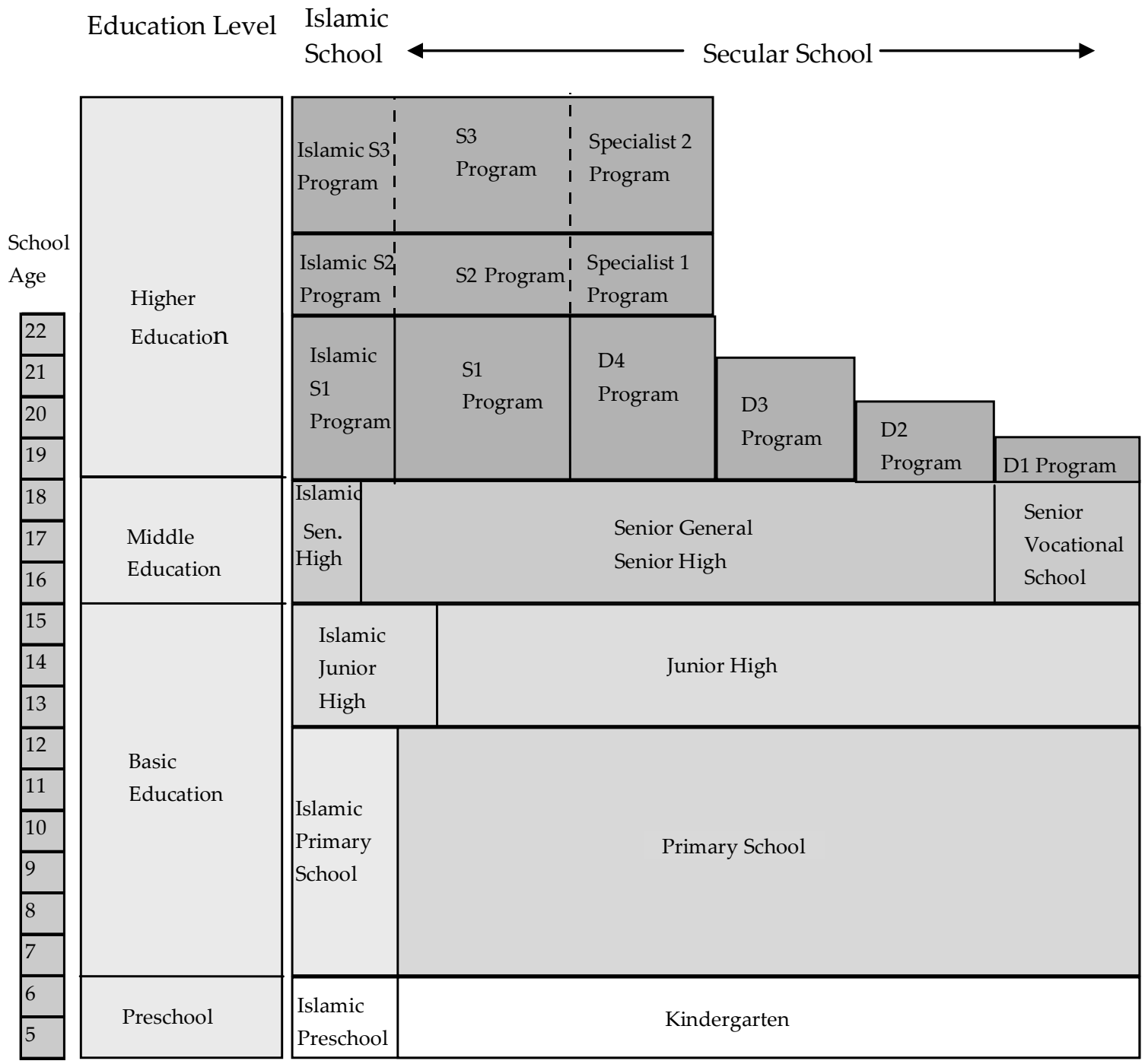

Source: Ministry of National Education \& Ministry of Religious Affairs (MONE \& MORA)

Notes: We study the 9 years of Basic Education of Indonesian children aged 6-15 which is defined as being their school age as opposed to birth age. While the starting school age for primary school is 7 years old, there are some children who start at 6 years old. In 1997, 18\% of children reported repeating one school grade once and in 2000,15\% of children reported repeating one school grade once in their progression through primary school and junior high. 
Figure 2.3 shows the expanded organizational structure of the education system that incorporates both formal schooling and alternative schooling. In this figure, formal schooling is represented by in-school education and non-formal and informal schooling are represented by out-of-school education. For disadvantaged children e.g. child workers who have fewer fulltime educational opportunities the education system provides two alternatives to the formal, mainstream system - the non-formal school and informal school / education by the family.

\section{Figure 2.3 National Educational System - Formal and Informal}

\begin{tabular}{|c|c|c|c|c|c|c|}
\hline School & \multicolumn{4}{|c|}{ In-School Education } & \multicolumn{2}{|c|}{ Out-of-School Education } \\
\hline & \multicolumn{4}{|c|}{ Formal } & Non Formal & Informal \\
\hline$>22$ & \multicolumn{4}{|c|}{$\begin{array}{l}\text { Higher Education / Religious Higher Education Post } \\
\text { Grad }\end{array}$} & & \multirow{9}{*}{$\begin{array}{l}\text { Education by } \\
\text { the Family }\end{array}$} \\
\hline $19-22$ & \multicolumn{4}{|c|}{$\begin{array}{c}\text { Higher Education / Religious Education Grad / } \\
\text { Diploma }\end{array}$} & & \\
\hline \multirow[t]{3}{*}{$16-18$} & \multicolumn{4}{|c|}{ Senior High } & Apprenticeship & \\
\hline & & eral & & tional & Packet C & \\
\hline & General & $\begin{array}{r}\text { Religious } \\
\text { Education }\end{array}$ & General & $\begin{array}{l}\text { Religious } \\
\text { Education }\end{array}$ & & \\
\hline \multirow[t]{2}{*}{$13-15$} & \multicolumn{4}{|c|}{ Junior High } & \multirow{2}{*}{$\begin{array}{c}\text { Junior High } \\
\text { Equivalent } \\
\text { Packet B }\end{array}$} & \\
\hline & & eral & Religio & Education & & \\
\hline \multirow{2}{*}{$\begin{array}{c}6 \text { or } 7- \\
12\end{array}$} & \multicolumn{4}{|c|}{ Primary School } & Primary School & \\
\hline & \multicolumn{2}{|c|}{ General } & \multicolumn{2}{|c|}{ Religious Education } & $\begin{array}{l}\text { Equivalent } \\
\text { Packet A }\end{array}$ & \\
\hline
\end{tabular}

The non-formal school system consists of equivalency educational programs, Packet A (equivalent to primary school) and Packet B (equivalent to junior high); and vocational training programs provided by non-governmental organizations. Private religious schools funded from charitable contributions and not administered by MORA also provide non-formal education. Children who choose the equivalency educational programs have the flexibility of customizing time for learning around time for working. For example, if a child has to work on the farm in the morning and late afternoon, s/ he can attend classes with a tutor in the early afternoon. 
In formal basic education, children are taught a compulsory curriculum of the national language Bahasa Indonesia and Mathematics. Other courses taught include Religion, Pancasila, Moral Education, Social Sciences, Natural Sciences, Sports and Health, Handicraft and Art, Regional Languages and courses termed as Local Indigenous Content. The ratio between the national and local curriculum content is $80 \%-20 \%$. Table 2.2 provides information concerning the national curriculum

Table 2.2 Structure of Academic Hours per Week for the National Curriculum by the Primary School Level and Junior High Level

\begin{tabular}{|c|c|c|c|c|c|c|c|c|c|c|}
\hline \multirow{4}{*}{1} & \multirow[b]{2}{*}{ Subject } & \multicolumn{6}{|c|}{ Primary School } & \multicolumn{3}{|c|}{ Junior High } \\
\hline & & 1 & 2 & 3 & 4 & 5 & 6 & 1 & 2 & 3 \\
\hline & Pancasila & 2 & 2 & 2 & 2 & 2 & 2 & 2 & 2 & 2 \\
\hline & Education & & & & & & & & & \\
\hline 2 & Religion & 2 & 2 & 2 & 2 & 2 & 2 & 2 & 2 & 2 \\
\hline 3 & Bahasa Indonesia & 10 & 10 & 10 & 8 & 8 & 8 & 6 & 6 & 6 \\
\hline 4 & Mathematics & 10 & 10 & 10 & 8 & 8 & 8 & 6 & 6 & 6 \\
\hline 5 & Natural Sciences & - & - & 3 & 6 & 6 & 6 & 6 & 6 & 6 \\
\hline 6 & Social Sciences & - & - & 3 & 5 & 5 & 5 & 6 & 6 & 6 \\
\hline 7 & Handicraft and Art & 2 & 2 & 2 & 2 & 2 & 2 & 2 & 2 & 2 \\
\hline 8 & Health and Sport & 2 & 2 & 2 & 2 & 2 & 2 & 2 & 2 & 2 \\
\hline 9 & English & - & - & - & - & - & - & 4 & 4 & 4 \\
\hline \multirow[t]{2}{*}{10} & $\begin{array}{l}\text { Local Indigenous } \\
\text { Content }\end{array}$ & 2 & 2 & 4 & 5 & 7 & 7 & 6 & 6 & 6 \\
\hline & Total & 30 & 30 & 38 & 40 & 42 & 42 & 42 & 42 & 42 \\
\hline
\end{tabular}

Source: Ministry of National Education (MONE)

Notes: Pancasila Education is concerned with studying the principles enshrined in Indonesia's

Constitution.

At the end of each school level children sit for the compulsory EBTANAS national standardized achievement tests or also known as the national end-of-cycle tests. It is a requirement that children sit for this test to enable them to transition to the next level. EBTANAS is considered to be a proxy for child ability and it is a standardized test designed by the Ministry of National Education. Standardization of the achievement tests was carried out in 1994. These tests enable quality comparisons to be made across schools in the different main islands and provinces in the country. 
Table 2.3 provides national level time series data that shows the proportion of children who complete the full course of 6 years of primary school and 3 years of junior high.

Table 2.3 Proportion of Grade 1 Cohorts Completing 9 Years of Education, Time Series 1997/98 - 2001/02

\begin{tabular}{ll}
\hline $1997 / 98$ & $80.00 \%$ \\
$1998 / 99$ & $75.00 \%$ \\
$1999 / 00$ & $73.30 \%$ \\
$2000 / 01$ & $52.40 \%$ \\
$2001 / 02$ & $52.60 \%$ \\
\hline
\end{tabular}

Source: Ministry of National Education \& Ministry of Religious Affairs (MONE \& MORA)

Notes: The Grade 1 cohort is defined as the group of children who start Grade 1 at the end of age 6 or beginning age 7 in the national education system in a given year. The proportion of a Grade 1 cohort completing 9 years of education is the number of children who complete each of the 6 full grades of primary school; qualifies and transitions to then complete each of the 3 full grades of junior high divided by the total number of children who start Grade 1. The numerator is smaller than the denominator when children drop out or repeat a grade. To illustrate, in 1997/98, $80 \%$ of all children who started Grade 1, 9 years before $1997 / 98$ completed the full course of primary school and junior high while $20 \%$ failed to complete the 9 years.

In the context of the Asian Financial Crisis, in the school year 1997 / $9880 \%$ of all children who started Grade 1, 9 years before 1997 / 98 completed the full course of primary school and junior high. However over the period of the crisis, this rate declined to $75 \%$ in the school year 1998 / 99 and to $73.30 \%$ in the school year 1999 / 00. By the school year $2001 / 01$ which is after the crisis, the rate deteriorated further to $52.40 \%$. Suryadarma, Suryahadi and Sumarto (2006) investigate this declining trend where they find that there is near universal primary school attendance but attrition occurs after the children sit for EBTANAS and do not transition to junior high.

Children who attend non-formal schools do not sit for EBTANAS. As a substitute they take the primary school level or junior high level equivalency tests (Packet A or Packet B) which are set at a lower level than EBTANAS. The timing of taking the equivalency tests is independent of the child's school age. This means that the child can sit for the primary school equivalency tests even though $\mathrm{s} /$ he is older than the school age of $7-12$. Likewise the child can sit for the junior high equivalency tests even though $\mathrm{s} /$ he is older than the school age of $13-15$. Because of the structure of equivalency tests in the national education system, one of the tradeoffs for the child choosing this source of skill formation is the s / he falls behind children of the same school age in the formal system. This is related to the lower amount of time allocated for learning and the flexibility in completing course work. Another 
tradeoff is that the child forgoes the EBTANAS credential for entering the labor market. This is unless the child enters the formal system and starts the education process from the beginning at grade 1 .

The informal school is a source of skill formation that is derived from education or skill development in the home. This includes apprenticeships, learning-on-the-job or home production / domestic work. Children from informal schools also do not sit for EBTANAS. However like children in non-formal school, they sit for the equivalency tests. Children who make this schooling choice experience different tradeoffs from children in non-formal schools. On the one hand, these children are developing productive skills within the family business or trade and these skills may also have private returns in the economy. The acquisition of such skills is consistent with Becker's theory of human capital accumulation. On the other hand the tradeoff is that these skills may be valued in the economy as unskilled or low skilled wages in comparison to the premium that skilled wages receive in the labor market. However the wage premium for skilled labor in the economy is dependent on the characteristics and relationships of the formal and informal sectors in Indonesia. Another tradeoff of skill acquisition from the informal school is that if parents perceive a higher value from the children working and learning within the family business, their children will spend more time in the household and be less inclined to allocate time for attending school.

For this chapter we focus on basic education consisting of primary school, ages 6 12; junior high school, ages $13-15$ and the alternative schooling equivalent for these school ages. But we do not provide an in-depth analysis of alternative schooling in this chapter. We will do this in Chapter 4 when we examine the incidence of simultaneous work-schooling behavior.

The education system is financed in broad terms by four sources: 1) funds from general government revenue 2) government revenues earmarked for education 3) tuition and other fees 4) voluntary contributions. In terms of the first two sources, this refers to central and regional government where by constitutional law, the central government should fund $20 \%$ of the total funding required each year. Revenues earmarked for education include foreign aid assistance. The third source of funding comes from the household and this varies based on the number of children being sent to school at the same time. The fourth source includes gifts from individuals, communities, charitable and religious bodies, domestic or foreign, whether in cash, kind or services; endowments, commercial or private loans; and the schools' own efforts to raise funds (Daroesman, 1971). Based on World Bank records (2007), the general split of funding sources for the education system is 1) central government, $20 \% 2$ ) regional / local government, $20 \%$ and 3 ) other sources including parents' contributions, $60 \%$. 
In end 1998, during the period of the financial crisis, MONE / MORA introduced a scholarship and block grant program for disadvantaged children in primary and junior high schools. This subsidy program was aimed at maintaining enrollments and maintaining the quality of basic education at pre-crisis levels. The scholarships were provided to the schools who then selected the children who would receive the scholarships. Groups of children identified by MONE / MORA as having the highest likelihood of dropping out of school because of the crisis were students from households with reduced incomes; primary school leavers who were not likely to transition to junior high; junior high school leavers who were not likely to transition to senior high; and girl teenagers who did not complete primary and junior high schooling. These groups of children were targeted by MONE / MORA as being in the poorest schools in a district and this was defined as schools in low income districts; schools that required parents to make higher than average monthly scheduled payments to cover operating costs; and schools that served students who live in government designated left behind villages (INPRES Desa Tertinggal, IDT). However it was acknowledged by MONE/MORA that it did not have full information concerning school conditions and the socio-economic background of the disadvantaged communities. This is because such information is mostly unavailable at the aggregate district level.

Using this description of the Indonesian education system, we document household spending behavior that includes the different groups of children defined as being at risk of dropping out. Given the institutional context, educational spending behavior entails credit constrained parents making decisions on whether to finance their children's education given upfront costs and delayed benefits and the mechanics of how their children receive an education. Various schooling participation strategies available to parents were - children could attend formal schooling or alternative schooling - religious schooling, home schooling apprenticeships, on-the-job training or a combination of methods. Within one school day, children could spend half their time in school and the other half of the time working with livestock, learning local animal husbandry.

\subsection{Data}

The dataset that is used is the RAND Corporation Indonesian Family Life Surveys (IFLS). We use Waves $2-1997$ and 3 - 2000. The sample size for Wave 2 is 10,356 individual observations and for Wave 3 it is 11,686 individual observations. Data for Wave 2 was captured at the end of 1997 when the financial crisis was about to occur and data for Wave 2 was captured at the end of the financial crisis in 2000. We use data from Wave 2 concerned with retrospective economic and schooling behavior covering the calendar year January - December 1997 and retrospective 
behavior for the school year July 1996 - June 1997. Similarly we use data from Wave 3 concerning retrospective economic and schooling behavior covering the calendar year January - December 2000 and the school year July 1999 - June 2000. IFLS consists of an additional Wave 2+ which was collected during the period of the financial crisis but this data is not publicly available. So we assume that the market source of price changes experienced by the household by its given location in 1999 is the same in 2000.

We merge observed data on household income to observed data on educational spending from separate IFLS books using an ID that matches the child aged 6-15 to the household ${ }^{7}$. Only biological parent-child relationships are considered. We then proceed to match income and education spending data to schooling data from another IFLS book. The schooling data that we have covers the schools available to the children within each community. In the observed data, all children can reach their school in not more than thirty minutes whether they go on foot or by using different modes of transportation. In the data, we find that a child can report attending more than one school in the community in a school year. This can be seen by the presence of more than one school ID matched to each child. The school types available are either MONE / MORA registered, publicly funded and managed; MONE / MORA registered, privately funded and managed or nonregistered schools with alternative learning methods. Also the schooling data covers information on whether the children benefitted from the national educational scholarship and whether schools participated in the block grant program for the school years 1999 and 2000. In the observed data, $4 \%$ of all children received MONE / MORA scholarships for the school years 1999 and 2000.

Educational spending data is captured in IFLS as the annual amount of household spending on education. In the observed data, educational expenditures consist of one time payments in the school year and streams of repeated payments across the school year. One time payments are the registration fee on the first day of the school year, the fee for taking the exams at the end of the school grade, a set of textbooks for the current school grade, writing supplies, uniform, sneakers and sports equipment. Repeated payments within the school year consist of the monthly scheduled parental contribution to the school's operating costs, transportation to and from school and private tuition outside of school hours. As described in Section 2.2.2 parental contributions for keeping the school running makes up a dominant $60 \%$ of total funding required.

As comparable income and education variables are available in Waves 2 and 3, we carry out a pair-wise matching of children in 1997 and 2000 that have the same age

\footnotetext{
${ }^{7}$ While the school age for starting primary school is 7 , some children start primary school at age 6 .
} 
group, household and schooling characteristics. These characteristics include where children reside and go to school in terms of island, province and urban-rural, school type; whether they have repeated a grade in primary school or in junior high ${ }^{8}$, the curriculum and by the school age of 12, the EBTANAS test score. Because of the consumer price variation over the period, we can then compare changes to spending strategies for children in the same age group progressing through the same educational system. In the next section, we will use general prices, income and education prices to document the changes.

\subsection{Prices, Income and Education}

\subsubsection{Price Indices}

In this sub-section, we describe the price deflators in use, why we choose certain price deflators over others and the reasoning for the type of goods and services to include or exclude from the computations.

As a departure point, we review the price and quantity data used by the Indonesia Central Bureau of Statistics (BPS) to calculate consumer prices and to estimate household purchasing power. BPS uses the Modified Lespeyres formula to calculate real prices. The bureau collects price and quantity data at the national level and provides information on household level consumption using the BPS SUSENAS household surveys. But we are unable to use the BPS price and quantity data for a more detailed analysis. This is because the BPS baseline quantities for urban areas are from 1996 and for rural areas from 1993, both periods that are before the financial crisis which are not representative of consumer prices during the crisis; and both baseline quantities had not yet been revised at the time of the crisis. To cover the period of prices before and during the financial crisis, we then reference Levinsohn, Friedman and Berry (1999) who have done extensive work measuring price changes and have the most available and reliable data. They use the Modified Lespeyres price deflator and the aggregate level SUSENAS data and their estimates capture 184 products and the price changes from January 1997 through October 1998. These changes are estimated across provinces and as a consequence might not capture changes at the disaggregated community level and household level. Nonetheless this helps us to understand the general movement of prices even though further price data until beginning 2000 is not available in their calculations. Their estimates are in Table 2.4 which captures the price changes of by aggregated product groups.

${ }^{8}$ In $1997,18 \%$ of children reported repeating a grade once and in 2000, $15 \%$ of children reported repeating a grade once. 
Table 2.4 Price Changes by Product Groups January 1997 to October 1998

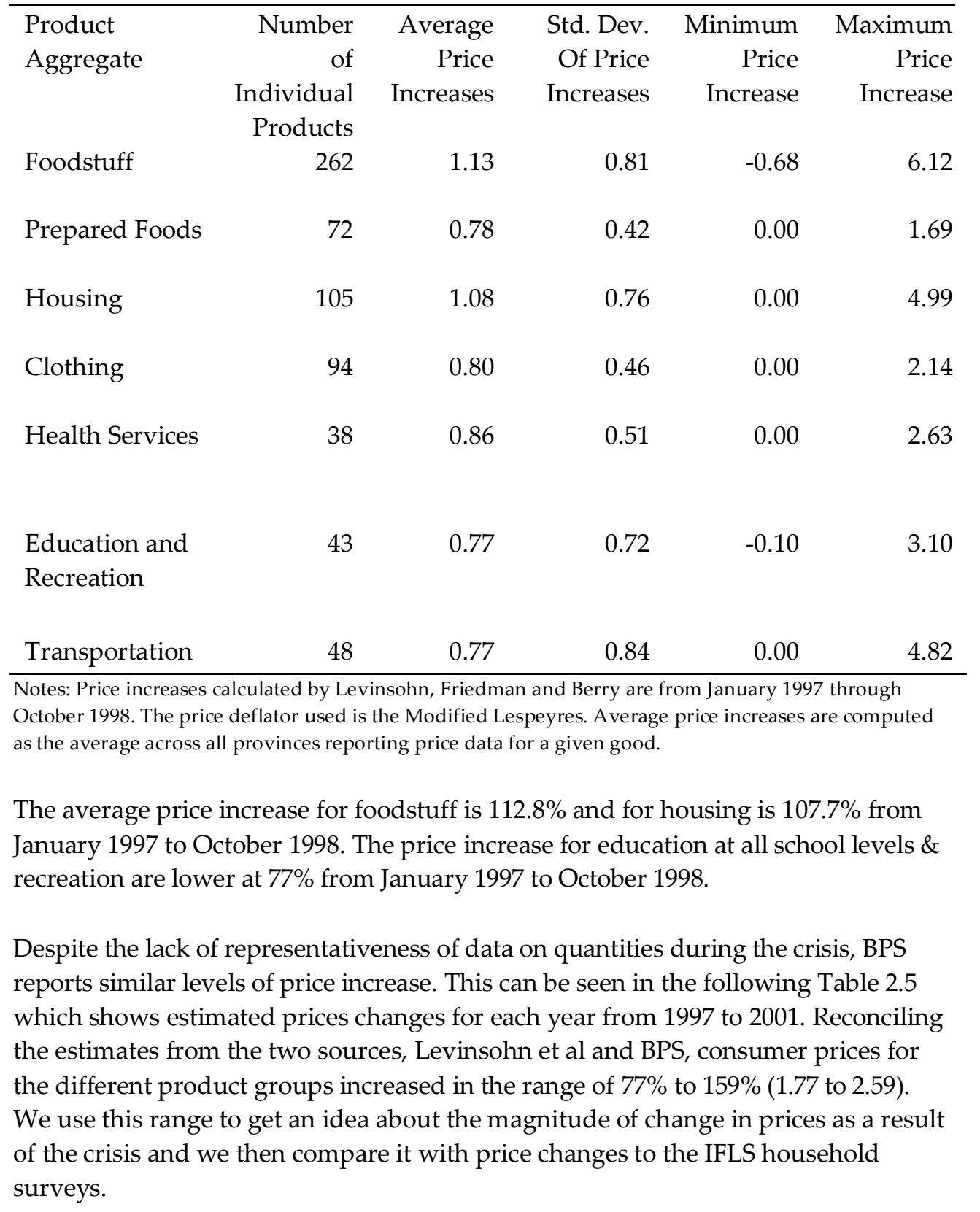




\begin{tabular}{|c|c|c|c|c|c|}
\hline Product Aggregate & 1997 & 1998 & 1999 & 2000 & 2001 \\
\hline General Index & 111.83 & 198.64 & 202.45 & 221.37 & 249.15 \\
\hline $\begin{array}{l}\text { Food and Food } \\
\text { Services }\end{array}$ & 120.54 & 263.22 & 249.54 & 259.53 & 290.74 \\
\hline $\begin{array}{l}\text { Prepared Food, } \\
\text { Beverages, Tobacco }\end{array}$ & 108.88 & 211.58 & 219.20 & 243.49 & 278.75 \\
\hline Housing & 107.84 & 159.03 & 166.77 & 183.61 & 208.57 \\
\hline Clothing & 110.58 & 219.71 & 233.21 & 256.98 & 277.90 \\
\hline $\begin{array}{l}\text { Pharmaceutical } \\
\text { Products \& Medical } \\
\text { Services }\end{array}$ & 114.18 & 212.54 & 220.37 & 241.46 & 262.99 \\
\hline $\begin{array}{l}\text { Education, Recreation } \\
\& \text { Sports }\end{array}$ & 117.27 & 161.84 & 170.44 & 200.28 & 224.12 \\
\hline $\begin{array}{l}\text { Transportation \& } \\
\text { Communication }\end{array}$ & 105.24 & 163.70 & 172.20 & 194.00 & 221.47 \\
\hline
\end{tabular}

Source: BPS

Using IFLS data for prices and quantities which were collected in 1997 and 2000, we measure disaggregated per capita household income using consumption and savings divided by the number of members in the household. By choosing the per capita measurement, we account for differences in household size. Regardless of how big or small the household size and how income is shared, we focus on the amount of consumption and savings for the child's education. We choose to use consumption instead of income because the latter suffers from measurement error. In the observed data, we find difficulties with substantial missing values for income which we do not think we can adequately manage through imputing values. Missing values were recorded for various reasons including lack of recall for monthly income over the year; different household interpretations of what constitutes as income such as gifts from extended family members; and inaccurate 
estimates stemming from various types of short term income generating activities over the period of the financial crisis. We include savings in the measurement based on the empirical evidence that savings in developing countries play an important role in financing education. As pointed out by Deaton (1989) savings in developing economies often play a crucial role as a buffer between income and consumption. In our calculation we assume savings to consist of currency, bonds and stocks on hand given the period of observation; there is no accumulated stock. Goods and services that originate from in-kind transfers and self-production are excluded from this calculation. This is because the schools in our observed data receive monetary payments and not goods or services as payments. As such we calculate consumption and savings on the basis of goods and services in the IFLS that have market prices and the price deflator used is Modified Lespeyres 9 . The price index computed for household income is 1.99 where the base year is 1997. By using the Modified Lespeyres deflator for household income, we have the same official price deflator that is used in Indonesia. However the price changes that we measure are at the household level and not at the aggregate national level. Nonetheless our computations show that price changes faced by the household are similar to the national level.

We do not use the alternative Tornquist-Spatial deflator which will give a different result from the Modified Lespeyres deflator. The computed index for TornquistSpatial is $2.06^{10}$ where the base year is 2000 using IFLS data. The main reason that we choose not to use the Tornquist-Spatial deflator is because we would like to study price differences while holding quality constant. The Tornquist-Spatial deflator uses 2000 instead of 1997 as the base year with the main reason to capture both price and quality effects to determine if the standards of living in 2000 after the crisis are the same as 1997 before the crisis. Also the Tornquist-Spatial deflator captures price differences geographically using Jakarta as the index because available price data from IFLS has an urban reporting bias ${ }^{11}$ which will overstate the value of goods and services from rural areas when compared with urban areas; and overstate the value of goods and services from other regions when compared with Jakarta. Furthermore the Tornquist-Spatial deflator does not capture the prices of seasonal goods and services while the Modified Lespeyres deflator does.

For calculating the cost of education, we construct our own price deflator for education using available data on the wages of primary and junior high school

\footnotetext{
${ }^{9}$ The modification for this deflator is a different treatment for elementary and seasonal goods and services. For elementary goods and services, the arithmetic mean for price relatives is used. For seasonal goods and services, the geometric mean is used.

${ }^{10}$ We thank the RAND Corporation for the price data to compute the Tornquist - Spatial index

${ }^{11}$ IFLS price data comes from BPS. Weekly price data is primarily collected from urban centers and less from remote rural areas.
} 
teachers that are in the same schools in the same communities in 1997 and 2000. Data on other education costs is not available. The price index computed for education is 2.47 where the base year is 1997 . Wages are used because changes over time are caused by the price effect and not the quality effect. The education price deflator enables us to hold school quality reasonably constant in 1997 and 2000 to isolate the pure income effect on education. One of the drawbacks of using teacher wages is family educational spending is primarily for school fees and monthly scheduled payments to cover school operational costs and not teacher wages. However the cost of schooling related fees are nonetheless indirectly related to teacher wages. We use this price deflator for education specifically covering primary school and junior high instead of using the Modified Lespeyres deflator which is computed using savings and all consumption goods including education at different school levels.

Table 2.6 provides a summary of the different price indices. A review of these price indices show that price changes for different consumer goods at the national aggregate level are in a similar range as at the disaggregated household level. As such our choice of the Modified Lespeyres deflator for household income and our self-constructed priced deflator for education are robust for computing real prices. 
Table 2.6 Price Indices

\begin{tabular}{|c|c|c|c|}
\hline Price Deflator & $\begin{array}{l}\text { Data for } \\
\text { Quantities }\end{array}$ & Base Year & Index \\
\hline $\begin{array}{l}\text { Modified Lespeyres for } \\
\text { income }\end{array}$ & $\begin{array}{l}\text { Levinsohn et al } \\
\text { calculations using } \\
\text { SUSENAS } \\
\text { household } \\
\text { surveys and BPS } \\
\text { (Table 2.4) }\end{array}$ & 1997 & $1.77-2.13$ \\
\hline $\begin{array}{l}\text { Modified Lespeyres for } \\
\text { income }\end{array}$ & BPS (Table 2.5) & $\begin{array}{l}1996 \text { - urban } \\
1993 \text { - rural }\end{array}$ & $1.94-2.59$ \\
\hline $\begin{array}{l}\text { Modified Lespeyres for } \\
\text { income }\end{array}$ & $\begin{array}{l}\text { Our calculations } \\
\text { using IFLS }\end{array}$ & 1997 & 1.99 \\
\hline $\begin{array}{l}\text { Tornquist-Spatial for } \\
\text { income }\end{array}$ & $\begin{array}{l}\text { Our calculations } \\
\text { using IFLS }\end{array}$ & 2000 & 2.06 \\
\hline $\begin{array}{l}\text { Our self constructed } \\
\text { deflator for education }\end{array}$ & $\begin{array}{l}\text { Our calculations } \\
\text { using IFLS }\end{array}$ & 1997 & 2.47 \\
\hline
\end{tabular}

\subsubsection{Income}

Using the Modified Lespeyres price deflator where the index is 1.99, we calculate changes to household income per capita between 1997 and 2000. These changes are expressed in log terms. We find that average household income per capita decreased by $1.89 \log$ points from 1997 to 2000 . Median income per capita has decreased by $1.97 \mathrm{log}$ points between the two periods. These descriptive statistics are in Table 2.7. 


\begin{tabular}{|c|c|c|c|c|c|}
\hline & Mean & Median & SD & Minimum & Maximum \\
\hline \multicolumn{6}{|l|}{1997} \\
\hline General & 16.3191 & 16.2909 & 0.8207 & 12.4408 & 21.8592 \\
\hline Urban & 16.3011 & 16.2639 & 0.8789 & 9.3359 & 21.8588 \\
\hline Rural & 15.9193 & 15.9366 & 0.8155 & 12.2584 & 20.3557 \\
\hline \multicolumn{6}{|l|}{2000} \\
\hline General & 14.4276 & 14.3259 & 0.8688 & 11.7272 & 19.2953 \\
\hline Urban & 14.2581 & 14.1296 & 0.9256 & 12.0122 & 19.2413 \\
\hline Rural & 13.7335 & 13.6622 & 0.7653 & 11.1641 & 18.1649 \\
\hline $\begin{array}{l}\text { Notes: The } \mathrm{n} \\
\text { using the ma } \\
\text { Indonesian c } \\
\text { which has ar } \\
\text { Indonesia. } \mathrm{T} \\
\text { using cash o }\end{array}$ & $\begin{array}{l}\text { usehold in } \\
\text { of goods a } \\
\text { speyres, in } \\
\text { se prices pr } \\
\text { d transfers } \\
\text { stocks at tl }\end{array}$ & $\begin{array}{l}\text { come is consu } \\
\text { hd services. Tr } \\
\text { dex is } 1.99 \text {. Th } \\
\text { edominantly c } \\
\text { and own prod }\end{array}$ & $\begin{array}{l}\text { tion and sc } \\
\text { rice deflat } \\
\text { LS price d } \\
\text { e from urb } \\
\text { ion are no }\end{array}$ & $\begin{array}{l}\text { vings. Consump } \\
\text { r used for the c } \\
\text { ata comes from } \\
\text { an outlets sprea } \\
\text { included. Savin }\end{array}$ & $\begin{array}{l}\text { tion is measured } \\
\text { lculations is the } \\
\text { PS price tracking } \\
\text { across } \\
\text { os is measured }\end{array}$ \\
\hline
\end{tabular}

From this table, rural incomes were lower than urban incomes in both periods. Reduced income and increased consumer prices point towards a severe deterioration in household purchasing power. This weakened purchasing behavior occurred for most households and this can be seen in the household income per capita distribution in the following Figure 2.4. There is a shift leftwards of the income distribution and there is a lower peak in the distribution in 2000 with more variability in income. 


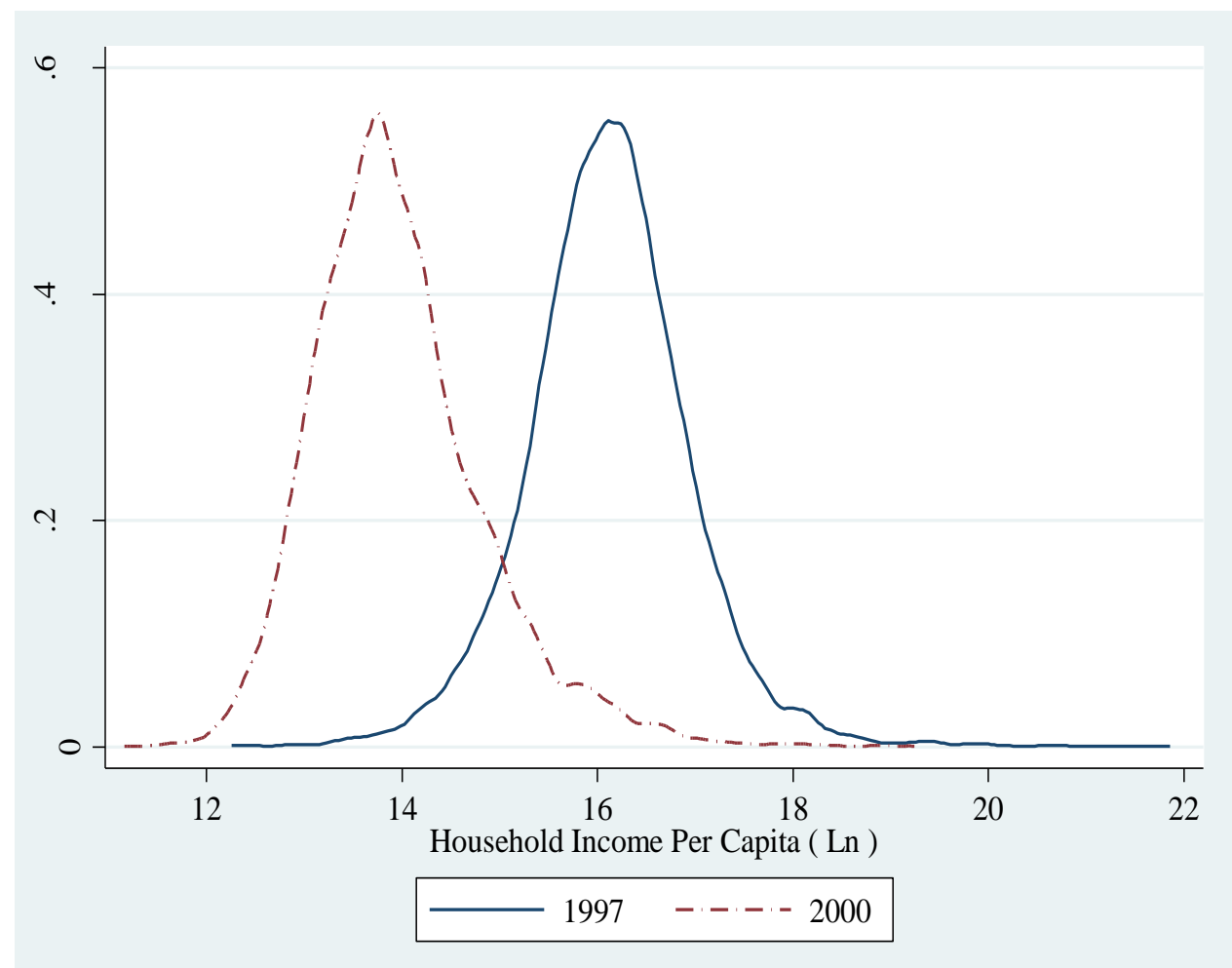

Notes: The measurement for annual household income is consumption and savings. Consumption is measured using the market valued prices of goods and services. The price deflator used for the calculations is the Indonesian official Modified Lespeyres, index is 1.99. The IFLS price data comes from BPS price tracking which has an urban bias because prices predominantly come from urban outlets spread across Indonesia. The values of in-kind transfers and own production are not included. Savings is measured using cash on hand, bonds and stocks at the point in time observed.

\subsubsection{Education}

Using the education price deflator, we find that average household spending on all education expenditures expressed in log terms fell by $0.13 \log$ points from 1997 to 2000. This can be seen in Table 2. 8 . 
Table 2.8 Household Spending on Education

\begin{tabular}{lccccc}
\hline $\begin{array}{l}\text { Mean } \\
\text { General }\end{array}$ & Median & SD & Minimum & Maximum \\
Urban & 10.5378 & 10.5966 & 0.8755 & 6.2146 & 12.6835 \\
Rural & 10.9312 & 11.0021 & 0.7759 & 7.4673 & 12.6835 \\
2000 & 10.2465 & 10.3089 & 0.8301 & 6.2146 & 12.5061 \\
General & & & & & \\
Urban & 10.4084 & 10.3979 & 0.8991 & 1.3983 & 13.2114 \\
Rural & 10.7594 & 10.7549 & 0.8329 & 6.0035 & 13.2114 \\
\hline
\end{tabular}

Notes: Education expenditures are calculated using the education price deflator, index is 2.47 .

In relation to the financial crisis, the average household could afford to only purchase a lower amount of education. In 1997, average educational expenditures were $10.53 \log$ points and in 2000 this fell to $10.40 \log$ points. In this respect, on average urban households were worse off than rural households, purchasing less education in 2000. But the minimum value for spending in rural households in 2000 was substantially lower at $1.39 \log$ points compared to urban households at $6.00 \log$ points.

Investigating this further in the following Figure 2.5, it can be seen that the distribution of spending in education has shifted from the right to the left from 1997 to 2000 . Also the 2000 distribution has a greater spread to the left towards zero. However the extent of the leftward shift in the educational spending distribution is less than the leftward shift in the income distribution. This implies that despite a severe reduction in household income, families are inclined to protect their children's education by continuing to spend albeit at a lower proportion than before the crisis. 


\section{Figure 2.5 Household Educational Expenditures}

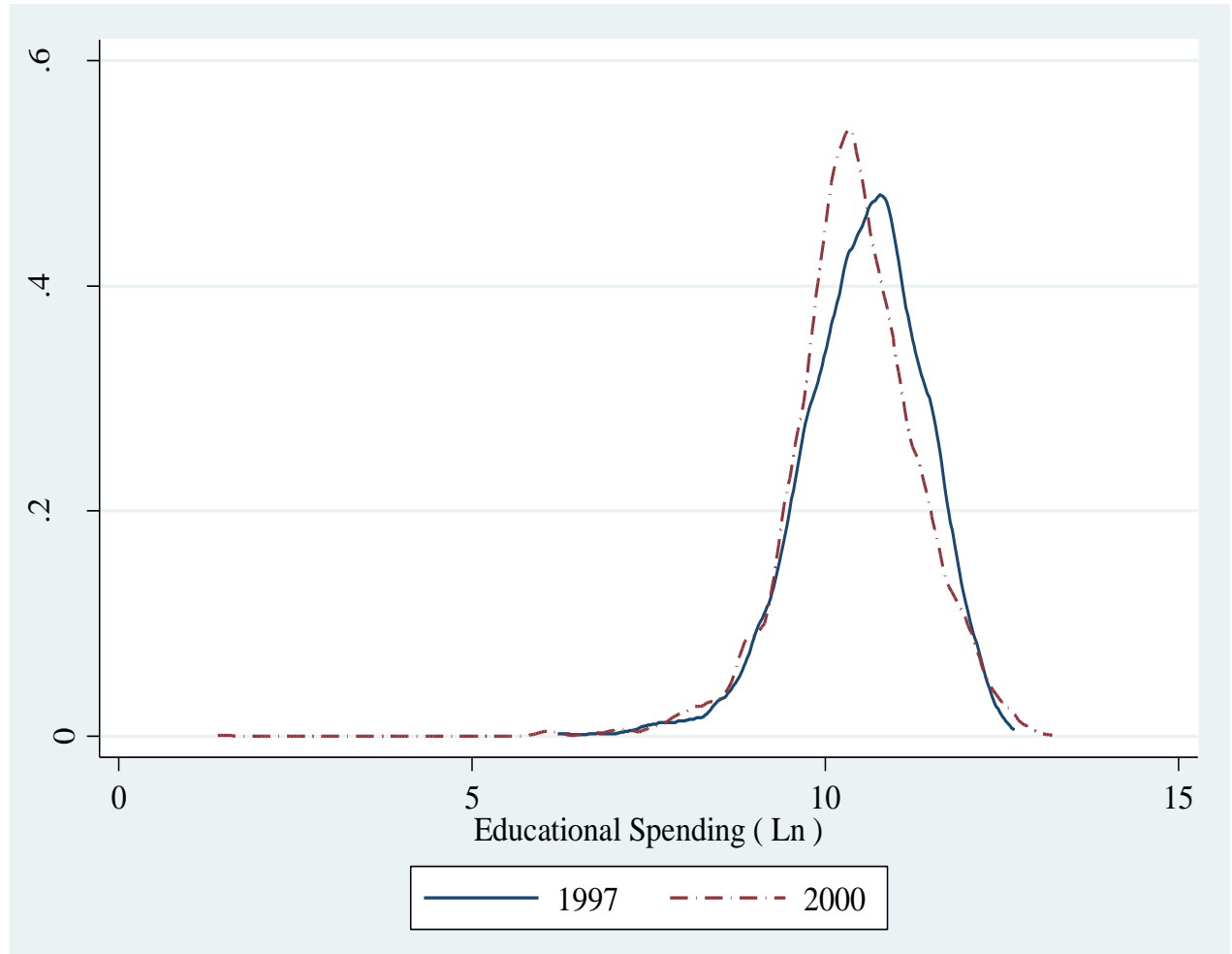

Notes: Annual education expenditures are calculated using our self constructed education price deflator, index is 2.47 .

Annual educational expenditures are split by type into registration fees, monthly scheduled fee payments, exam fees, books and writing supplies, school uniform and sports equipment; and transportation. Table 2.9 provides information concerning each expenditure type as a share of total expenditure on education. 
Table 2.9 Expenditure Type as Share of Total Educational Expenditures

\begin{tabular}{lcc}
\hline Expenditure Type & $\begin{array}{c}1997 \\
\text { (Means) }\end{array}$ & $\begin{array}{c}2000 \\
\text { (Means) }\end{array}$ \\
Registration Fee & 0.07 & 0.04 \\
Monthly Scheduled Fee Payments & 0.26 & 0.30 \\
Exam Fee & 0.03 & 0.03 \\
Books \& Writing Supplies & 0.34 & 0.38 \\
Uniform \& Sports Equipment & 0.26 & 0.21 \\
Transportation & 0.04 & 0.04 \\
\hline
\end{tabular}

Spending on books and writing supplies takes up the highest share of educational expenditures. Payment of monthly scheduled fees takes up the second highest share of educational spending. However, the one-time payment for the registration fee and the payment of the monthly scheduled fees are the crucial educational expenditures for continued participation in the full school year. These expenditures for fees are more important for uninterrupted schooling compared to other educational expenditures that can be compressed (e.g. uniform and sports equipment spending). As documented by Jones and Hagul (2001), registration fees enable the child to be enrolled in a school grade. The monthly scheduled fees enable the child to continue attending classes throughout the school year. Failure by parents to make the timely monthly payments results in the child being penalized by the school and withheld from class. Interestingly, Jones, Hagul and Damayanti (2000) also document the incidence of children who chose not to attend school during the crisis because parents could not afford to pay for a set of school uniforms.

Based on MONE / MORA district level school record data, a school that serves in a tax jurisdiction that receives lower fiscal transfers from government tends to set the level of monthly scheduled fees higher. Also based on World Bank documentation, privately funded and managed schools are more dependent on these monthly fees compared to publicly funded and managed schools. This is because public schools receive up to $40 \%$ of their total operating costs from central and local government fiscal transfers. Given this situation, parents have to ensure that a timely and reliable flow of fee payments are made each month. This situation is exacerbated when general price changes in the economy have volatile fluctuations. As such it can be strongly inferred that it is parental funding for school registration and monthly scheduled fees that ensures schooling participation continues throughout the school year. 
Table 2.10 presents the number of households that report zero spent by expenditure type. The expenditure type reported with highest zero spending is registration fees. The percentage of respondents reporting zero expenditure for registration fees is 0.65 in 1997 and this increases to 0.75 in 2000. This may at first appear to mean that far fewer children were enrolled in school in 2000 compared to 1997. But based on unobserved factors, there are two possible reasons why this may not be the case.

Table 2.10 Households Reporting Zero Spent by Educational Expenditure Type

\begin{tabular}{lccc}
\hline Expenditure Type & 1997 & 2000 & \% Point Diff. \\
Registration Fee & 0.65 & 0.75 & 10 \\
Monthly Scheduled Payments & 0.09 & 0.17 & 9 \\
Exam Fee & 0.67 & 0.60 & $(7)$ \\
Books \& Writing Supplies & 0.03 & 0.08 & 5 \\
Uniform \& Sports Equipment & 0.30 & 0.41 & 11 \\
Transportation & 0.92 & 0.91 & $(1)$ \\
\hline
\end{tabular}

First, the registration fees may be waived by the school or the state or second, the child is not registered to attend formal school. If not registered in formal school, this may then mean that the child is at home, at work or in an alternative to formal school. As the percentage of zero expenditure for registration fees has increased in 2000, this may mean that more children are not registered and / or not attending formal school during the crisis. To further investigate these registration fee statistics, we study the pattern of monthly scheduled fee payments. In marked contrast to a high proportion with zero spending on registration fees, only 0.09 of respondents reported a zero amount spent on monthly scheduled payments in 1997 and this percentage figure was 0.17 in 2000 . This means that the non-payment of registration fees does not necessarily mean that the child is not attending school as the household is still paying the monthly scheduled fees; children are still attending some form of schooling.

We un-censor the distributions of these two main educational expenditure types required for uninterrupted schooling participation to enable a comparison between 1997 and 2000. See the following Figure 2.6 which is a kernel density for registration fees. 
Figure 2.6 Registration Fees Censored Distribution

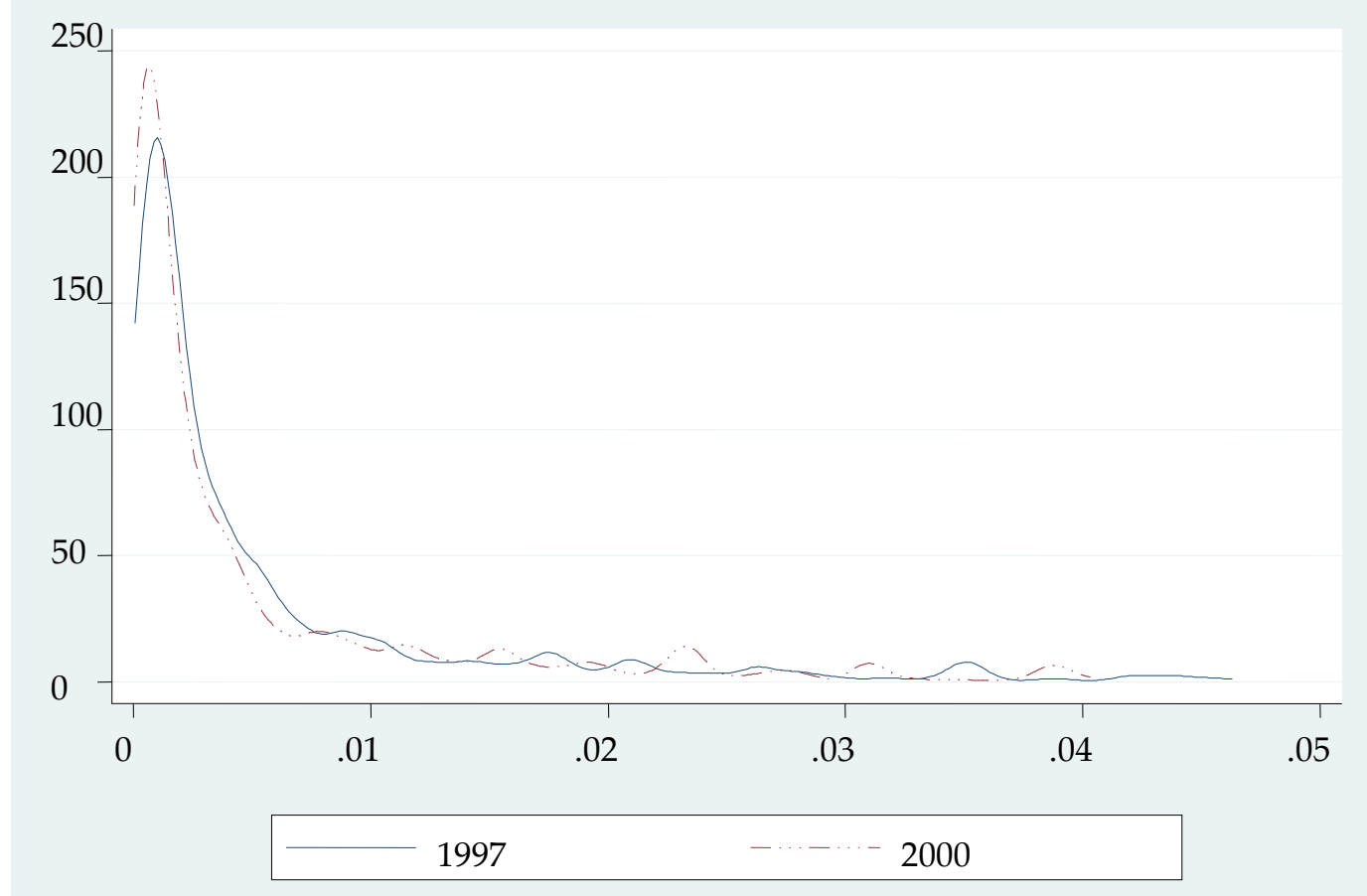

There is a peak for 1997 and 2000 where most values are clustered around zero. This does not imply that this is the true density. In Figure 2.7, the distribution from Figure 2.6 is un-censored. 


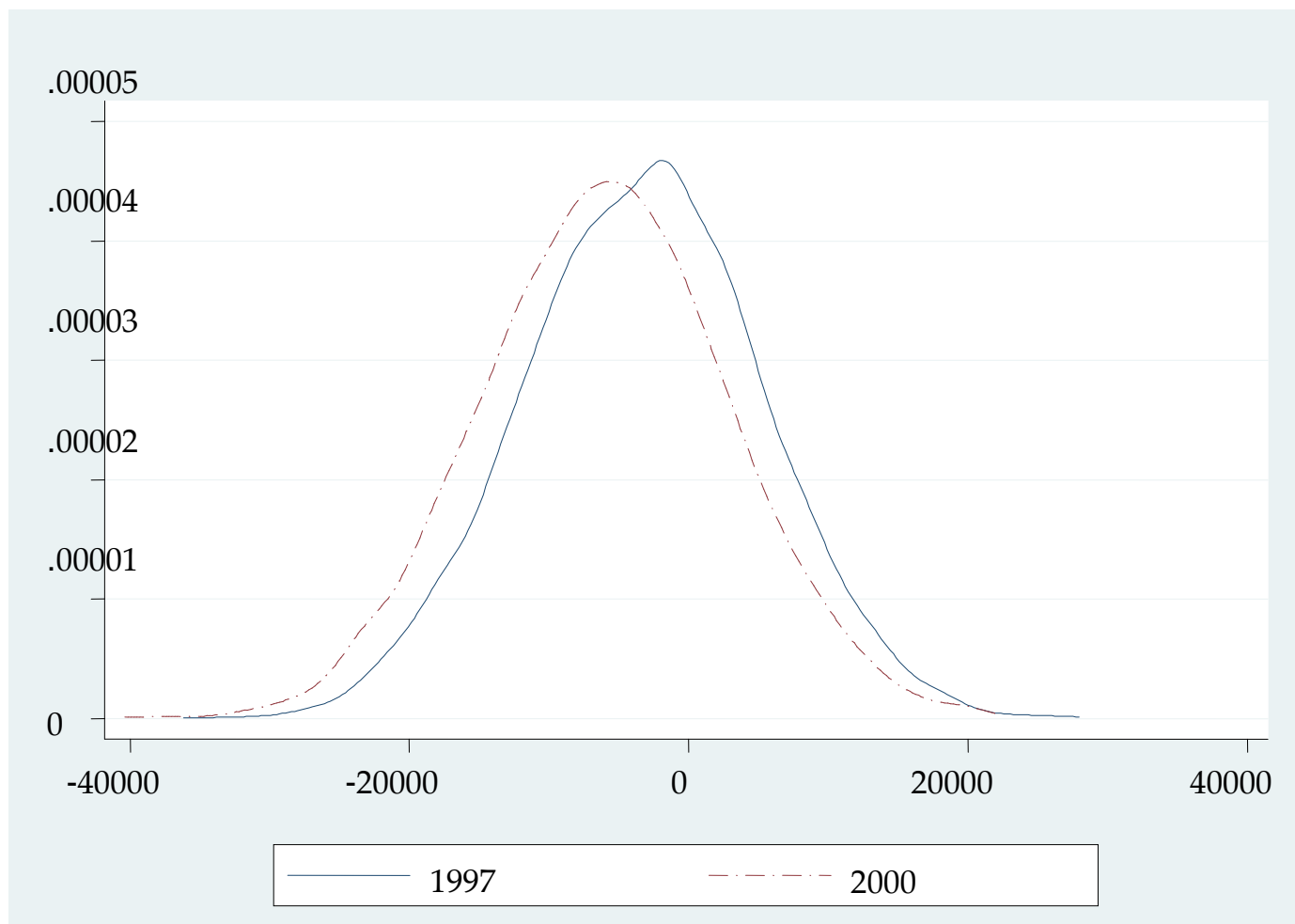

The selection problem can be seen where the un-censored distribution in 2000 compared to 1997 has shifted further to the left. This may be interpreted as a worsening of household behavior in registering their children for school. But as previously discussed, this household behavior may either be related to a registration fee waiver by the state subsidy program for education during the financial crisis or children are not enrolling in formal schooling. We attempt to investigate this further by referring to the observed data to disentangle the two possible explanations. In the data, we find only $4 \%$ of children reporting that they received any assistance from the state subsidy program. As such the alternative explanation may be non-enrollment in formal schooling and instead enrollment in alternative schooling.

The kernel density for monthly scheduled fee payments is in Figure 2.8. Again the highest density is around the zero value. This does not provide us with enough information. But based on Figure 2.9 the un-censored distribution, it can be seen that the shape of the distribution has changed from a tall peak in 1997 to a flattening 
out in 2000. There is greater variability in the pattern of monthly fees paid across households in 2000. Upon a more in-depth look at responses in the data concerning monthly scheduled fees, we find that parental contributions in 2000 are being made to not just formal schools that are regulated but to also alternative schools.

Figure 2.8 Monthly Scheduled Fees Censored Distribution

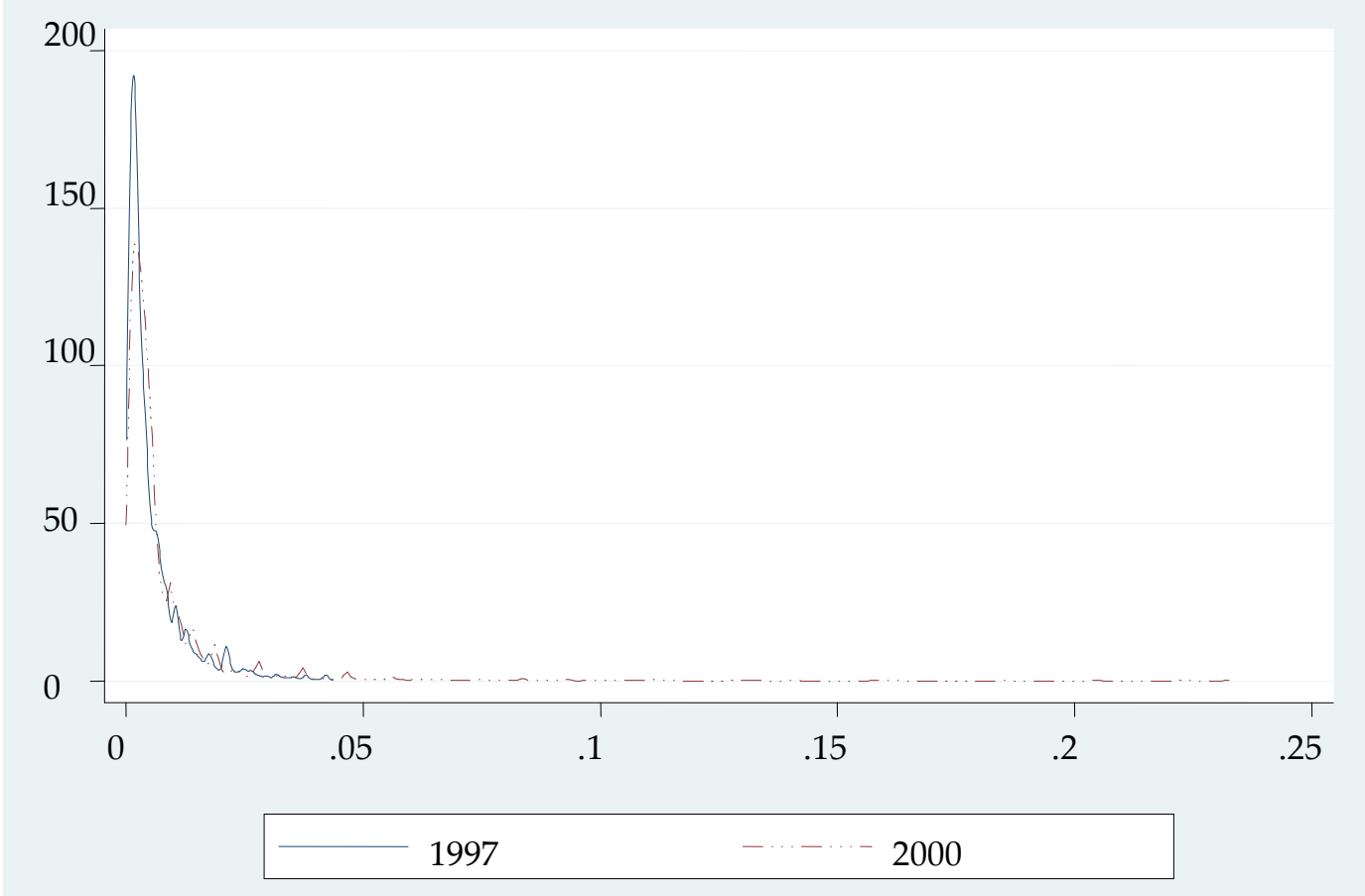




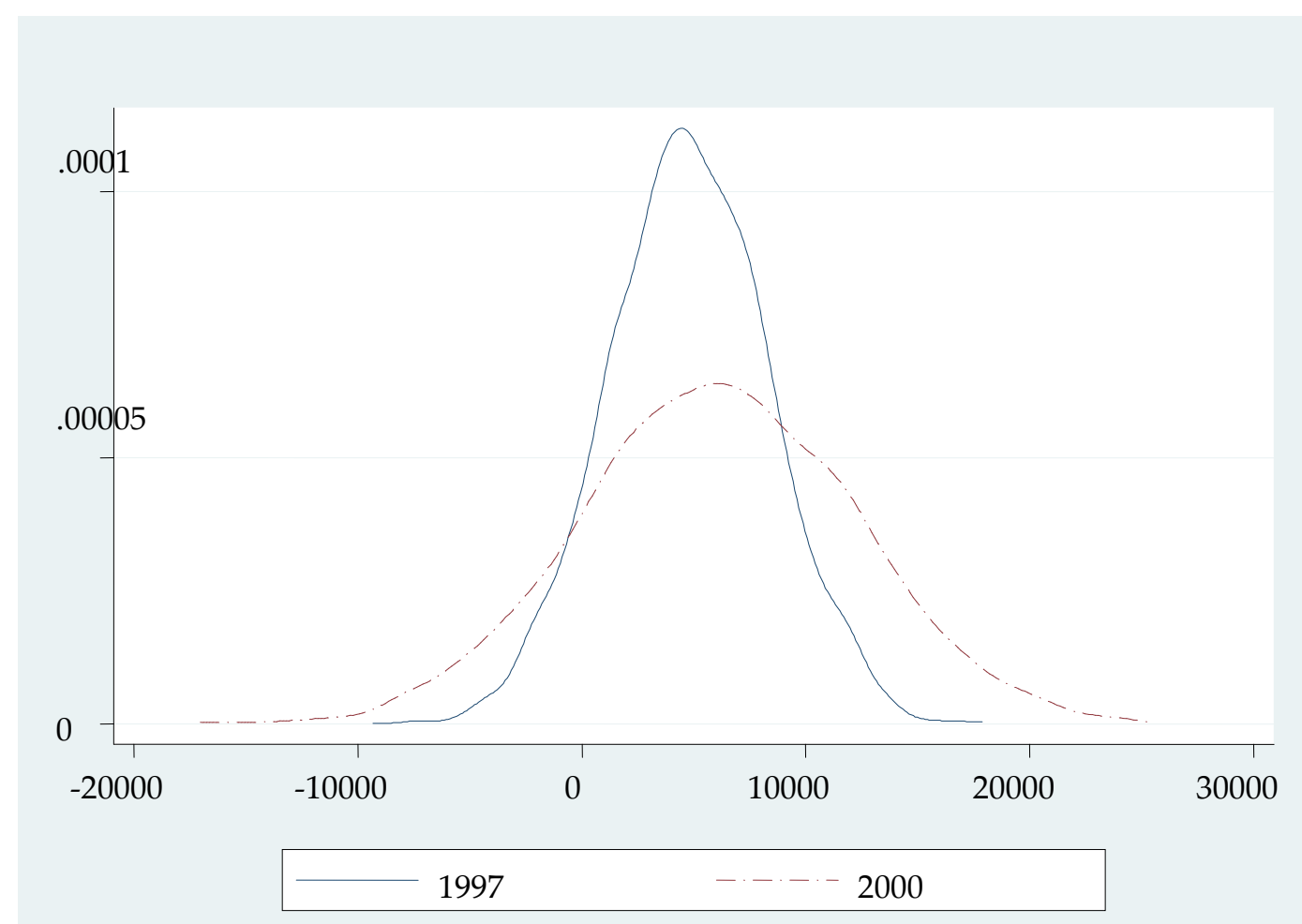

Since we have found that the fall in educational spending is in a smaller proportion than the fall in income (Figures 2.4 and 2.5), this leads us to follow the possible line of inquiry that parents may have maintained a similar or slightly smaller proportion of the total household budget for education in both periods but could only then purchase lower quality schooling in 2000. This line of enquiry is carried out in the next sub-section where we document the different educational strategies taken and the ensuing outcomes.

\subsubsection{Family Strategies for Education}

We start by looking at the fulltime schooling choices available to households. Table 2.11 shows that in $1997,87 \%$ of children were in public schools and $13 \%$ of children were in private school. In contrast in $2000,69 \%$ of children were in public schools, $24 \%$ of children were in private schools and $7 \%$ were in alternative schools. 


\begin{tabular}{|c|c|c|c|c|c|}
\hline School Type & \multicolumn{2}{|c|}{1997} & \multicolumn{3}{|c|}{2000} \\
\hline Public & \multicolumn{2}{|c|}{0.87} & \multicolumn{3}{|c|}{0.69} \\
\hline Private & \multicolumn{2}{|c|}{0.13} & \multicolumn{3}{|c|}{0.24} \\
\hline Alternative & \multicolumn{2}{|c|}{0.00} & \multicolumn{3}{|c|}{0.07} \\
\hline \multicolumn{6}{|c|}{ Children Attending Different School Types by Urban / Rural } \\
\hline School Type & \multicolumn{2}{|c|}{1997} & \multicolumn{3}{|c|}{2000} \\
\hline & Rural & Urban & $\mathrm{Ru}$ & & Urban \\
\hline Public & 0.60 & 0.40 & 0. & & 0.33 \\
\hline Private & 0.40 & 0.60 & 0. & & 0.46 \\
\hline Alternative & & & & & 0.21 \\
\hline \multicolumn{6}{|c|}{$\begin{array}{l}\text { Children from the Different Provinces by School Type Attended } \\
\text { Province (Geo-Code) }\end{array}$} \\
\hline & \multicolumn{2}{|c|}{1997} & \multicolumn{3}{|c|}{2000} \\
\hline & Public & Private & Public & Private & Alternative \\
\hline Sumatera Utara (12) & 0.81 & 0.19 & 0.74 & 0.22 & 0.04 \\
\hline Sumatera Barat (13) & 0.86 & 0.14 & 0.80 & 0.17 & 0.03 \\
\hline Sumatera Selatan (16) & 0.86 & 0.14 & 0.74 & 0.17 & 0.09 \\
\hline Lampung (18) & 0.81 & 0.19 & 0.72 & 0.21 & 0.07 \\
\hline Greater Jakarta (31) & 0.74 & 0.26 & 0.60 & 0.37 & 0.03 \\
\hline Jawa Barat (32) & 0.91 & 0.09 & 0.75 & 0.15 & 0.10 \\
\hline Jawa Tengah (33) & 0.91 & 0.09 & 0.67 & 0.28 & 0.05 \\
\hline Yogyakarta (34) & 0.71 & 0.29 & 0.52 & 0.47 & 0.01 \\
\hline Jawa Timur (35) & 0.83 & 0.17 & 0.65 & 0.29 & 0.06 \\
\hline Bali (51) & 0.97 & 0.03 & 0.87 & 0.06 & 0.07 \\
\hline Nusa Tenggara Barat (52) & 0.95 & 0.05 & 0.82 & 0.07 & 0.11 \\
\hline Kalimantan Selatan, (63) & 0.94 & 0.06 & 0.74 & 0.17 & 0.09 \\
\hline Sulawesi Selatan (73) & 0.96 & 0.04 & 0.83 & 0.06 & 0.09 \\
\hline
\end{tabular}

Notes: Children are asked to report on the school type that they attend fulltime. 
In the IFLS surveys in both years, households were asked to write down the type of schooling received if the other closed ended school type options (formal public or private schools) did not apply. We determined these open ended written descriptions to be alternative ways of learning which corresponds to descriptions provided by MONE and MORA in Section 2.2.2 and Figure 2.3. We add this alternative method into the portfolio of school choice. As argued by Heckman and Lochner (2000), we recognize non-institutional sources of skill formation like families, neighborhoods and firms to be as important as the formal school system for learning. Alternative schooling and the characteristics of children who attend these schools such as child laborers and child apprentices will be examined further in Chapter 4.

From Table 2.11, in terms of the urban-rural split, in $199760 \%$ of children from rural households went to public school and $40 \%$ went to private school. For urban children, the reverse pattern occurred where $40 \%$ went to public school and $60 \%$ went to private school in 1997. In 2000 the rural household public - private school split remained the same as in 1997. But there were changes for children from urban households. In $2000,33 \%$ of urban children were in public school; $46 \%$ of urban children were in private school and $21 \%$ of urban children were in a third type being alternative school.

$32 \%$ of total observed alternative schools in Indonesia were located in Java and Bali Islands and the rest split up between the Outer Islands. Because of modernization and consequently urbanization, Java and Bali Islands have attracted the majority of the population. Java and Bali based on BPS estimates in 2003 is home to $60 \%$ of the total country population but represents less than $7 \%$ of total land mass in Indonesia. Particularly the urbanization of Java is seen through the greater Jakarta area which is characterized by slum dwellings and landless labor and this is documented by BPS. Perhaps the majority population in Java and Bali has promoted the availability of more alternative schooling choices.

From these findings it is inferred that given the larger school type choice available to urban households, they had various ways to adjust their behavior when income fell. It is posited that parents could look for market driven solutions (unregulated by MONE and MORA) to maintain their children's education. Given these different strategies, households appear to vary the amount of school quality that they can afford to purchase. They choose to substitute between low quality and high quality schools. One of the possible consequences is the increased incidence of children attending low quality non-formal and informal schools while working. In the next section, we study whether this substitution in schooling quality has negatively affected the children in terms of educational outcomes. 


\subsubsection{Quality of Educational Outcomes}

Based on the observed data, there are EBTANAS test scores for children who on the basis of their scores have qualified to transition from formal primary school to formal junior high school. This means that in 1997, we have test scores for children who were at the junior high level. This level of schooling consists of three years. As such there are score records for students in the first, second or third year in this level. For a student in the first year of junior high in 1997, his / her test score is from 1996. For a student in the second year, the score is from 1995. For the third year, the score is from 1994. The same sequence applies to 2000 for the first, second and third school years being 1999, 1998 and 1997 respectively. We use EBTANAS to study which children succeeded or failed to transition and relate this to the period of the financial crisis. We use this measure of transition instead of years of schooling because entry into the Indonesian formal labor market is primarily determined by completion of successive school levels. ${ }^{12}$ As such the school level completed instead of schooling years completed is a more valid measure of human capital accumulation.

From the following Table 2.12, we find that there are two types of schooling behavior in the observed data. The first type consists of children who completed primary school, took EBTANAS and transitioned to junior high. The second type consists of children who completed primary school, took EBTANAS but failed to transition to junior high. For both periods, children who chose to transition have higher average test scores than children who do not transition. This suggests that higher ability children selected to progress on to junior high.

12 The level after SMP is senior high school for minimum entry into the formal labor market. 
Table 2.12 Characteristics of Children who Transition and Do Not Transition to Junior High

\begin{tabular}{|c|c|c|c|c|c|}
\hline \multicolumn{6}{|l|}{1997} \\
\hline \multicolumn{6}{|c|}{ Transitioned to Junior High: } \\
\hline \multicolumn{2}{|c|}{ Percentage Transitioned in 1997} & \multicolumn{2}{|l|}{0.87} & & \\
\hline \multicolumn{6}{|c|}{ Transitioned by Urban / Rural } \\
\hline \multicolumn{2}{|c|}{ Urban } & \multicolumn{2}{|l|}{0.51} & & \\
\hline Rural & & 0.49 & & & \\
\hline \multicolumn{6}{|c|}{ Transitioned by School Type } \\
\hline \multirow{2}{*}{\multicolumn{2}{|c|}{ Public }} & \multicolumn{2}{|l|}{0.89} & & \\
\hline & & \multicolumn{2}{|l|}{0.11} & & \\
\hline Private & Mean & Median & SD & Min & Max \\
\hline EBTANAS Score & 32.00 & 31.55 & 5.36 & 18.31 & 46.40 \\
\hline Income & 16.3491 & 16.3093 & .7547 & 14.0391 & 20.6554 \\
\hline \multicolumn{6}{|c|}{ Did Not Transition to Junior High: } \\
\hline Percentage Did N & & 0.13 & & & \\
\hline \multicolumn{6}{|c|}{ Did Not Transition by Urban / Rural } \\
\hline Urban & & 0.25 & & & \\
\hline & & 0.75 & & & \\
\hline \multicolumn{6}{|c|}{ Did Not Transition by School Type } \\
\hline Public & & 0.94 & & & \\
\hline \multirow[t]{2}{*}{ Private } & & 0.06 & & & \\
\hline & Mean & Median & SD & Min & $\operatorname{Max}$ \\
\hline EBTANAS Score & 27.57 & 27.57 & 5.53 & 14.61 & 39.61 \\
\hline Income & 16.0401 & 16.5964 & .7626 & 14.2409 & 18.4817 \\
\hline \multicolumn{6}{|l|}{2000} \\
\hline \multicolumn{6}{|c|}{ Transitioned to Junior High: } \\
\hline Percentage Transi & & 0.83 & & & \\
\hline \multicolumn{6}{|c|}{ Transitioned by Urban / Rural } \\
\hline Urban & & 0.49 & & & \\
\hline \multirow{2}{*}{$\begin{array}{l}\text { Rural } \\
\text { Transitioned by School Type }\end{array}$} & & 0.51 & & & \\
\hline & & & & & \\
\hline \multicolumn{2}{|c|}{ Public } & 0.88 & & & \\
\hline \multirow[t]{2}{*}{ Private } & & 0.12 & & & \\
\hline & Mean & Median & SD & Min & Max \\
\hline EBTANAS Score & 33.53 & 33.45 & 5.56 & 14.10 & 46.5 \\
\hline Income & 13.93 & 13.8327 & .8429 & 11.97 & 17.62 \\
\hline \multicolumn{6}{|c|}{ Did Not Transition to Junior High: } \\
\hline Percentage Did N & & 0.17 & & & \\
\hline Did Not Transitio & & & & & \\
\hline Urban & & 0.22 & & & \\
\hline Rural & & 0.78 & & & \\
\hline Did Not Transitio & & & & & \\
\hline Public & & 0.95 & & & \\
\hline Private & & 0.05 & & & \\
\hline & Mean & Median & SD & Min & Max \\
\hline EBTANAS Score & 30.04 & 29.81 & 5.34 & 13.90 & 43.30 \\
\hline Income & 13.3981 & 13.3669 & .6601 & 12.1711 & 16.6185 \\
\hline
\end{tabular}


Also average test scores overall are higher in 2000 compared to 1997. But there is a larger spread of scores in 2000 compared to 1997. In 2000, 17\% of students did not sit for all 5 tests compared to 1997 where only $1 \%$ of students did not sit for all tests $^{13}$. This affected the lower bound of the cumulative test score reported in 2000.

The second type of schooling behavior, qualifying but not transitioning was also observed by Suryadarma, Suryahadi and Sumarto (2006). They investigate the causes of low junior high enrollment despite near universal primary school attendance. They find that attrition during the transition between primary school and junior high is the main cause. Our findings concerning this second type of schooling behavior can be seen in Table 2.11 and the following Figure 2.10.

${ }^{13}$ We carried out tabulations for the EBTANAS test scores by of the five individual subjects but do not report them in this chapter. 


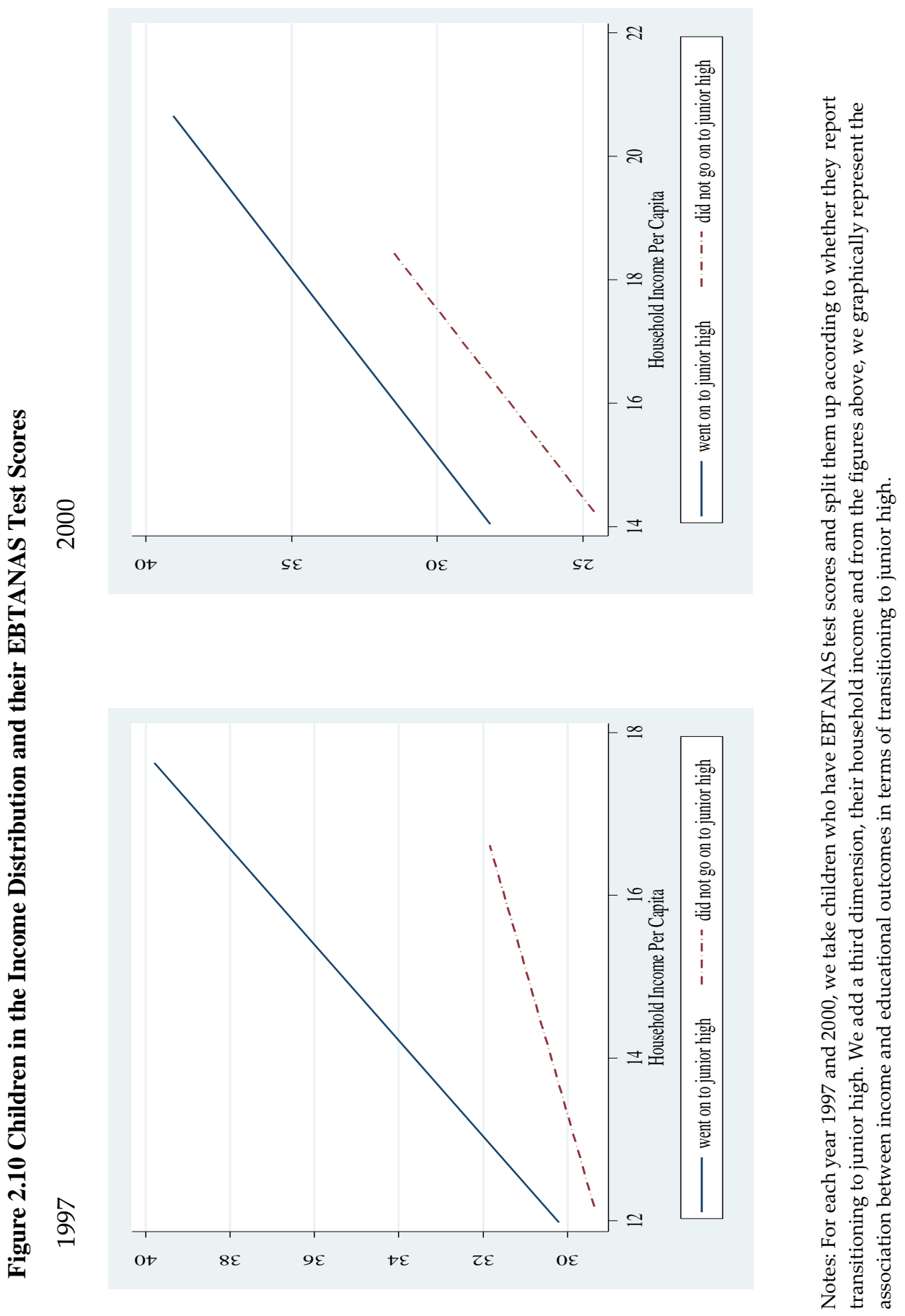


In Figure 2.10, for each year observed, we split children with EBTANAS test scores into two groups by whether they qualified and transitioned to junior high or not. As seen first in Table 2.12 and then in Figure 2.10, there are then two groups each for 1997 and 2000 and their position in the household income distribution.

Children who qualify but do not transition to junior high in both periods are fewer than those who do qualify and transition. But when comparing the percentage of all qualified children who do not transition for 1997 and 2000, we find a deterioration of this outcome in 2000. In 2000, 30\% more children qualified but did not transition compared to 1997.

In the observed data a majority of almost $90 \%$ of the children who transition come from public schools and this appears to be a naturally occurring trend because the same proportion is seen in both periods. This may because most children select into public schools because of higher quality than private schools and this is also observed by Newhouse and Beegle (2005). When viewed in terms of the income distribution, in 2000, the non-transitioned children come from households with lower incomes than in 1997. In Figure 2.10, upon further investigation there is a greater distance in test scores between non-transitioned and transitioned children in 2000. In 1997 children up to the 50th percentile of the distribution did not transition. But in 2000 this became worse where children all the way up to the $60^{\text {th }}$ percentile of the distribution did not transition to junior high. Since these children were still in primary school in the prior crisis years of 1998 and 1999, it can be inferred that reduced household incomes for up to the $60^{\text {th }}$ percentile resulted in failure to transition to junior high. Also it may appear that some of these children chose alternative schooling which would have compromised their eligibility to sit for EBTANAS.

\subsection{Conclusions}

In this chapter we documented family spending behavior adjusting to an unanticipated reduction in household income. We find that the amount of education that is purchased is reduced and in relation to this, the quality of educational outcomes over the period of the AFC is compromised. By analyzing un-censored distributions for education related expenditures, we are able to document and infer unobserved differences in education spending behavior. It is found that parents used various strategies to maintain their children's schooling participation - struggling to keep up with making timely monthly scheduled fee payments, substituting between public and private school, choosing alternative schooling and deciding for their children to combine work with learning. The ability of the child on the basis of EBTANAS test scores is also a factor that parents 
took into consideration where children with a better educational performance qualified and transitioned to junior high. But despite the different education strategies taken there were children with household incomes up to the $60^{\text {th }}$ percentile who qualified but did not transition to junior high. This raises the question whether the children continued their formal education later in time after the AFC or never resumed their formal schooling.

The effects of the AFC washed away relatively quickly at the macroeconomic level. But we argue that given the empirics on family background and intergenerational mobility (Becker and Tomes, 1964), such associated effects can be profound in terms of labor market outcomes and social changes. By losing out even temporarily on a quality education in the formal education system, there may be a generation of children who have come of age now a decade later and unable to effectively compete in the formal labor market. Or this generation of children may have lost out on further building socially productive skills.

Given this documentation and our arguments, we have provided justification for the use of the AFC as an instrumental variable that is relevant and exogenous. We show that the AFC is relevant because it is correlated with income and it is plausibly exogenous because it is not directly correlated with educational spending but through its correlation with income. As such we will use the AFC as an instrumental variable in Chapters 4 and 5 . However we are fully cognizant of the possibility of the differential effects of the AFC on education across the archipelago. As such we will examine this aspect of regional variation in Chapter 3. 


\section{Appendix 2.7 Censored Normal Distribution}

We remove the assumption of normality for the distributions of interest. This is to enable the analysis of a dependent variable that is a zero for a non-negligible proportion of the observations. Formally, the problem reads as follows. Let $\mathrm{Y}$ be a random variable that is normally distributed with mean $\mu$ and variance $\sigma^{2}$. Let $y_{i}, i=1, \ldots, N$ be independent draws from this distribution. Let $y_{i}^{*}=y_{i}$ if $y_{i}>0$ and 0 otherwise. Suppose only $y_{i}^{*}$ is observed and the following method will recover $\mu$ and $\sigma^{2}$ from the data on $y_{i}^{*}$

From the theorem of the moments of the censored normal variable, we have:

$$
\begin{aligned}
& E\left[Y^{*}\right]=(1-\Phi(\alpha))(\mu+\sigma \lambda) \\
& \Phi(\alpha)=\operatorname{Pr}\left[Y^{*}=0\right]
\end{aligned}
$$

where $\lambda=\frac{\phi(\alpha)}{1-\Phi(\alpha),} \alpha=-\frac{\mu}{\sigma}$ and $\sigma$ and $\Phi$ respectively are the standard normal PDF and CDF.

We replace the moments with their empirical counterparts. Note that $\operatorname{Pr}\left[Y^{*}=0\right]$ is the share of zeroes in the data. By inverting the standard normal at $\operatorname{Pr}\left[Y^{*}=0\right]$ gives us $\alpha=\Phi^{-1}\left(\operatorname{Pr}\left[Y^{*}=0\right]=\frac{\mu}{\sigma}\right.$. Knowing $\alpha$ we can calculate $\lambda=\frac{\phi(\alpha)}{1-\Phi(\alpha)}$. We end up with a system of 2 linear equations with 2 unknowns $\mu$ and $\sigma$ in the form:

$$
\begin{aligned}
& \mu=-\sigma \Phi^{-1}\left(\operatorname{Pr}\left[Y^{*}=0\right]\right) \\
& \mu=\frac{E\left[Y^{*}\right]}{(1-\Phi(\alpha))}-\lambda \sigma
\end{aligned}
$$


3. Electricity Access, Use and Children's Educational Performance 


\subsection{Introduction}

In developing countries, promoting schooling includes establishing and maintaining physical infrastructure. One of these basic facilities is the availability of electricity in the school and the household. This enables children to learn efficiently where studying can take place in both the classroom and at home. Doing homework and study revision at home complements classroom instruction. However in a large developing country like Indonesia, there is wide regional variation in the distribution of electricity where underdeveloped areas have less access to electricity compared to industrial and growth areas. Unequal access to electricity is a potential constraint for educational performance.

The aim of this chapter is to study the proposed correlational relationship between the availability and use of electricity and educational performance; given regional variation ${ }^{14}$. We investigate the standardized achievement test scores of Indonesian children aged 12 where we exploit variation in the availability and in the use of electricity in the school and the household across different communities. We examine whether available electricity is used as electric light for learning or whether different uses of electricity influence outcomes. We study the children's educational performance using test scores for two periods, 1997 and 2000.

In the literature, Glewwe and Kremer (2005) write about the wide variation in educational input levels and education systems across developing countries which affect the quality of schooling. Teachers are often absent from classrooms and many children learn much less than the learning objectives set in the official curriculum (Lockheed and Verspoor, 1991; Harbison and Hanushek, 1992; Hanuskek, 1995; Glewwe, 1999). Also many schools lack the most basic equipment and school supplies and sometimes even classrooms, in which case classes meet outside and are cancelled when it rains (World Bank, 1997 and Glewwe, 2004). But Kremer et al (2005) find that in India one of the positive correlates of teacher presence is school infrastructure which represents better working conditions. In Honduras, Bedi and Marshall (2001) find that better school facilities increase primary school attendance. Also Alatas (2000) finds that the introduction of basic infrastructure in left behind villages in Indonesia improves school enrollment. More specifically, Bacalod and Tobias (2006) find that minimal basic facilities in the school, particularly electricity matter more for test score performance in the Philippines than class size and teacher training programs. This chapter contributes to this strand of the literature by focusing on the availability and use of electricity in the school and household in Indonesia on educational achievement.

\footnotetext{
${ }^{14}$ This chapter does not use the Asian Financial Crisis as an instrument and instead focuses on regional variation.
} 
The rest of the paper is set up in the following way. Section 3.2 provides a description of the energy sector in Indonesia and how electric energy is delivered from the source to the final user. This description consists of the layout of the energy sources, power plants and transmission lines in the main islands. We also include the distribution trends for industrial, household (including school) and transport use. Section 3.3 provides a description of schooling provision in Indonesia and how school quality is documented by the national school census. Section 3.4 covers the empirical specification and the data we use, the Indonesian Family Life Surveys (IFLS). In Section 3.5 we provide descriptive statistics followed by results in Section 3.6. Conclusions are made in Section 3.7.

\subsection{The Energy Sector in Indonesia}

According to the Energy Information Administration of the US Government which compiles energy statistics from around the world, Indonesia's power generation sector is dominated by the state-owned electric utility PT PLN (Persero), formerly known as Perusahaan Listrik Negara. The history of PT PLN in Indonesia began at the end of 19th century stemming from the Dutch East India Company establishing power generation for its trading interests in certain geographical areas in the archipelago. The electrical energy enterprise then expanded into the public interest company, NV.NIGM. In World War II, the Japanese seized control of the electric companies. After Indonesian Independence in 1945 the Republic of Indonesia assumed ownership of the energy infrastructure. PT PLN operates 45 power plants and transmission lines for on-grid energy supply, or roughly two-thirds of the country's generating capacity.

Indonesia's electricity sector faces severe underinvestment, and the country's energy officials have set out on a program to expand generation capacity. The consequences of underinvestment are bottlenecks in provincial level interconnections between bulk transmission and sub-transmission levels, overloading and voltage problems at sub-transmission levels (World Bank, 2003). The bottlenecks in provincial level interconnections negatively affect the efficient transmission of electric power. As such the outcome of transmission inefficiencies is uneven and interrupted electricity transmission. These interruptions can manifest themselves in terms of brownouts where there is a drop in voltage and lights dim and / or; blackouts where there is a total loss of power.

One of the major obstacles to increasing Indonesia's power generating capacity is pricing. The government sets the price at which PT PLN sells electricity in the country. In relation to the Asian Financial Crisis, from end 1997 - end 2006 the central government suspended PT PLN automatic tariff adjustments annually for 
the price of electricity and made a guarantee of electricity distribution for nonindustrial sector use i.e. households. In certain regions of the country there is then the rationing of how much electricity that a household can consume. PT PLN's financial difficulties, coupled with its inability to increase power prices, have prevented the company from investing in new infrastructure projects to build up capacity.

The following Figure 3.1 provides the layout of power plants, existing bulk transmission lines and planned transmission lines. Sub-transmission lines at the provincial level are not included due to unavailability of data. Tracing the bulk transmission lines without going on to trace the sub-transmission lines provides sufficient information for which islands receive most of the electricity capacity; without the main transmission lines electricity cannot be delivered.

\section{Figure 3.1 Indonesia Main Power Plants and Transmission Lines}

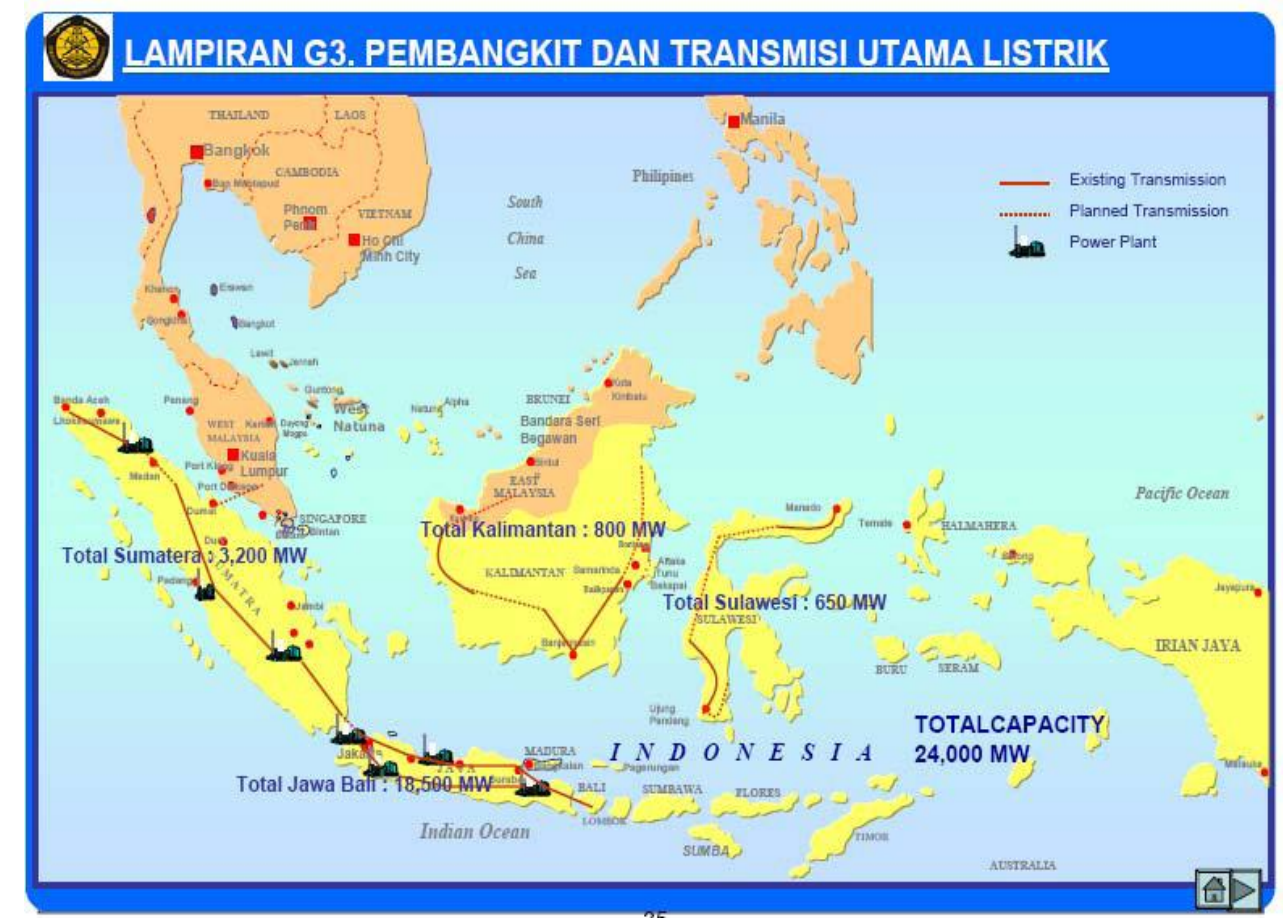

Source: Perusahaan Listrik Negara (PLN)

In this map, it can be seen that the islands of Java and Bali have four power plants and transmission lines extending from one tip of Bali Island and connecting to the other tip in Java Island. The concentration of power plants and main transmission lines on these two islands are a part of the legacy of the Dutch East India Company. 
As such, much of Java and Bali are on the grid where up to $77 \%$ of total country capacity is available to the residents of these two islands. These transmission lines extend west toward Sumatera Island where there are three power plants. Sumatera receives $13.3 \%$ of total country capacity available. The disproportionate distribution when measured in spatial terms is exacerbated for Kalimantan which receives only $3 \%$ of total capacity available. This disproportionately low percentage is associated with the absence of any power plant on the island. Kalimantan is located on Borneo Island and this island is shared by three countries - Brunei, Indonesia and Malaysia. Kalimantan to a certain extent is dependent on the Malaysian grid for the transmission and distribution of electricity. The more underdeveloped Eastern Indonesia which consists of Sulawesi and the Nusa Tenggara \& Papua cluster of small islands, receive the remaining miniscule percentage of capacity available. Areas that are not covered by the main and sub-transmission lines are off-grid and rely on alternative energy sources and delivery of electricity such as gas power generators and the use of firewood or candles for light.

The measurement of electricity distribution and consumption in Indonesia is by final use in a given sector. From Table 3.1, when reviewing the periods 1997 - 2000, total installed capacity in the country increased but at a slower rate compared to consumption needs.

Table 3.1 Indonesia Total Installed Capacity and Electricity Consumption 1997 2000

Indonesia

Recent Total Installed Capacity

(Billion Kilowatt Hours)

Rate of Increase

Electricity Consumption

Rate of Increase

1997

1998

1999

2000

Source: Department of Energy, US Government

Notes: "Recent Total Installed Capacity" is the measure for how much cumulative capacity a country has to generate electricity. "Electricity Consumption" measures how much electrical power is used by all sectors in the country.

Table 3.2 provides the national distribution trend from 1990 - 2005 for use in i) industry ii) household (including school) and commercial enterprise iii) transport and iv) others. 
Table 3.2 Distribution of Final Energy Use by Sector in Indonesia

\begin{tabular}{ccccc}
\hline Year & $\begin{array}{c}\text { Industry } \\
\text { (\% Use) }\end{array}$ & $\begin{array}{c}\text { Household \& } \\
\text { Commercial } \\
\text { (\% Use) }\end{array}$ & $\begin{array}{c}\text { Transportation } \\
(\% \text { Use })\end{array}$ & $\begin{array}{c}\text { Others } \\
(\% \text { Use })\end{array}$ \\
1990 & 33.25 & 23.93 & 34.91 & 7.90 \\
1991 & 32.56 & 23.64 & 35.64 & 8.16 \\
1992 & 33.75 & 22.63 & 35.87 & 7.75 \\
1993 & 34.11 & 22.18 & 35.13 & 8.58 \\
1994 & 35.67 & 21.94 & 33.52 & 8.87 \\
1995 & 36.03 & 21.50 & 33.26 & 9.21 \\
1996 & 34.16 & 21.63 & 34.43 & 9.78 \\
1997 & 34.60 & 21.91 & 33.98 & 9.52 \\
1998 & 34.79 & 23.34 & 34.71 & 7.16 \\
1999 & 39.93 & 21.68 & 32.08 & 6.31 \\
2000 & 41.81 & 21.05 & 31.21 & 5.94 \\
\hline
\end{tabular}

Source: Indonesia Ministry of Energy and Natural Resources

Notes: This table provides a breakdown of electrical power consumed by different users from 1990 - 2000. The users are defined as i) industry ii) household and commercial use (including schools) iii) transportation and iv) others. The definition for electrical power used includes all sources of energy - petroleum, dry natural gas, coal, net hydro, nuclear, geothermal, solar, wind, wood and waste electric power. But biomass energy is excluded.

But there is no information available on sub-national distribution trends. Industrial use dominates in the range of $33 \%$ to $42 \%$ of total consumption in this time series; energy for transport use takes up 31\% to 35\% while household, school and commercial use tend to make up about 20\% of electricity consumption. From 1997 to 2000, percentage use by industry increases for each year. The percentage use for household / school and commercial use increases by 6\% from 1997 to 1998 and then dips by 7\% from 1998 to 1999 and falls again by 3\% from 1999 to 2000 .

\subsection{School Quality and the National School Census}

Since the end of the Suharto regime and the introduction of regional autonomy laws, there is an increasing trend of schooling provision adjusted to a greater extent to meet local indigenous needs. These needs include the curriculum adjusted based on the religious, social and cultural characteristics of a community, flexible classroom sessions in the mornings or afternoons and classroom sessions on weekends. For a full description of the curriculum and the national education 
system, refer to Chapter 2. Geographic factors in relation to building schools and maintaining school quality also have to be taken into consideration. As such schools that are regulated and managed by MONE and MORA are registered in the national school census. To ensure that the registered schools maintain a minimum standard of school quality such as the level of teacher qualification and the availability of teaching and learning material, there is also a checklist for required physical school conditions that will promote an effective learning environment. The checklist is in Table 3.3 .

\section{Table 3.3 MONE / MORA School Census Data - School Conditions Checklist}

1. What is the number of seats in the classroom? (If one bench can be used for 6 students, then the count is 6 seats)

2. Are the blackboards, chalk and erasers in the classroom usable?

3. Is teaching in this classroom ever disrupted by inadequate lighting from the main source of light, like window, door and opening?

4. Does the classroom use any electric lighting?

5. If yes, what is the main source of electricity?

- PLN

- Local Government Agency

- School Generator

- Social Self Reliance

- Private Company or Cooperative

6. Did this classroom ever lose electrical power, and did this disrupt the study activities?

7. When disruptions occur, is a substitute electricity source available?

8. Describe the floor of the classroom

9. Describe the walls in this classroom

10. Describe the roof used in this classroom

11. During the rainy season, did this classroom experience problems with: leakage / floods / flash rains 
Ensuring that schools have physical conditions that meet the minimum standards of school quality is considered a pressing issue for schools serving in the central government designated INPRES Desa Tertinggal (IDT) or Villages Left Behind Program. This redistribution program is designed to identify underdeveloped villages for the reduction of regional inequality. These neglected villages tend to be characterized as being underdeveloped communities that include farm laborers, peasants, fishermen, forest dwellers and young dropouts. These villages are classified as left behind using population statistics; data on the village's local economic characteristics; whether the local population lives below the poverty line; and the presence or absence of basic infrastructure and provincial government provided facilities such as health services, schools, marketplaces, potable water, electricity, and roads. ${ }^{15}$ Based on the program's statistics, $94 \%$ of the villages classified as IDT are located in rural areas. The $6 \%$ located in urban areas are in slums. Because of underdevelopment, school quality in IDT villages is lower than schools that are not serving in IDT villages. Consequently children's educational performance in IDT villages is very likely to be negatively affected.

\subsection{Empirical Strategy}

The dependent variable is educational performance as measured by the children's standardized achievement tests EBTANAS taken at the school age of 12. EBTANAS assesses the child's historical performance from age $6 / 7$ at grade $1^{16}$, to age 12 at grade 6 . EBTANAS is used to assess cognitive skills in the Indonesian language, math, science, social studies and religious studies. The maximum score possible for EBTANAS is 50 points. We compare the children's EBTANAS educational performance over two periods, 1997 and 2000 using pooled cross sections. We investigate whether there exists a relationship between the availability of electricity and electricity use in schools and households within a community and the child's educational performance. As our investigation is carried out when the Asian Financial Crisis occurred in 1998, 1999 and to some extent in 2000, we factor this context into our analysis.

We carry out the analysis at the community level which consists of the child's school and home. Our sample is restricted to communities that have schools and households that report on whether they have access to electricity or not, if yes the source of electricity (on the grid or off grid) and subsequently electricity use. We do not have sufficient observations for schools that have access to the other types of school infrastructure as described in Table 3.3. As such the sample is restricted to

\footnotetext{
${ }^{15}$ The selection of villages into the program will also be politically driven and this was pointed out by Perdana and Maxwell (2004). But our main consideration is the classification of this set of villages which we will use in our empirical specification to identify villages that have low access to electricity.

${ }^{16}$ While the starting school age for primary school is 7 years old, some children start at 6 years old.
} 
electricity access in the school as well as in the household. We start with an OLS base specification consisting of teacher quality, textbook loans to students and IDT schools as educational inputs explaining the child's educational achievement. From IFLS, textbook loans are represented by Indonesian language and Math textbooks only. The IDT variable represents underdevelopment in the child's school and household where there is only basic infrastructure available. The IDT variable is then a proxy for low access to electricity. This is because in IFLS there is no data available on the number of watts used in each community and there is no data on the frequency of blackouts and brownouts. This base specification is similar to Glewwe and Jacoby (1995) who attempt to isolate the school based determinants of school achievement - teacher experience, the availability of textbooks and the physical quality of a school. Also we include the availability of textbooks following findings by Newhouse and Beegle (2005) where public schools in Indonesia that have textbooks available for use are of higher quality. The number of subtransmission lines and connections to the national PLN grid in IDT are lower than in developed communities. It is then more likely that schools and households in an IDT community have low access (number of connections, volume and frequency) to electricity compared to other communities that have high access to electricity. Also the IDT variable is highly likely to be associated with low quality of educational inputs compared to a developed community. That is, there may be fewer highly qualified teachers who are willing to be posted to an underdeveloped community and the latest textbooks may not be easily available.

We then expand the OLS base specification to include the endogenous explanatory variables family income and the amount of the family budget allocated for educational expenses. We do this to determine if the family has any role in influencing test score variation. Then we introduce various variables measuring electricity access and use to determine if there exists a relationship between electricity and educational performance, after controlling for the child's school characteristics, household characteristics and underdevelopment in the community (IDT).

We add an island control variable to the specification where a community is located in Java and Bali Islands or not because of the placement of the grid and the main transmission lines across the Main Islands. As 77\% of the country's total energy capacity (both on-grid and off-grid) is available to Java and Bali, communities located on these two islands are more likely to have access to electricity as opposed to communities in Sumatera, Kalimantan, Sulawesi and the cluster of small islands in Nusa Tenggara and Papua. The bulk of energy capacity available on these two main islands also demonstrates that the major concentration of economic activity, $60 \%$ of the country's GDP is in Java and Bali (Hill, 1992; Hill et al, 2008) In addition, we add a control variable for the community being located in 
an urban area where there is presumably more waged economic activity than a rural area.

As we investigate the proposed correlational relationship between electric light and educational outcomes between 1997 and 2000, there are potential unobserved community characteristics that drive the correlation between using electric light and educational performance. For example, a family with limited access to electricity because of poor electricity infrastructure may choose to substitute away from activities that depend on the use of electricity. This may then enable their children to use the limited electricity available for studying. To address this issue, we add community level fixed effects in some of the specifications to capture time invariant community characteristics that may be related to educational performance.

The empirical specification to estimate the relationship between electric light and educational performance are first in the following reduced forms:

$$
\begin{gathered}
a_{i j}=\beta_{0}+\beta_{1} s_{i j}+\beta_{2} r_{j}+\varepsilon_{i j} \\
a_{i j}=\beta_{0}+\beta_{1} s_{i j}+\beta_{2} r_{j}+\beta_{3} y_{i j}+\varepsilon_{i j}
\end{gathered}
$$

where $a_{i j}=$ child $i$ educational performance in community $j ; \beta_{0}=$ child constant / base state; $s_{i j}=$ child $i$ attends school $s$ in community $j$ which has the educational inputs of teacher quality measured using the percentage of teachers in the school with an undergraduate degree; the number of students who borrow Indonesian language and Math textbooks because they do not have any of their own and the characteristic of whether the school serves in an IDT (dummy variable); $r_{i}=$ controls for the regional distribution of electricity to Java and Bali Islands and the Outer Islands (dummy variable) and distribution to urban areas (dummy variable) that have industrial and commercial activity compared to rural areas that have agricultural activity and subsistence economies; $y_{i j}=$ child $i$ household characteristics of income per capita and educational spending expressed in log terms. Specification (1) provides estimates for the relationship between school educational inputs and test scores. Specification (2) incorporates the role of income and family background in terms of willingness to finance education into the estimation. These two specifications provide estimates for how educational performance is influenced by school quality and the family at the community level without yet factoring in the availability of electricity. These two specifications cover underdeveloped and developed communities. Measures of electricity access in the school and household and community level fixed effects are added in specification (3) as follows:

$$
a_{i j}=\beta_{0}+\beta_{1} s_{i j}+\beta_{2} y_{i j}+\beta_{3} r_{j}+\beta_{4} e_{i j}+c_{j}+\varepsilon_{i}
$$


where $e_{i j}=$ school and household have access to electricity in community $j$ (dummy variables); $c_{j}=$ fixed effects to capture time-invariant community characteristics that may be related to educational outcomes. There is a small percentage of missing values for the electricity access variables which we do not drop. Finally specification (4) introduces the interaction between community underdevelopment, electricity availability and electricity use as follows:

$$
a_{i j}=\beta_{0}+\beta_{1} s_{i j}+\beta_{2} y_{i j}+\beta_{3} r_{j}+\beta_{4} e_{i j}+\beta_{5} u_{i j}+\beta_{6} s u_{i j}+c_{j}+\varepsilon_{i j}
$$

where $u_{i j}=$ uses of electricity in the school and the household in community $j$ (dummy variables); $s u_{i j}=$ the interaction of the school characteristic of serving in an IDT (Left Behind Village) with electricity use in school and at home in community $j$. The interpretation of $\beta_{6}$ is the number of EBTANAS points increased that is explained by the availability of electricity in the child's school and home and electricity use for schooling and learning (low availability, low use if IDT, high availability, high use if not IDT).

The data that we use is the RAND Corporation Indonesian Family Life Surveys (IFLS) Waves 2 - 1997 and 3-2000. In IFLS, there is information on family income and family spending on education. Educational expenditures are detailed by expenditure types and whether spending is on a one time basis in the year or a monthly flow of payments throughout the school year. The expenditure types consist of registration fees, scheduled fee payment / contributions to the school, textbooks for each course taken, writing supplies, uniforms, transportation costs, private tuition, special courses and field trips. There is also a detailed description of the household's physical living environment; and whether it has any electricity connection, a television and a refrigerator to store perishable food. Watching television may be of indirect if not direct educational value which we will include in our analysis. We exclude the refrigerator variable from our estimations because the IFLS question is concerned with the use of the refrigerator to store perishable food. There is no direct relationship with education. This dataset also provides information on schooling inputs which consists of teachers, textbooks and classrooms equipped with electricity. The data on schooling inputs is the same as the MONE / MORA school census data. The questionnaire for the school physical conditions component can be seen in Table 3.3. In the data there is also the child's officially reported EBTANAS test scores. The regional variables that we use from the data are by island, community, urban / rural and whether the village is underdeveloped (IDT).

We merge the variables of interest for community level of analysis using available identifiers for the school, the household and the child. Because children can shift between available schools of close proximity within the same community, we do not observe the same individual children from the same household and from the 
same school over the two periods of time. Also we do not observe a large sample of the same households ${ }^{17}$ with two siblings the older aged 12 and the younger aged 9 in 1997 or aged 12 and 9 in 2000. As such we use the two pooled cross sections to observe children from a given household attending school within a given community. In addition, the use of repeated cross sections increases sample size and power for analysis.

The main potential concern faced is the endogenous explanatory variables representing where the family resides and whether there is out-migration for schooling reasons. We address this in various ways. First, within our sample we analyze family responses to IFLS questions concerning migration and the education of primary school age children. This is done for 1997 and for 2000. From our analysis, the family does not move to another community even if the choice of schools available or the quality of schooling is low within the existing community. Also we find that there is no household breakup since none of the children aged 12 in the sample have moved away from their parents for schooling reasons. Second, we cross check these family responses by their location at the sub-district level and the district level and find that there is still no movement at the higher administrative levels. Third, further observations show that in the $99^{\text {th }}$ percentile, the children take not more than 30 minutes to travel from home to school be it on foot, by bicycle or another mode of transportation. This means that the home and the school are located in the same community. However these observations are only based on the families observed once in 1997 and families observed once in 2000. There may have been out-migration from the community to schools in other communities in prior periods.

An additional potential issue faced in this estimation is that the endogenous exploratory variables representing schooling inputs and access to electricity are time lagged with respect to the dependent variable. That is, the inputs are used in the educational production function over the 6 grades of primary school and the outcome is only observed at the end of the primary school level. The outcome variable EBTANAS test scores are only arrived at when the child is age 12. So in the first period of observation 1997, the 12 year old has educational performance that is related to schooling inputs and unobserved variables from 1996 and 1995.

Correspondingly in the second period of observation 2000, performance is related to time-lagged variables from 1999 and 1998. To address this issue, in our sample we limit the time lagged schooling input variables to two prior years to observing the outcome because it is likely that the children's preparation for EBTANAS is more focused when the child is aged 10 and 11, closer to age 12. Also this two prior year limit enables us to capture the child's schooling behavior during the two years

${ }^{17}$ The balanced panel for households was only a small sample of 45 units. 
of the financial crisis 1998 and 1999 and how this affects educational performance in 2000 .

In Tables 3.4, 3.5 and 3.6 we further outline the proposed relationship of children having and using electric light for improving educational performance.

Table 3.4 Measures of Association between Educational Performance, Electricity in School and Electricity at Home in 1997

Test Scores for Children with the Characteristics of i) Using Electricity in School ii)

Using Electricity at Home iii) Attending School in IDT in 1997

Means and SD (in Parentheses) Are Reported

School is in IDT in 1997? Then Does House Use Electricity?

\begin{tabular}{|c|c|c|c|c|c|c|}
\hline \multirow{2}{*}{$\begin{array}{l}\text { Using } \\
\text { Electricity } \\
\text { at School? }\end{array}$} & \multicolumn{3}{|c|}{ No, School is Not in IDT in 1997} & \multicolumn{3}{|c|}{ Yes, School is in IDT in 1997} \\
\hline & $\begin{array}{l}\text { No, House } \\
\text { Doesn't } \\
\text { Use } \\
\text { Electricity }\end{array}$ & $\begin{array}{l}\text { Yes, House } \\
\text { Uses } \\
\text { Electricity }\end{array}$ & Total & $\begin{array}{l}\text { No, House } \\
\text { Doesn't } \\
\text { Use } \\
\text { Electricity }\end{array}$ & $\begin{array}{l}\text { Yes, House } \\
\text { Uses } \\
\text { Electricity }\end{array}$ & Total \\
\hline No & $\begin{array}{l}29.14 \\
(4.38)\end{array}$ & $\begin{array}{l}30.19 \\
(5.80)\end{array}$ & $\begin{array}{l}30.07 \\
(5.65)\end{array}$ & $\begin{array}{l}28.07 \\
(3.85)\end{array}$ & $\begin{array}{l}30.14 \\
(4.43)\end{array}$ & $\begin{array}{l}29.38 \\
(4.33)\end{array}$ \\
\hline Yes & $\begin{array}{l}27.67 \\
(5.51)\end{array}$ & $\begin{array}{l}32.04 \\
(4.97)\end{array}$ & $\begin{array}{l}31.67 \\
(5.16)\end{array}$ & $\begin{array}{l}25.81 \\
(0.65)\end{array}$ & $\begin{array}{l}31.75 \\
(4.98)\end{array}$ & $\begin{array}{l}31.50 \\
(5.02)\end{array}$ \\
\hline Total & $\begin{array}{l}28.22 \\
(5.13)\end{array}$ & $\begin{array}{l}31.50 \\
(5.29)\end{array}$ & $\begin{array}{l}31.19 \\
(5.36)\end{array}$ & $\begin{array}{l}27.84 \\
(3.72)\end{array}$ & $\begin{array}{l}31.10 \\
(4.82)\end{array}$ & $\begin{array}{l}30.43 \\
(4.80)\end{array}$ \\
\hline
\end{tabular}

Table 3.4 provides 1997 measures of association for EBTANAS test scores along three dimensions IDT status, school electricity access and household electricity access. If a child in a non-IDT is in a school and house that do not have access to electricity, average test scores are 29.14 points. But when the house has electricity access average test scores are a higher 30.19 points. In the reverse, if a child in a non-IDT is in a school with electricity access but in a house without electricity, average test scores are a lower 27.67 points. The positive measure of association electricity in the household and test scores is higher than for electricity in the school and test scores. However the combination of available electricity in the school and the home in a non-IDT, average test scores are the highest in all the reported cells in Table 3.4 at 32.04 points. If a child in an IDT is in a school and house that do not 
have access to electricity, average test scores are 28.07 points. But when the house has electricity access average test scores are a higher 30.14 points. Interestingly in the reverse, if a child in an IDT is in a school with electricity access but in a house without electricity, average test scores are 25.81 points which is the lowest score in all the reported cells in Table 3.4. For the combination of available electricity in the school and the home in an IDT, average test scores are at 31.75 points which is lower than the same combination in a non-IDT.

Table 3.5 provides 2000 measures of association for EBTANAS test scores along three dimensions IDT status, school electricity access and household electricity access.

Table 3.5 Measures of Association between Educational Performance, Electricity in School and Electricity at Home in 2000

Test Scores for Children with the Characteristics of i) Using Electricity in School ii) Using Electricity at Home iii) Attending School in IDT in 2000 Means and SD (in Parentheses) Are Reported

School is in IDT in 2000? Then Does House Use Electricity?

\begin{tabular}{|c|c|c|c|c|c|c|}
\hline \multirow{2}{*}{$\begin{array}{l}\text { Using } \\
\text { Electricity } \\
\text { at School? }\end{array}$} & \multicolumn{3}{|c|}{ No, School is Not in IDT in 2000} & \multicolumn{3}{|c|}{ Yes, School is in IDT in 2000} \\
\hline & $\begin{array}{l}\text { No, House } \\
\text { Doesn't } \\
\text { Use } \\
\text { Electricity }\end{array}$ & $\begin{array}{l}\text { Yes, House } \\
\text { Uses } \\
\text { Electricity }\end{array}$ & Total & $\begin{array}{l}\text { No, House } \\
\text { Doesn't } \\
\text { Use } \\
\text { Electricity }\end{array}$ & $\begin{array}{l}\text { Yes, House } \\
\text { Uses } \\
\text { Electricity }\end{array}$ & Total \\
\hline No & $\begin{array}{l}29.49 \\
(4.25)\end{array}$ & $\begin{array}{l}32.16 \\
(4.49)\end{array}$ & $\begin{array}{l}31.83 \\
(4.54)\end{array}$ & $\begin{array}{l}28.67 \\
(3.57)\end{array}$ & $\begin{array}{l}30.54 \\
(5.03)\end{array}$ & $\begin{array}{l}29.88 \\
(4.63)\end{array}$ \\
\hline Yes & $\begin{array}{l}31.67 \\
(5.87)\end{array}$ & $\begin{array}{l}34.43 \\
(5.26)\end{array}$ & $\begin{array}{l}34.26 \\
(5.34)\end{array}$ & $\begin{array}{l}30.17 \\
(5.11)\end{array}$ & $\begin{array}{l}30.67 \\
(6.97)\end{array}$ & $\begin{array}{l}30.64 \\
(6.88)\end{array}$ \\
\hline Total & $\begin{array}{l}30.79 \\
(5.35)\end{array}$ & $\begin{array}{l}33.87 \\
(5.17)\end{array}$ & $\begin{array}{l}33.63 \\
(5.25)\end{array}$ & $\begin{array}{l}29.10 \\
(4.05)\end{array}$ & $\begin{array}{l}30.64 \\
(6.61)\end{array}$ & $\begin{array}{l}30.43 \\
(6.34)\end{array}$ \\
\hline
\end{tabular}

If a child in a non-IDT is in a school and house that do not have access to electricity, average test scores are 29.49 points. But when the house has electricity access average test scores are a higher 32.16 points. In the reverse, if a child in a non-IDT is in a school with electricity access but in a house without electricity, average test scores are a lower 31.67 points. The positive measure of association electricity in the household and test scores is higher than for electricity in the school and test scores. 
However the combination of available electricity in the school and the home in a non-IDT, average test scores are the highest in all the reported cells in Table 3.5 at 34.43 points. If a child in an IDT is in a school and house that do not have access to electricity, average test scores are 28.67 points. But when the house has electricity access average test scores are a higher 30.54 points. If a child in an IDT is in a school with electricity access but in a house without electricity, average test scores are 30.17 points. This measure of association for 2000 in contrast to 1997 is not the lowest reported average score in all cells in Table 3.5. The lowest average score in Table 3.5, 28.67 points is the cell for a child in IDT where there is no electricity in the school and house. For the combination of available electricity in the school and the home in an IDT, average test scores are at 30.67 points which is lower than the same combination in a non-IDT.

The following Table 3.6 presents the pooled cross section measures of association for EBTANAS test scores along three dimensions IDT status, school electricity access and household electricity access. The positive measures in Table 3.6 follow the same pattern as in Table 3.5 for 2000.

Table 3.6 Measures of Association between Educational Performance, Electricity in School and Electricity at Home for 1997 / 2000

Test Scores for Children with the Characteristics of i) Using Electricity in School ii) Using Electricity at Home iii) Attending School in an IDT Program in 1997/2000 Means and SD (in Parentheses) Are Reported

School is in IDT in 1997 / 2000? Then Does House Use Electricity?

\begin{tabular}{|c|c|c|c|c|c|c|}
\hline \multirow{2}{*}{$\begin{array}{l}\text { Using } \\
\text { Electricity } \\
\text { at School? }\end{array}$} & \multicolumn{3}{|c|}{$\begin{array}{l}\text { No, School is Not in IDT in } \\
1997 / 2000\end{array}$} & \multicolumn{3}{|c|}{ Yes, School is in IDT in $1997 / 2000$} \\
\hline & $\begin{array}{l}\text { No, House } \\
\text { Doesn't } \\
\text { Use } \\
\text { Electricity }\end{array}$ & $\begin{array}{l}\text { Yes, House } \\
\text { Uses } \\
\text { Electricity }\end{array}$ & Total & $\begin{array}{l}\text { No, House } \\
\text { Doesn't } \\
\text { Use } \\
\text { Electricity }\end{array}$ & $\begin{array}{l}\text { Yes, House } \\
\text { Uses } \\
\text { Electricity }\end{array}$ & Total \\
\hline No & $\begin{array}{l}29.35 \\
(4.27)\end{array}$ & $\begin{array}{l}31.33 \\
(5.16)\end{array}$ & $\begin{array}{l}31.09 \\
(5.10)\end{array}$ & $\begin{array}{l}28.24 \\
(3.76)\end{array}$ & $\begin{array}{l}30.26 \\
(4.60)\end{array}$ & $\begin{array}{l}29.53 \\
(4.42)\end{array}$ \\
\hline Yes & $\begin{array}{l}29.90 \\
(6.02)\end{array}$ & $\begin{array}{l}33.55 \\
(5.28)\end{array}$ & $\begin{array}{l}33.29 \\
(5.42)\end{array}$ & $\begin{array}{l}28.38 \\
(4.45)\end{array}$ & $\begin{array}{l}31.18 \\
(6.13)\end{array}$ & $\begin{array}{l}31.05 \\
(6.08)\end{array}$ \\
\hline Total & $\begin{array}{l}29.68 \\
(5.39)\end{array}$ & $\begin{array}{l}32.96 \\
(5.34)\end{array}$ & $\begin{array}{l}32.69 \\
(5.42)\end{array}$ & $\begin{array}{l}28.26 \\
(3.86)\end{array}$ & $\begin{array}{l}30.89 \\
(5.70)\end{array}$ & $\begin{array}{l}30.43 \\
(5.51)\end{array}$ \\
\hline
\end{tabular}


If a child in a non-IDT is in a school and house that do not have access to electricity, average test scores are 29.35 points. But when the house has electricity access average test scores are a higher 31.33 points. In the reverse, if a child in a non-IDT is in a school with electricity access but in a house without electricity, average test scores are a lower 29.90 points. For the combination of available electricity in the school and the home in a non-IDT, average test scores are the highest in all the reported cells in Table 3.6 at 33.55 points. If a child in an IDT is in a school and house that do not have access to electricity, average test scores are 28.24 points. But when the house has electricity access, average test scores are a higher 30.26 points. If a child in an IDT is in a school with electricity access but in a house without electricity, average test scores are 28.38 points. For the combination of available electricity in the school and the home in an IDT, average test scores are at 31.18 points which is lower than the same combination in a non-IDT. To summarize for the pooled cross sections, the highest positive measure of association for test scores is when the child is in a developed community attending a school and residing in a household that have access to electricity. The lowest positive association is when the child is in an underdeveloped community without energy infrastructure or only with basic energy infrastructure where both the school and household do not have access to electricity.

\subsection{Descriptive Statistics}

\subsubsection{Educational Performance}

Table 3.7 provides the descriptive statistics for individual EBTANAS test scores; and the school and household characteristics of the children in the sample selected on observable outcomes and measures of electricity access and use in 1997 and 2000. In 1997, average individual test scores were 31 points with a standard deviation of 5.18 points. In 2000, average scores were 32.98 points with a standard deviation of 5.64 points. The maximum possible EBTANAS score is 50 points. The scores in 2000 have a wider spread than in 1997. In 1997, the minimum score is 14.61 points and the maximum score is 44.38 points. In contrast in 2000 , the minimum score is 3.88 points and the maximum is 46.5 .

\subsubsection{School Characteristics}

From the following Table 3.7, we present the statistics for school characteristics for 1997 and 2000. The percentage of teachers in a primary school with an undergraduate degree increased from 59\% in 1997 to $76 \%$ in 2000 . The average number of hours the teachers worked per week is lower in 2000 compared to 1997; teachers reported working 31 hours per week in 1997 and 25 hours per week in 2000. Work includes classroom instruction and administrative tasks. 
Table 3.7 Descriptive Statistics for Educational Performance, School Characteristics and Household Characteristics

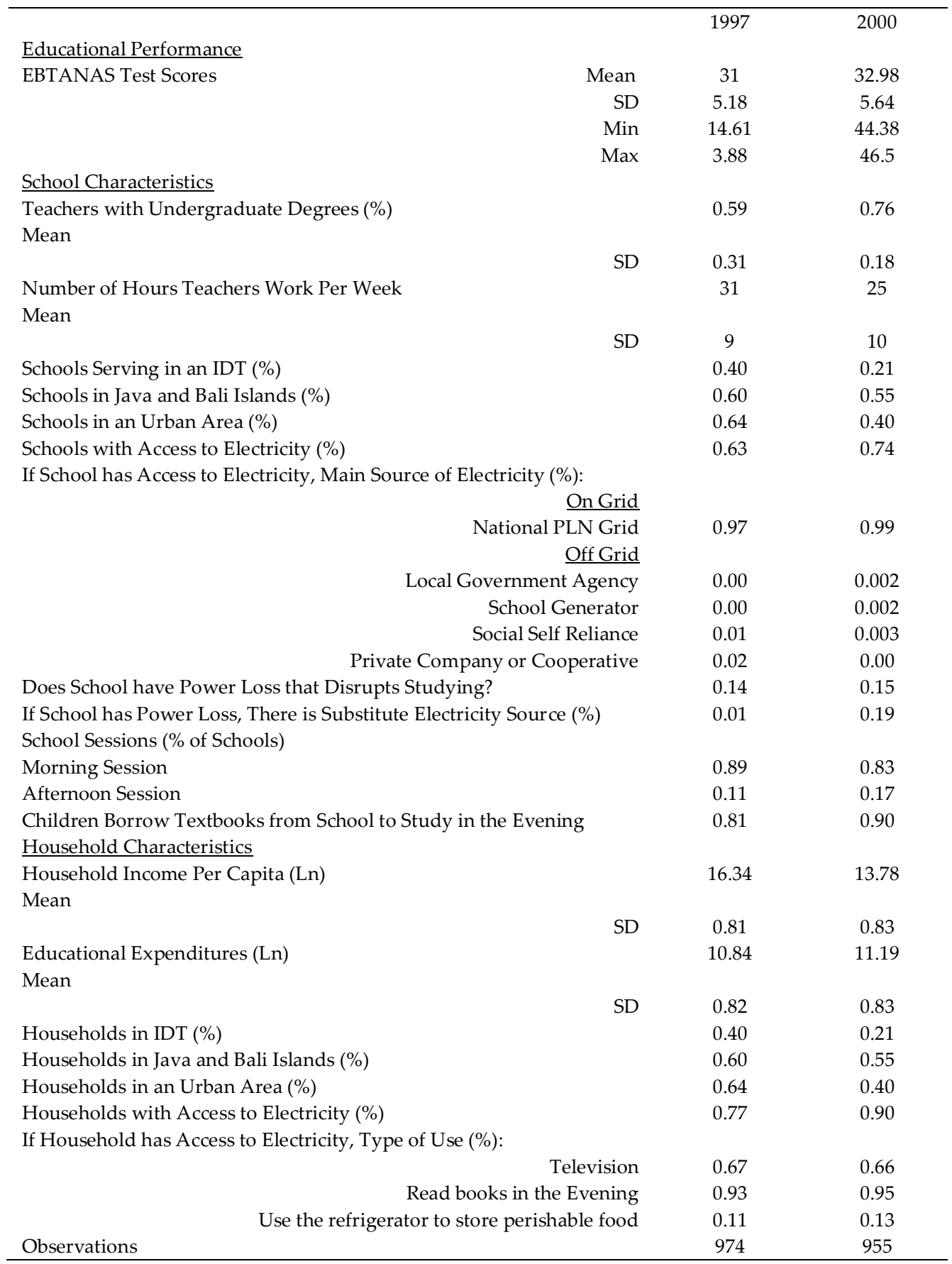


Notes: Reported teacher hours worker per week consists of classroom instruction and administrative tasks. For households with access to electricity, there are three possible types of use as asked by IFLS (television, reading books in the evening and using the refrigerator to store perishable food). Each use is separate from the other as IFLS does not ask if these uses overlap.

Based on the national curriculum, the number of teacher classroom instruction hours should be 42 hours per week for fifth grade and sixth grade (our two grades of interest in the specifications) but reported hours worked from Table 3.7 is lower. The percentage of schools targeting children residing in an IDT is $40 \%$ in 1997 in contrast to $21 \%$ in 2000. In the data we check that the children attend a school and reside in a village within the boundaries of the same community classified as an IDT. There is no incidence of a child for example attending a non-IDT designated school while residing in an IDT.

Table 3.7 also provides statistics on the availability of electricity in schools. In 1997, $63 \%$ of schools observed report having electricity available. In $2000,74 \%$ of schools observed report electricity availability. For schools that have electricity, they also report on the main source of electricity. In both 1997 and 2000, the main source of electricity reported is the PLN grid; 97\% of schools observed in 1997 and 99\% of schools observed in 2000. The remaining schools report other main sources of electricity as the local government agency, school generator, social self reliance and a private company or cooperative. In comparing school and household access to electricity, in $1997,63 \%$ of schools have electricity access compared to $77 \%$ of households with electricity access. In 2000, the percentage of schools with electricity access increases to $74 \%$ and there is also an increase to $90 \%$ in the percentage of households being able to access electricity. In the IFLS questionnaire, the schools are also asked if they lose electrical power which disrupts schooling. In 1997, 14\% responded that there is power loss; in 2000 this response was 15\%. A subsequent IFLS question asked is when there is power loss the school has a substitute electricity source available. In 1997, only $1 \%$ of schools observed reported the availability of a substitute source but in 2000, an increased $19 \%$ of schools have a substitute.

From IFLS, there is also information on start and end times for classroom sessions. If schooling time is in the morning and afternoon, then natural sunlight is a substitute for reading what is written on the blackboard, reading a book or writing in class. However if an afternoon school session is running, classes end at 18:00h. Natural sunlight ceases to be a substitute for electric light as the sun sets at 17:53h in Western Indonesia and at 18:53h in Eastern Indonesia. In Table 3.7, schools report that they offer two school sessions a day which maximizes the use of classroom space. The two sessions are in the morning and in the afternoon. There are no evening sessions. 
In relation to how much learning material children can cover in the school day, children can borrow Indonesian language and Math textbooks from the school. Schools provide the children textbook loans for various reasons as documented in IFLS - parents cannot afford to purchase the textbooks; parents can afford to purchase the textbooks but the latest textbooks are not stocked in the local bookstore; the school substitutes for the parents by purchasing and making available the textbooks for use but the school budget is limited and children have to share the textbooks during class time; and only a few children can access a photocopier to make textbook copies. Because of these various reasons, in 1997 81\% of children borrow textbooks; and in 2000 this percentage increased to $90 \%$.

\subsubsection{Household Characteristics}

Table 3.7 shows that average household income per capita in log terms for this sample fell from $16.34 \mathrm{log}$ points in 1997 to $13.78 \mathrm{log}$ points in 2000. As detailed in chapter 2, this is as a result of extreme price changes and depressed purchasing power over the period of the financial crisis. The average deterioration in income for this sample is larger than for the unrestricted sample in Chapter 2. In contrast average household spending on education increased from 10.84 log points in 1997 to $11.19 \mathrm{log}$ points in 2000 . The percentage of households residing in an IDT is $40 \%$ for 1997 and 21\% in 2000. The percentage of all observed households that reside in Java and Bali is $60 \%$ for 1997 and $55 \%$ for 2000 . The percentage of households residing in an urban area in 1997 is $64 \%$ and in 2000 it is $40 \%$.

For household measures of electricity access and use, the percentage of households that have access to electricity in 1997 is $77 \%$ and this rises to $90 \%$ in 2000 . For households that have access to electricity, the IFLS questionnaire asks if the electricity is used for a television, a refrigerator to store perishable food or to read books in the evening. The percentage of households that have electricity and use it to watch television is $67 \%$ in 1997 and this percentage is $66 \%$ in 2000 . In terms of the use of light bulbs, the IFLS questionnaire asks if children bring home textbooks from school to read in the evening. The percentage of children who responded "Yes" to this question is 93\% in 1997 and 95\% in 2000. But there is no further information on whether the children actually do read the textbooks that they bring home from school.

\subsection{Results}

In Table 3.8 we present the output for specifications (i), (ii) and (iii) from Section 3.4. In column (1), using only the school characteristics base specification, the percentage of undergraduate level qualified teachers and the facility for borrowing school textbooks are positively related to EBTANAS test scores. Teacher quality increases test score points by only 0.02 points and this is statistically significant at 
the $1 \%$ level. Borrowing Indonesian language and Math textbooks from school raises test scores by 0.25 points and this is statistically significant at the $5 \%$ level. These very small gains to educational achievement compared to the other explanatory variables can be seen across all specifications in columns (1) - (8). This finding is then similar to what Bacalod and Tobias (2006) report that class size and teacher training programs in Philippines' primary schools matter less than expected for test score performance. 
Table 3.8 Electricity Availability and Educational Performance

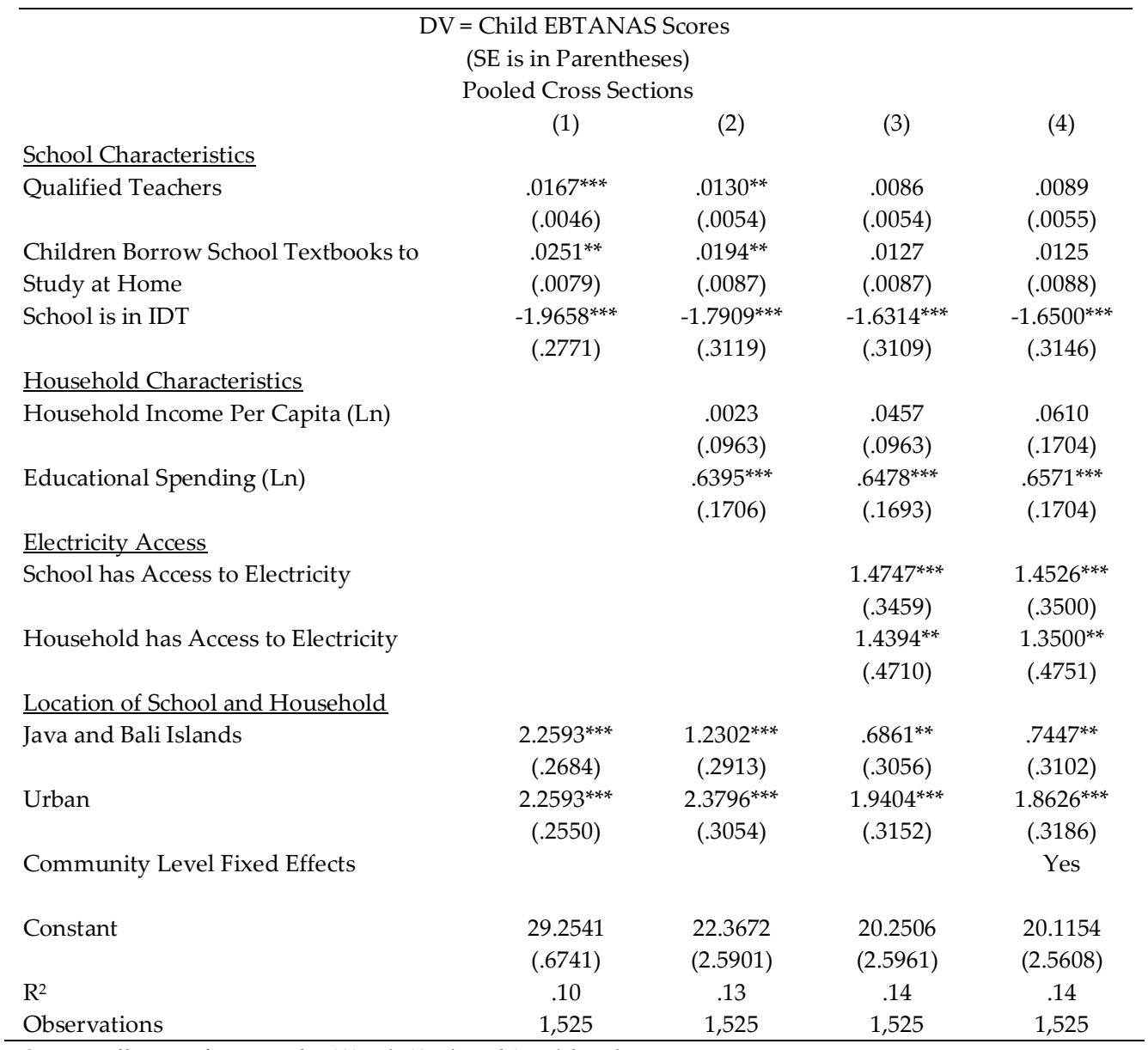

Statistically significant at the ${ }^{* *} 1 \%, * 5 \%$ and ${ }^{*} 10 \%$ level

Notes: Teacher quality is measured as the percentage of undergraduate level qualified teachers in the whole. Schools provide an Indonesian language and Math textbook loan service to students. As such the school textbook loan is measured in this specification as the number of 12 year old children who borrow these Indonesian language and Math textbooks because they do not have any of their own. 
From Table 3.8, column (1) the negligible gains of teacher qualification and school textbook loans are negated if the school is in an IDT where test scores drop by 2 points and this is statistically significant at the $1 \%$ level. The constant $\beta_{0}$ is 29 points. If a child is in an IDT, the child has a lower starting score of 27 points compared to a child in a developed area with 29 points. The result that a disadvantaged child in an IDT school is in a lower starting position than a child who is not in an IDT school is consistent across columns (1) - (4) in Table 8. This suggests that a 12 year old child who attends school and resides in an IDT is in an environment that negatively affects educational performance.

For the regional control variables, a child in Java and Bali Islands has a 1 point advantage over a child in the other islands and a child in an urban area has a 2 point advantage over a child in a rural area. This implies that even if a child is in an IDT and the IDT is in Java or Bali, instead of scoring 2 points less than a child in a non-IDT, the performance gap is reduced to a 1 point difference. The estimate that children in Java and Bali have better test scores than children in other islands, holding other variables constant is seen across the specifications in columns (1) (8). But the size of the coefficient is reduced when household characteristics and electricity access and use measures are included. This implies that children who attend school and reside in Java and Bali have better educational performance because school quality and the quality of the household environment including access to electricity are higher in these islands compared to the other islands. Similarly the estimate that children in urban areas have better test scores than children in rural areas, holding other variables constant is seen across the specifications in columns (1) - (8). However the coefficient size for urban areas across the specifications is larger than the coefficient size for Java and Bali. This may possibly suggest that within each of the main islands, when a child attends school and resides in an urban area, this environment is conducive for schooling and learning compared to a rural area.

In column (2), household characteristics are added to the specification. Household income is positively related to test scores where a $1 \log$ point change in income shows a 0.002 change in test scores. But this estimate is not statistically significant. A similar result is found across all specifications in columns (1) - (8). However educational expenditures for the child show a positive relationship where a $1 \log$ point change in spending provides a 0.64 point change in test scores. This result is statistically at the $1 \%$ level and is consistent across the specifications in columns (2) - (4). This implies that family willingness to spend on education is far more advantageous for a child's education and this can be observed through educational expenditures instead of family income. Also when taking into account in the unpredictability of events of the Asian Financial Crisis in 1998, 1999 and to some 
extent 2000, this result suggests that for this restricted sample reduced income has less negative effect on outcomes than expected. The coefficients for school characteristics have the same direction and magnitude in the second specification as in the first specification. When viewing the influence of both the school and the home on outcomes, it appears that the family has a more favorable role in improving educational performance. This appears to be particularly the case when the family is willing to set aside a proportion of available income specifically for schooling expenditures. When considering that in this sample, families are less inclined to migrate for schooling reasons, the family manages the existing quality of schooling that they are confronted with by spending on different educational expenditures that may improve performance e.g. private tuition, special courses, writing supplies and different types of books.

In Table 3.8 columns (3) and (4), we now introduce measures of electricity availability in the school and household. Community level fixed effects are controlled for in column (4). The endogenous explanatory variables qualified teachers and the school textbook loan lose statistical significance while the negative relationship of an IDT school and test scores continues to hold and be statistically significant at the $1 \%$ level. However the introduction of electricity access slightly reduces the magnitude of the IDT school variable by 0.1 points. Of the two measures of electricity access, school availability of electricity is related to slightly higher test scores than household electricity availability. When the school has access to electricity, test scores increase by 1.4 points and this is statistically significant at the $1 \%$ level. When the home has access to electricity, test scores increase by 1.4 points in column (3) and increase by 1.3 points when community level fixed effects are added which can be seen in column (4). Both estimates are statistically significant at the $1 \%$ level. Based on our empirical specification, the availability of electricity has a time lagged effect on test scores. So the increase in test scores is likely to be cumulative over the period of time the child has access to electricity in school and the household. This implies that when the child is in an environment where both the school and the home have continued access to electricity, educational performance improves substantially. Since in this sample, families do not move to communities that have better quality schools, by merely having electrical connections in school and the household, children's educational performance can improve.

In Table 3.9 we present the output for specification (iv) from Section 3.4. This expanded specification introduces measures of electricity use in the school and household. While the use of electricity in school is for studying, families use electricity at home for various work and leisure activities. These activities may directly or indirectly influence learning over time. To examine the potential pathways from electricity availability to electricity use in the household, Table 3.9 
columns (5) and (6) provide estimates of the child who studies at home using borrowed textbooks from school and the child who watches television at home. Columns (7) and (8) sub-divide these activities by IDT to assess if within an underdeveloped environment, unobserved factors will influence these two activities differently compared to a developed community. For example, in an IDT basic infrastructure provides lower access to electricity. Scholastically motivated families may then choose to use the limited or rationed electricity by substituting away from non-learning related activities to learning activities in favor of their child's development. 
Table 3.9 Electricity Availability, Use and Educational Performance

\begin{tabular}{|c|c|c|c|c|}
\hline \multicolumn{5}{|c|}{$\begin{array}{c}\text { DV = } \\
\text { (SE is in Parentheses) }\end{array}$} \\
\hline & (5) & (6) & (7) & (8) \\
\hline \multicolumn{5}{|l|}{$\underline{\text { School Characteristics }}$} \\
\hline$\overline{\text { Qualified Teachers }}$ & $\begin{array}{l}.0099^{*} \\
(.0055)\end{array}$ & $\begin{array}{l}.0099^{*} \\
(.0056)\end{array}$ & $\begin{array}{l}.0102^{*} \\
(.0055)\end{array}$ & $\begin{array}{l}.0101^{*} \\
(.0056)\end{array}$ \\
\hline Children Borrow School Textbooks to & .0280 & .0415 & .0334 & $.0551^{* *}$ \\
\hline Study at Home & $(.0275)$ & $(.0283)$ & $(.0280)$ & $(.0290)$ \\
\hline School is in IDT & $\begin{array}{c}-1.3700^{* * *} \\
(.3179)\end{array}$ & $\begin{array}{c}-1.3638^{* * *} \\
(.3228)\end{array}$ & $\begin{array}{l}-.1153 \\
(.9197)\end{array}$ & $\begin{array}{l}.4837 \\
(.9389)\end{array}$ \\
\hline \multicolumn{5}{|l|}{ Household Characteristics } \\
\hline$\overline{\text { Household Income Per Capita (Ln) }}$ & $\begin{array}{l}.0350 \\
(.0988)\end{array}$ & $\begin{array}{l}.0642 \\
(.1001)\end{array}$ & $\begin{array}{l}.02131 \\
(.0989)\end{array}$ & $\begin{array}{l}.0563 \\
(.1002)\end{array}$ \\
\hline Educational Spending (Ln) & $\begin{array}{l}.6511^{* * *} \\
(.1739)\end{array}$ & $\begin{array}{l}.6794^{* * *} \\
(.1750)\end{array}$ & $\begin{array}{l}.6169^{* * *} \\
(.1746)\end{array}$ & $\begin{array}{l}.6504^{* * *} \\
(.1754)\end{array}$ \\
\hline \multicolumn{5}{|l|}{ Electricity Access } \\
\hline School has Access to Electricity & $\begin{array}{c}1.4257^{* * *} \\
(.3494)\end{array}$ & $\begin{array}{c}1.3996^{* * *} \\
(.3545)\end{array}$ & $\begin{array}{l}1.7951^{* * *} \\
(.4061)\end{array}$ & $\begin{array}{c}1.7671^{* * *} \\
(.4111)\end{array}$ \\
\hline Household has Access to Electricity & $\begin{array}{l}1.6506^{* *} \\
(.7905)\end{array}$ & $\begin{array}{l}1.8376^{* *} \\
(.7950)\end{array}$ & $\begin{array}{l}2.076^{* *} \\
(.9799)\end{array}$ & $\begin{array}{c}2.7780^{* *} \\
(.9947)\end{array}$ \\
\hline \multicolumn{5}{|l|}{ Electricity Use } \\
\hline $\begin{array}{l}\text { Household has Access to Electricity, } \\
\text { Study Using Borrowed Textbooks }\end{array}$ & $\begin{array}{r}-.02151 \\
(.0288)\end{array}$ & $\begin{array}{l}-.0359 \\
(.0295)\end{array}$ & $\begin{array}{l}-.0301 \\
(.0299)\end{array}$ & $\begin{array}{l}-.0556^{*} \\
(.0309)\end{array}$ \\
\hline $\begin{array}{l}\text { Household has Access to Electricity, } \\
\text { Watch Television } \\
\text { Electricity Access in IDT }\end{array}$ & $\begin{array}{l}.9311^{* *} \\
(.3345)\end{array}$ & $\begin{array}{l}.8183^{* *} \\
(.3367)\end{array}$ & $\begin{array}{c}1.1344^{* *} \\
(.3963)\end{array}$ & $\begin{array}{c}1.0204^{* *} \\
(.3985)\end{array}$ \\
\hline School has Access to Electricity & & & $\begin{array}{c}-1.3009^{*} \\
(.7268)\end{array}$ & $\begin{array}{c}-1.2345^{*} \\
(.3985)\end{array}$ \\
\hline Household has Access to Electricity & & & $\begin{array}{c}-.3968 \\
(1.1092)\end{array}$ & $\begin{array}{l}-1.3557 \\
(1.1267)\end{array}$ \\
\hline \multicolumn{5}{|l|}{ Electricity Use in IDT } \\
\hline Household has Access to Electricity, & & & .0227 & .0363 \\
\hline Study Using Borrowed Textbooks & & & $(.02428)$ & $(.0245)$ \\
\hline \multicolumn{5}{|l|}{ Location of School and Household } \\
\hline Java and Bali Islands & $\begin{array}{l}.8542^{* *} \\
(.3112)\end{array}$ & $\begin{array}{l}.9727^{* *} \\
(.3171)\end{array}$ & $\begin{array}{l}.8269^{* *} \\
(.3114)\end{array}$ & $\begin{array}{l}.9544^{* *} \\
(.3173)\end{array}$ \\
\hline Urban & $\begin{array}{l}1.6977^{* * *} \\
(.3279)\end{array}$ & $\begin{array}{l}1.5940^{* * *} \\
(.3325)\end{array}$ & $\begin{array}{c}1.7182^{* * *} \\
(.3289)\end{array}$ & $\begin{array}{c}1.6161^{* * *} \\
(.3337)\end{array}$ \\
\hline Community Level Fixed Effects & No & Yes & No & Yes \\
\hline Constant & $\begin{array}{l}19.5914 \\
(2.7077)\end{array}$ & $\begin{array}{l}18.7886 \\
(2.7045)\end{array}$ & $\begin{array}{l}19.3972 \\
(2.7541)\end{array}$ & $\begin{array}{l}18.0490 \\
(2.7615)\end{array}$ \\
\hline $\mathrm{R}^{2}$ & .15 & .15 & .15 & .15 \\
\hline Observations & 1,514 & 1,514 & 1,514 & 1,514 \\
\hline
\end{tabular}

Statistically significant at the ${ }^{* *} 1 \%,{ }^{* *} \%$ and ${ }^{*} 10 \%$ level 
Notes: Teacher quality is measured as the percentage of undergraduate level qualified teachers in the whole. Schools provide an Indonesian language and Math textbook loan service to students. As such the school textbook loan is measured in this specification as the number of 12 year old children who borrow these Indonesian language and Math textbooks because they do not have any of their own.

In Table 3.9 columns (5) - (8), household access to electricity now provides larger estimates for test score performance compared to school access to electricity. When the home has electricity access scores increase by 1.65 points (column (5)) and 1.83 points (column (6)). Column (6) includes community level fixed effects. In contrast, when the school has electricity access scores increase by 1.42 points (column (5)) and 1.39 points (column (6)). All four estimates are statistically significant. This result appears to be the case because of the introduction of the variables representing the type of use for electricity at home. When the household has access to electricity and this variable interacts with the number of children who borrow school Indonesian language and Math textbooks to read at home, test scores are at a lower 0.02 points in column (5) and a lower 0.03 points in column (6). But these results are statistically insignificant. This may suggest the children are less likely to read their Indonesian language and Math textbooks in the evening. Instead they may prefer to read other textbooks that their parents have purchased such as science, social studies and religious studies. Children from Muslim households and who attend MORA religious schools may prefer to recite the Koran. Or they may prefer to read other types of books, comics and newspapers, all of which can positively influence their cognitive skills. More interestingly, in columns (5) and (6) when the household has access to electricity and this interacts with the variable for whether the child watches television, test scores increase by 0.93 points. With a control for community fixed effects, scores increase by 0.81 points. Both results are statistically significant at the $5 \%$ level. A possible interpretation is that when the child is able to watch television after school, the child watches programs with educational content such as the Indonesian television channel Television Pendidikan Indonesia (TPI or Education Television Indonesia). Or the child is able to watch general programs on television that improve his or her language skills. Our findings are similar to Gentzkow and Shapiro (2008) who use the American Coleman Study data to show that younger children with an additional year of television exposure have higher reading and verbal test scores when they are older.

In Table 3.9 columns (7) and (8), we study more in-depth the access and use of electricity in the household by IDT status. Without controls for community level fixed effects, if the child is in an IDT school, test scores fall by 0.11 points. But unexpectedly, with fixed effects a child in an IDT school now has an increase in test scores by 0.48 points. While these results are not statistically significant, they may be of education significance. This may be of significance because despite disadvantages faced in a community, families in such a community still have a high preference for their children to have high educational achievement. The 
magnitude of the IDT school coefficient in these two specifications is much smaller than the specifications in columns (1) - (6). This is because of the introduction of electricity access and use in IDT communities. When children attend an IDT school that has access to electricity, test scores fall by 1.3 points (column (7)) and with fixed effects fall by 1.2 points (column (8)). Both estimates are statistically significant at the $10 \%$ level. In comparison, all children without conditioning on IDT, access to electricity in school and test score performance is positive at 1.7 points and statistically significant at the $1 \%$ level. Similarly children are in IDT households that have access to electricity, test scores fall by 0.4 points and with community level fixed effects scores fall by 1.3 points. But these estimates are not statistically significant. A possible interpretation is that in an IDT community, schools and households have only basic infrastructure and electricity access may be capturing the negative effect of underdevelopment on children's performance. IDT underdevelopment where there is poverty, a lack of employment opportunity and a lack of public services including quality schooling may perhaps be viewed as a source of disadvantage for children.

From Table 3.9, when we assess the use of electricity by IDT status, interestingly we find that in an IDT household with electricity and children study using borrowed Indonesian language and Math textbooks, test scores increase by 0.02 points. With community level fixed effects scores increase by 0.03 points. In contrast, the association for these two variables is negative for all children who have electricity available for reading textbooks. This may imply that given the disadvantaged position that children have in education in IDT communities, the mere opportunity to borrow school textbooks and to be able to have electricity at home to read these textbooks may motivate them to study. However the coefficient for the interaction between household access to electricity and watching television has a negative sign for children in IDT and is statistically insignificant. This is as opposed to all children who watch television. Possible reasoning for this negative relationship is IDT households while able to watch television may not have a reliable signal reception since they may be located in a remote area. In the literature, Olken (2009) finds that the variation in television signal reception and strength in Java Island affects how many hours a day that Indonesians can watch television. If this is the case for children in IDT households, they may be less likely able to watch educational programs (e.g. the TPI channel). As such the television variable in the specification may not be able to capture the positive effect on test scores.

In reconciling the estimates for IDT school status and the use of electricity in an IDT household, the specification in column (8) with community level fixed effects raises an interesting observation. In this specification, the negative relationship between a child attending an IDT school and educational performance reverses and becomes positive. The possible pathway from basic infrastructure that introduces access 
(albeit low access) to electricity in an IDT community may lead to parents preferring to let their children use the limited electricity available for studying in the evening. This implies that low income families from underdeveloped areas may demonstrate a preference for education if the physical environment is conducive for them to choose learning for their children instead of other activities.

\subsection{Conclusions}

In this chapter we have investigated if there is a relationship between the availability and use of electricity and the educational performance of 12 year old Indonesian children in primary school. Using EBTANAS test scores which capture the child's historical performance from grade 1 to grade 6 of primary school we find that for 1997 and 2000, the availability of electricity in school and the household raises test scores substantially and these results are statistically significant. In establishing a potential pathway between electricity availability and test scores, we find that how families use electricity in the household influences outcomes. When children watch television at home, test scores markedly increase after controlling for community level fixed effects. This may perhaps be attributed to educational programming on national television. Conditioning on attending school in an underdeveloped, below the poverty line, left behind village (IDT) children who borrow school textbooks to study at home in the evening have slightly improved test scores. While households use electricity for various reasons, there is evidence that there are families who choose to use electricity for activities where their children can learn better. This may be particularly the case for families in underdeveloped areas where they are constrained in electricity access because of rationing by the state.

Over the period of 1997 and 2000, more schools and households in our sample are connected to the national PLN grid as well as off the grid to access electricity. Particularly there are a higher proportion of households than schools that have access to electricity. Studying and doing homework in the evening most likely complement what the child learns in the classroom in the day. By having access to electricity in the child's daily environment both in school and at home, it is very likely that the child is more motivated to learn and complete primary school. This is regardless of a disadvantaged background such as the child coming from an underdeveloped community or regardless of volatilities faced by the family during the Asian Financial Crisis. However given the fixed placement of the national PLN grid, where over $70 \%$ of energy is allocated for industrial use (industrial sector and transport sector) and where Java and Bali receive $77 \%$ of total energy capacity, not all communities are able to receive full access to electricity. Also children who attend school and reside in urban areas tend to have more access to electricity and better educational outcomes. This strongly implies that access to electricity is a 
potential resource constraint on children's educational outcomes. This is unless families move from areas that have low access to electricity to areas with high access to electricity in order to ensure that their children have a favorable learning environment. However using available data, we are unable to conclude whether a family's out-migration for schooling reasons in Indonesia will improve outcomes.

On the basis of these results, the supply and provision of electricity to the communities of the Outer Islands - Sumatera, Kalimantan, Sulawesi and Nusa Tenggara is a concern. The public policy issue then is about the distribution of energy for final use to all islands and not just the availability of energy. The distribution of energy should cover all parts of an island and not just the urban areas that have more waged economic activity. By considering that electricity access promotes an environment that is conducive for schooling more children will be motivated to pass their achievement tests at the primary school level. Then they are more likely to progress on to junior high. But until then, the lack of access to electricity in certain regions of Indonesia is a constraint on educational achievement. 
4. Household Income, Simultaneous WorkSchooling and Human Capital 


\subsection{Introduction}

This chapter studies the phenomenon of joint child work-schooling decisions in Indonesia from the view of human capital theory. Productive skills are developed in childhood for generating future returns. Human capital can be accumulated not just by attending formal schooling but also through informal schooling such as learning skills from the family. In Indonesia the national labor force starts at age 10 and this consists of economically active children who have either never attended school or who combine work with schooling. For children who are in the labor force while simultaneously attending school, this raises the question as to the extent that the child's labor supply affects the amount of time available to develop skills. To address this, consideration has to be given to the timing of schooling, whether this timing conflicts with work and the extent of this conflict. If there is conflict this arises from the joint work-schooling decision that is influenced by whether the child's income augments household income and possibly the social norms towards children working.

This chapter studies Indonesian child workers aged 6-15 who simultaneously attend school. Two questions are asked. Does a reduction in parental income change simultaneous work-schooling behavior? If yes, do these changes impair human capital accumulation? In this chapter, I view child labor in terms of economic work and unpaid household production / domestic work and I use the terms schooling and skill formation interchangeably. I sequence the behavior of simultaneous work-schooling as a child who first works and then second attends school. As child labor and school decisions are joint outcomes out of a single time allocation problem, I analyze the joint decision-making by studying the children's types of work and learning activities in and outside of the household and time allocated to these activities. Using the Indonesian education system which recognizes the phenomenon of child labor and provides skill development alternatives for child workers ${ }^{18}$, I study three sources of skill formation. The first is the formal and mainstream system of primary school and junior high. The second is non-formal school which consists of alternatives to the mainstream system that target child workers (refer to Chapter 2 for a full description of these three sources of skill formation and how they are structured with the education system). Educational service delivery for non-formal schooling includes the use of privately managed religious schools; learning time is flexibly built around the child's working time. The third is informal school which consists of the provision of independent study modules to complement the skills acquired from education

\footnotetext{
${ }^{18}$ The previous chapters were related to the formal and mainstream education system. This chapter expands on the system to examine alternative schooling for child workers.
} 
within the home. Households that typically have informal schooling are parents who are traders or entrepreneurs and have children who act as apprentices. Apart from skill development, children who work in the household should face fewer safety and health risks compared to children working outside without parental supervision or monitoring.

In the literature on household income and child labor, Basu, Das, and Dutta (2007) provide a discussion on child labor responses to variations in household income. These responses include whether the child shifts from work within the household to work outside the household. Work within the household is more likely if the household has its own business as discussed by Edmonds and Turk (2004) for Vietnamese households. In the overwhelming majority of cases, the work performed by children takes place within the household - usually household chores and work on the family farm (Basu and Ray, 2002). Wage work and work in small enterprises which take place outside the household remains an exception (ILO, 2002). The UNICEF definition of child labor reflects the distinction made between working outside and in the household as well as recognizing that the intensity of child labor is higher when the child is older ${ }^{19}$. In Asia, a further distinction is made where child labor is primarily regarded as an urban as opposed to rural phenomenon (Fafchamps and Wahba, 2006). However it is unclear whether the activities carried out in the household necessarily constitute child labor if the child is an apprentice in the family enterprise, building skills through on-the-job learning. Given the state of the literature, my contribution is to produce more insight on how joint work-schooling does not impair human capital accumulation.

The rest of the chapter is organized in the following way. In Section 4.2 I describe national level trends of child labor in Indonesia and how this changed over the period of the financial crisis. Section 4.3 describes the natural experiment and a description of the dataset, the RAND Corporation Indonesia Family Life Surveys (IFLS). Limitations arising from the observed data i.e. child labor as the dependent variable is a censored variable (Basu et al, 2007) are discussed. Section 4.4 details the child and household characteristics associated with work-schooling behavior which I use for the estimations. Section 4.5 reports the results. Conclusions are in Section 4.6.

\footnotetext{
${ }_{19}$ UNICEF definition of child labor: children aged $5-11$ who work at least 1 hour of economic work or 28 hours of domestic work per week; children aged $12-14$ who work at least 14 hours of economic work or 28 hours of domestic work per week.
} 


\subsection{National Child Labor and Schooling Trends}

The Asian Financial Crisis (AFC) occurred at the end of 1997 with effects in the financial markets felt until the beginning of 2000. For the household, much of the impact of the aggregate shock was felt in the 52.16 percentage point or eightfold increase in inflation rates from 1997 to 1998. With reference to Chapter 2 Table 2.1, annual inflation rates increased from $6.23 \%$ in 1997 to $58.39 \%$ in 1998 and then improving to $20.49 \%$ in 1999 before resuming a considerably lower rate of $3.72 \%$ in 2000. Inflation rates were then less substantial in 1999. The significant increases in inflation rates for the two years 1998 and 1999 compared to 1997 and 2000 severely weakened household purchasing power of all goods including education.

In terms of schooling indicators, between 1997 and $1998^{20}$ the percentage of 13-19 year olds that were not currently enrolled in school rose. The percentage not enrolled increased more in urban centers - from 33 percent in 1997 to 38 percent in 1998 , a change that is statistically significant. Children from poorer households in general were more likely not to be enrolled in school compared to children from higher income households - a phenomenon that intensified between 1997 and 1998. Younger children were less likely to be in school in 1998 as well. This is especially true for the poorest. The percentage of $7-12$ year olds in the bottom quartile of the distribution of per capita expenditure that were not enrolled implying delayed starting in school doubled, from about 6\% in 1997 to about $12 \%$ in 1998. But based on an empirical investigation carried out by Cameron (2001) in Indonesia declines in schooling do not appear to be accompanied by a rise in formal employment amongst children.

In terms of the occurrence of child labor, the Indonesian Census Bureau of Statistics, BPS national labor force surveys SAKERNAS show that at least $1 \%$ of children starting from age 5 to 9 are economically active (SAKERNAS 1998; Asra et al 1995 and 1997). However detailed information is not available for this age group. Using SAKERNAS, available data shows that the percentage and absolute number of economically active children in Indonesia becomes noticeable when the child is aged 10 onwards. With reference to Figure 4.1, it can be seen that there is a trend where there are children who simultaneously work and attend school.

${ }^{20}$ World Bank Indonesia Statistics 
Figure 4.1 National Level Trend of Average Hours Worked Per Week, Ages 10 17

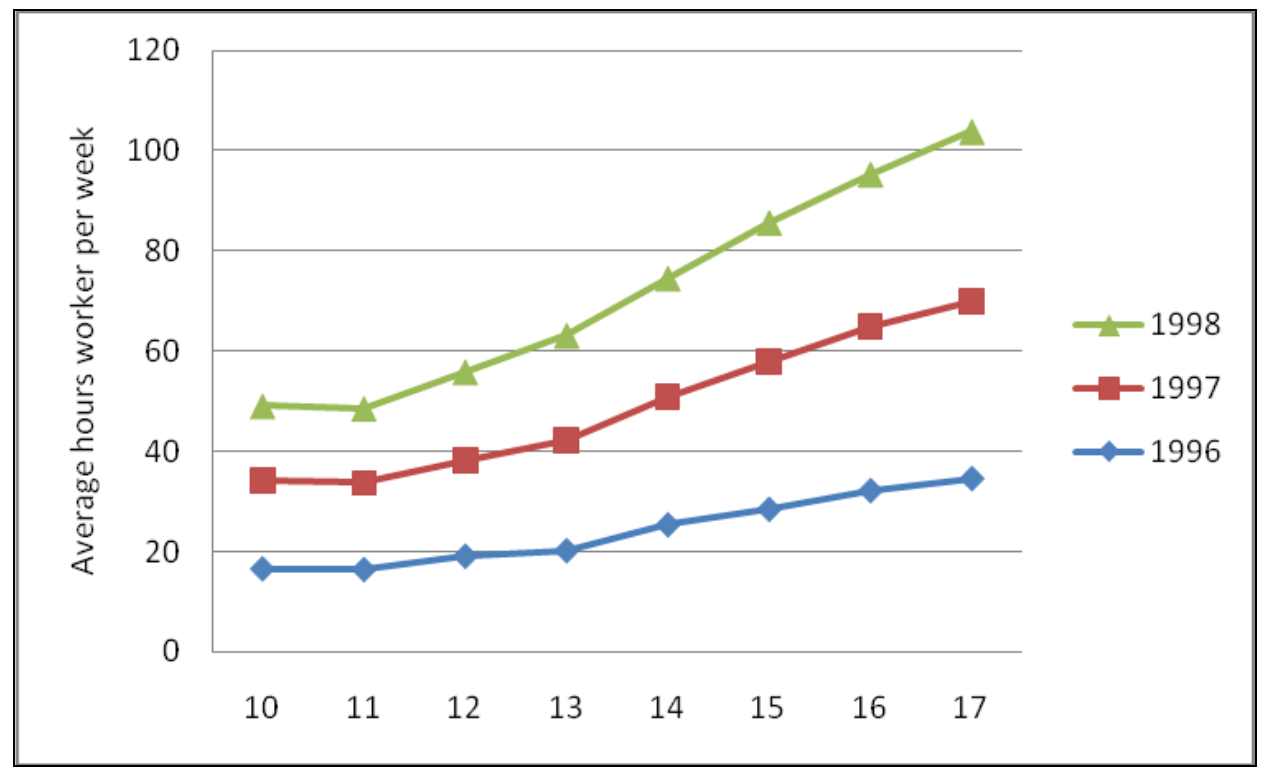

Source: Census Bureau of Statistics BPS National Labor Force Surveys SAKERNAS

Notes: This figure shows the time series for the group of children who simultaneously work and attend school. This figure corresponds to the same sample of children from Figure 4.3. Data is only available to the author for the period of $1996-1998$.

While children at age 10 are less inclined to work while attending school, the following time series in Figure 4.2 will show that for each additional year of aging up to 17 , the percentage that reports working full time increases and inversely the percentage that reports combining work with schooling decreases. 
Figure 4.2 National Level Trend of Simultaneous Work-Schooling Behavior, Ages 10 - 17

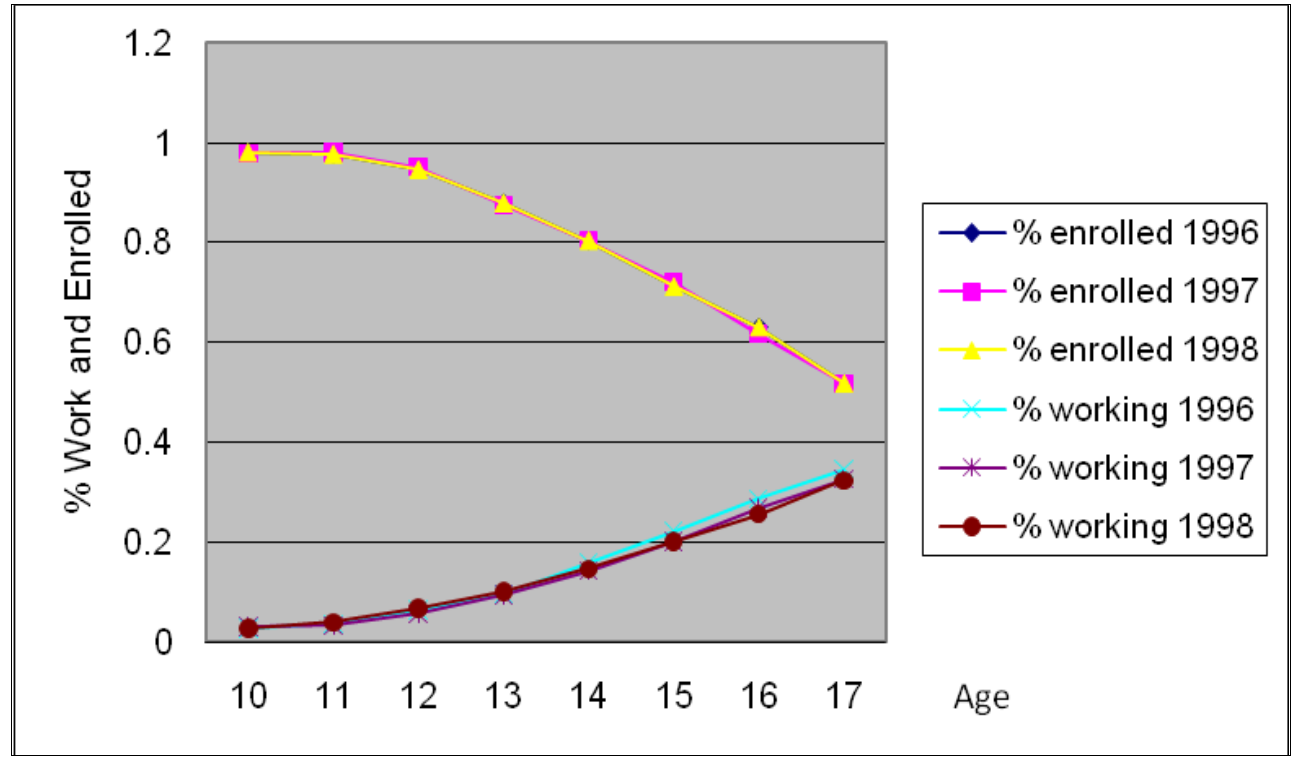

Source: BPS National Labor Force Surveys SAKERNAS

Notes: These national labor force surveys interview individuals who are economically active from age 10 onwards. The respondent is first asked if $\mathrm{s} /$ he is working and then asked if $\mathrm{s} / \mathrm{he}$ is enrolled in school. Responses are then aggregated and reported by the age of the individual. The formula for calculating school enrollment is the individuals at age $\mathrm{x}$ are currently in school divided by all individuals aged $x$ who have never been in school or or who have finished school. Data is only available to the author for the period of $1996-1998$.

Within the age range of $10-17$ in Figure 4.2, it can be seen that at the legal minimum employment age of $15,0.7 \%$ of the children work and within this age group $0.2 \%$ points or $71 \%$ of them attend school and the remaining $29 \%$ work full time. The relationship between working and schooling changes further when the individual is aged 17 where $0.3 \%$ of all those aged 17 work. Within this group, $0.5 \%$ points or $40 \%$ attend school while the remaining $60 \%$ work full time. As such these national labor survey trends suggest that as child workers become older, they attend school less and work more or leave school completely and work full time.

According to SAKERNAS, the incidence of child labor is gradually shifting away from rural areas to urban centers. Possible explanations for this have been offered by Pardoen et al (1996). First, as the contribution of the agricultural sector to the gross domestic product has become smaller over time, employment opportunities in rural areas have become fewer. Second, the informal sector in urban, economic growth centers tends to attract unskilled laborers like children in the age group of $10-14$ and this is prior to the child reaching the legal employment age of 15 where 
labor laws can afford protection to the child. Also when comparing urban employment with rural employment opportunities, it has been reported that the urban informal sector provides higher and more stable incomes for child workers. Particularly over the period of the financial crisis, Imawan (1999) documented that in urban centers the number of working children rose from $1 \%$ to $1.5 \%$ in the period of August 1997 to December 1998. Although the majority of the children observed in this period still worked in the agricultural sector (64.4\%), it is reported that $14.7 \%$ worked in the manufacturing sector and $20.9 \%$ worked in the services sector which includes street children who will provide services for a fee (BPS, 1998).

The gradual shift from the primary (agricultural) sector to secondary (manufacturing) and tertiary (services) sectors has also gradually reduced the number who work for less than 24 hours a week (Pardoen et al, 1996). This is associated with children shifting from non-wage employment to wage employment. Non-wage employment tends to occur when the child is engaged in work in the household such as family farm production or home production / domestic work. As a result, their working status as classified by BPS and SAKERNAS as changing from unpaid family workers to laborers is when they shift from non-wage employment to wage employment. With reference to the publicly available BPS household survey SUSENAS 2000 as detailed in Table 4.2, the working status of children can be defined as being i) self employed without family assistance ii) self-employed with family assistance iii) self-employed with nonfamily assistance iv) paid worker and v) unpaid worker in the family. For definitions i) to iii), the child worker may or may not receive a wage. 
Table 4.1 Working Status of Children by Urban / Rural and Gender

(\% and Count is in Parentheses)

\begin{tabular}{lcccc}
\hline $\begin{array}{l}\text { Self-employed without } \\
\text { family assistance (paid and } \\
\text { unpaid) }\end{array}$ & $9.4(63)$ & $5.7(287)$ & $5.0(107)$ & $6.8(243)$ \\
$\begin{array}{l}\text { Self-employed with family } \\
\text { assistance (paid and unpaid) }\end{array}$ & $3.9(26)$ & $4.0(202)$ & $3.6(77)$ & $4.2(151)$ \\
$\begin{array}{l}\text { Self-employed with non- } \\
\text { family assistance (paid and } \\
\text { unpaid) }\end{array}$ & $0.3(2)$ & $0.2(8)$ & $0.6(6)$ & $0.4(4)$ \\
$\begin{array}{l}\text { Paid worker } \\
\text { Unpaid worker in the family }\end{array}$ & $54.5(366)$ & $82.7(4,160)$ & $78.8(1,693)$ & $79.6(2833)$ \\
\begin{tabular}{l} 
Total \\
\hline
\end{tabular} & $100(673)$ & $100(5,032)$ & $100(2,143)$ & $100(2,889)$ \\
\hline
\end{tabular}

Source: BPS Household Survey SUSENAS 2000.

Notes: Given restrictions on accessing data, this is the only nationally representative sample publicly available on child labor.

From Table 4.1, definitions i) and ii) when contrasted against iii) suggests that the child worker may face higher safety and health risks without the presence of the family. From this table too, it appears that the vast majority of child workers are unpaid workers in the family located in rural areas. Also both female and male child workers tend to be unpaid workers in the family.

The labor surveys also show that the proportion of male children who are economically active has tended to rise over time (SAKERNAS 1998 - 1993, Pardoen et al, 1996). However, according to Irwanto et al (2001) the national level trends may be under-reporting the incidence of girls working. This is because they tend to engage in home production / domestic production for the family and are not remunerated. 


\subsection{Empirical Strategy}

My research design is a natural experiment where I exploit the timing of the RAND Corporation Indonesia Family Life Surveys (IFLS) wave 2 (1997) and wave 3 (2000) to identify an exogenous source of variation in income - the Asian Financial Crisis. This instrument enables me to study the variations to simultaneous work-schooling behavior.

I define child work as i) a child aged $6-15$ who works outside the household and may or may not receive a wage and ii) a child aged $6-15$ who works in the household and does not receive a wage. I define schooling in terms of the three sources of skill formation - formal, non-formal and informal. I have the two definitions for work outside and in the household which follows from the analytical model by Edmonds (2008) and the generalized child labor model by Cigno and Rosati (2005). Both models imply that for most children the return to time for work in the household (household production) is at least as large as the value the family places on the child's wage contribution from working outside the household. These two labor definitions are also operationally similar to the UNICEF definition of child labor and the information that I have concerning the work status of children as defined in Table 4.2 particularly that the vast majority of children are unpaid workers in the household. Work activities in the household include participating in the family enterprise, farming, home production and domestic work. I only consider the age range of $6-15$ because children in the formal education system start basic education either at end of age 6 or beginning age 7 and complete their education at the end of age 14. Starting age 15, the child can legally enter the labor market.

There are 3 different specifications for the dependent variable, child labor for its response to a reduction in household income. This is because I would like to capture different dimensions of child labor to prevent understating the magnitude of child labor. Also these specifications enable me to study the dynamics of child time allocation between work and learning activity. Using these specifications, I explore i) the changes to the shift between work activity and schooling activity, ii) changes between working outside the household and within the household; and iii) if the child works outside the household, changes to the number of hours worked per week. I match the children in the 1997 wave and the 2000 wave using the same household characteristics, child characteristics and schooling type / source of skill formation. These characteristics and how they relate to my two research questions are detailed in Section 4.4. Only biological parent - child relationships are considered. The estimates for child labor are then specified in the following reduced form: 


$$
y_{i t}=\alpha_{0}+\beta_{1} m_{i t}+\beta_{2} c_{i t}+\beta_{3} s_{i}+\beta_{4} f_{t}+\varepsilon_{i t}
$$

where $y_{i c}$ is the dependent variable with three different specifications for work by child $i$

i) if child works and attends school then 1 and if child has no work and attends school full time then 0 ,

ii) if child works outside the household and attends schools then 1 but if child works in the household and attends school then 0 and

iii) if child works outside the household and attends school, the number of hours worked per week; $m_{i t}$ represents household characteristics that vary before and after the financial crisis - income and educational expenditures; $c_{i t}$ captures child characteristics over time $t ; s_{i}$ is a dummy variable that represents each of the three schooling types / sources of skill formation and $f_{t}$ is a dummy variable for the financial crisis.

Since I can only observe child and household behavior in 1997 and 2000, it is acknowledged that I cannot observe anything spread across 1998 and 1999 given data unavailability; this is where there is severe unpredictability in behavior. Consequently, I carry out instrumental variable estimation to isolate the relationship between parental income and simultaneous work-schooling behavior. The IV approach is used to manage the omitted variable bias problem that is faced from not being able to observe child and household behavior over the period of 1998 and 1999 as well as to enable a discussion of alternative explanations for variations in child labor. As the instrument I use is the financial crisis, this instrument works through the value of child time where the variation in child labor is owing to the family's need for the child's contribution to household income or the relative return to work rather than school. This is written as equation (2) where the endogenous explanatory variable income $m_{i t}$ is a linear function of the exogenous variable the AFC $z$, a dummy variable and an error term.

$$
m_{i t}=\pi_{0}+\pi_{1} z_{1}+\pi_{2} z_{2}+\pi_{3} z_{3}+\pi_{4} z_{4}+v_{i t}
$$

I run OLS and IV regressions using the three different specifications for the dependent variable. An alternative method considered would have been a multinomial logit (MNL). But I do not choose this alternative because I am unable to determine or order the hierarchy of choices for MNL. In the first restricted sample, the dependent variable consists of both children who combine work with school or who combine zero work with school full time. In the second restricted sample, the dependent variable consists of both children who work outside the household or in the household and gain a skill from one of the schooling types - 
formal, non-formal and informal. Children who attend school full time are not included in this second restricted sample. The size for the second sample is larger than for the first sample because in the data there are more children who demonstrate the behavior of work combined with schooling compared to children attend school full time. In the third restricted sample, I then proceed to focus only on children who work outside the household who report the number of hours worked while simultaneously attending one of the school types. This is because in IFLS waves 2 and 3 only children who work outside the household report the number of hours worked. The sample size becomes substantially smaller which then inevitably reduces the power of the analysis. However by comparing the direction and magnitude of the relationship between the main variables of interest using all 3 samples, I will have more information for analysis and interpretation.

A limitation of IFLS which is unavoidable and I account for this in my empirical strategy is the possibility of household break-up in longitudinal study designs. This limitation arguably cannot simply be explained away in terms of attrition. As explained by Rosenzweig and Foster (2001) this design problem stems in part from the relative absence of attention in the theoretical and empirical literature to the determination of household structure. I try to address this problem by looking at the data in terms of household splitting. That is, there may be children who outmigrate for employment reasons. But none of the children aged $6-15$ report leaving the household to start a new household in another location.

\subsection{Child and Household Characteristics in Simultaneous Work-Schooling Behavior}

The allocation of child time is an important component of a household's decisionmaking process. The household must weigh the value of child time spent in many activities including schooling, wage work, work inside the household, and work in household chores or other components of household production. The value of child time in any of these activities depends on both child and household attributes. In this section I consider how observable child and household characteristics are associated with the degree to which household income is improved over the period of the financial crisis. To do this I carry out semi-parametric estimation and I assume a normal distribution.

To capture child characteristics I use the variables gender, age and schooling type or source of skill formation. But there is a limitation where there is no data available on the type of work activity that the child carries out outside the household or in the household. As detailed in Section 4.3, these are the characteristics that are associated with the value of child time. National level trends 
show that boys tend to work outside the household and this work can be waged or non-waged. Wage work can be valued in terms of hourly wages or a fixed wage for a given amount of work. In contrast girls tend to work in the household or also known as attending informal school, primarily in farming, home production or domestic work which is unremunerated. It is then difficult to monetize the value of their work and how it improves family welfare. It is also difficult to measure the number of hours girls allocate to work because there is no incentive to determine the monetary value of an hour's work. Because of these intrinsic differences in how the work effort of boys and girls are viewed, there will also be differences in terms of how boys and girls shift more towards work and less towards schooling given joint work-schooling decisions. I capture these differences using the two definitions of child work - work outside the household and work in the household.

In terms of household characteristics, I focus on the variables annual total household income and household educational expenditures. Household income is proxied by household reported expenditures on all market valued goods and services. Educational expenditures consist of spending in the whole school year related to learning activity such as books, private tuition and transportation to school or the learning center. Because of the unanticipated reduction in household income, adjustments to household expenditures may necessitate reducing or foregoing educational expenditures entirely. However scholastically motivated parents may likely continue to allocate a proportion of the household budget to learning activity.

In relation to child and household attributes, I consider too the regional differences. This is because of the vastness of the country and its different socio-economic characteristics. To capture the regional differences, I use two variables - all households residing in Java and Bali Islands and households split by urban and rural in each of the main islands. Because of modernization and consequently urbanization, Java and Bali Islands have attracted the majority of the population. Java and Bali based on BPS estimates in 2003 are home to $60 \%$ of the total country population but represent only $7 \%$ of the total land mass in Indonesia. In contrast the Outer Islands are considered to have less industrialization, are less developed and have a lower population density.

\subsubsection{Distribution of Time for Work and Schooling}

I present the distribution of hours worked per week while attending school and one of the sources of skill formation. The kernel densities to be presented in Figures 4.3, 4.4 and 4.5 represent child work outside of the household but not child work in the household. Based on the survey question asked in IFLS, children report on actual number of hours worked in the previous week and the hours reported do 
not reflect any other related activity such as travel time to work. The following Figure 4.3 presents children who work and attend the formal and mainstream education system where children in 1997 have a lower spread of hours worked per week compared to 2000.

Figure 4.3 Kernel Density for Number of Hours Worked Per Week outside the Household \& Attending Formal School

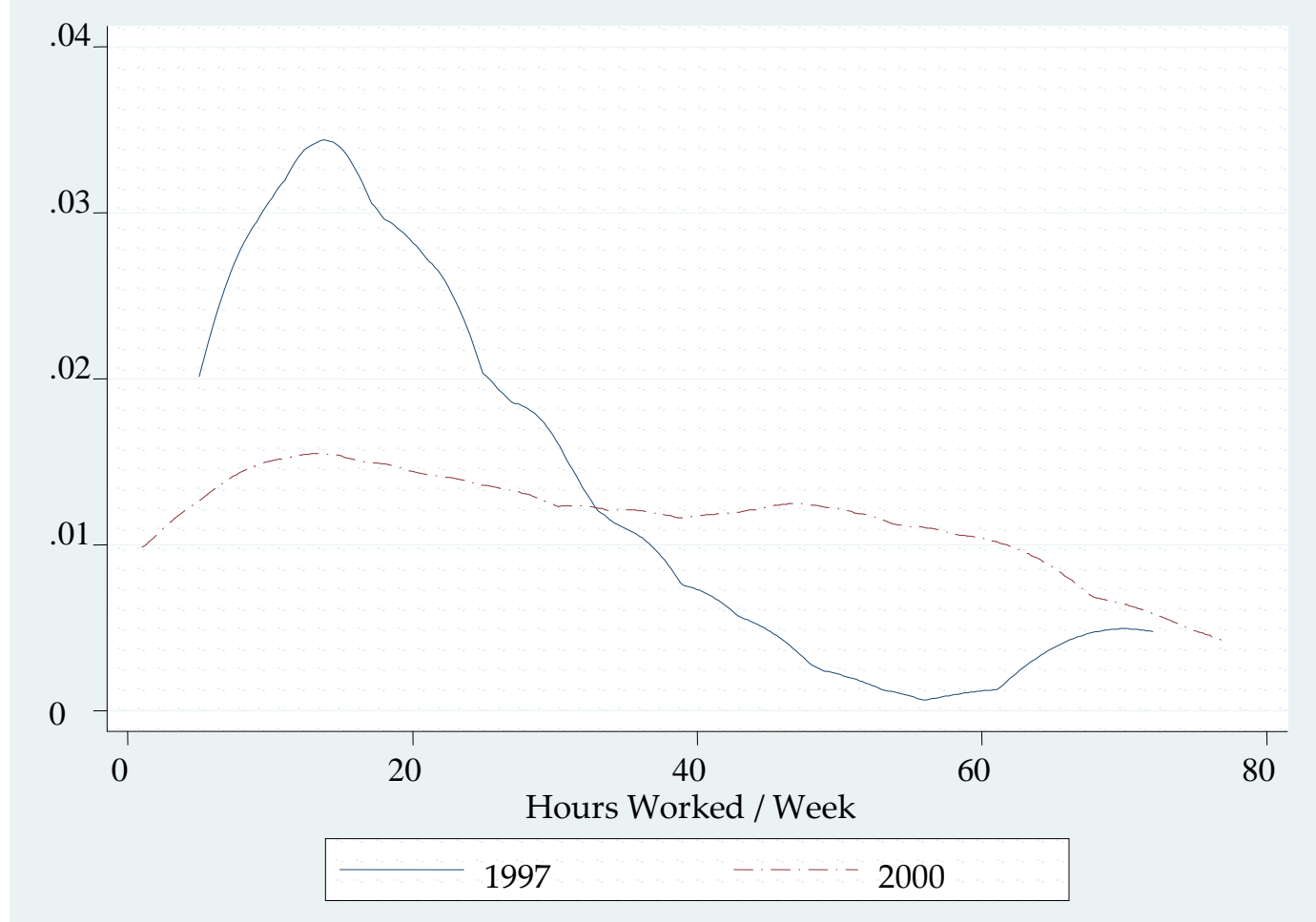

In 1997 there is a peak in the range of $0-20$ hours but this peak disappears for in 2000. While the density is higher in the range of $0-30$ hours in 1997 compared to 2000, this becomes different after 30 hours. The density is then higher in the range of 30 - 80 hours in 1997 compared to 2000. As such it can be seen from Figure 4.3, the children in 2000 work more hours a week than the children in 1997 while attending formal schooling. The total time allocation for work and at least 42 hours a week for classroom learning as dictated by the national curriculum for $11-15$ year olds (refer to Chapter 2) is in the range of 72 hours - 142 hours a week in 2000. In contrast the total time allocation for joint work-schooling in 1997 is in the range of 42 hours -72 hours a week for $11-15$ year olds. The total time allocation is less for children aged $7-8$ as the national curriculum requires a fewer 30 hours per 
week of classroom instruction. But classroom learning time increases to 38 hours for 9 year olds and 40 hours for 10 year olds.

The following Figure 4.4 presents child workers who attend Packet A and Packet B equivalency programs. The density of hours worked in 1997 peaks at $0-20$ hours. In comparison, the distribution is further spread out in 2000 where children work from $20-80$ hours after the financial crisis. However information on the total time allocated to work and skill formation is not available for this segment. This is because the equivalency programs are designed by the Ministry of Education in a flexible manner where the children can decide how much time to allocate for curriculum learning (refer to Chapter 2).

Figure 4.4 Kernel Density for Number of Hours Worked Per Week outside the Household \& Attending Non-Formal School

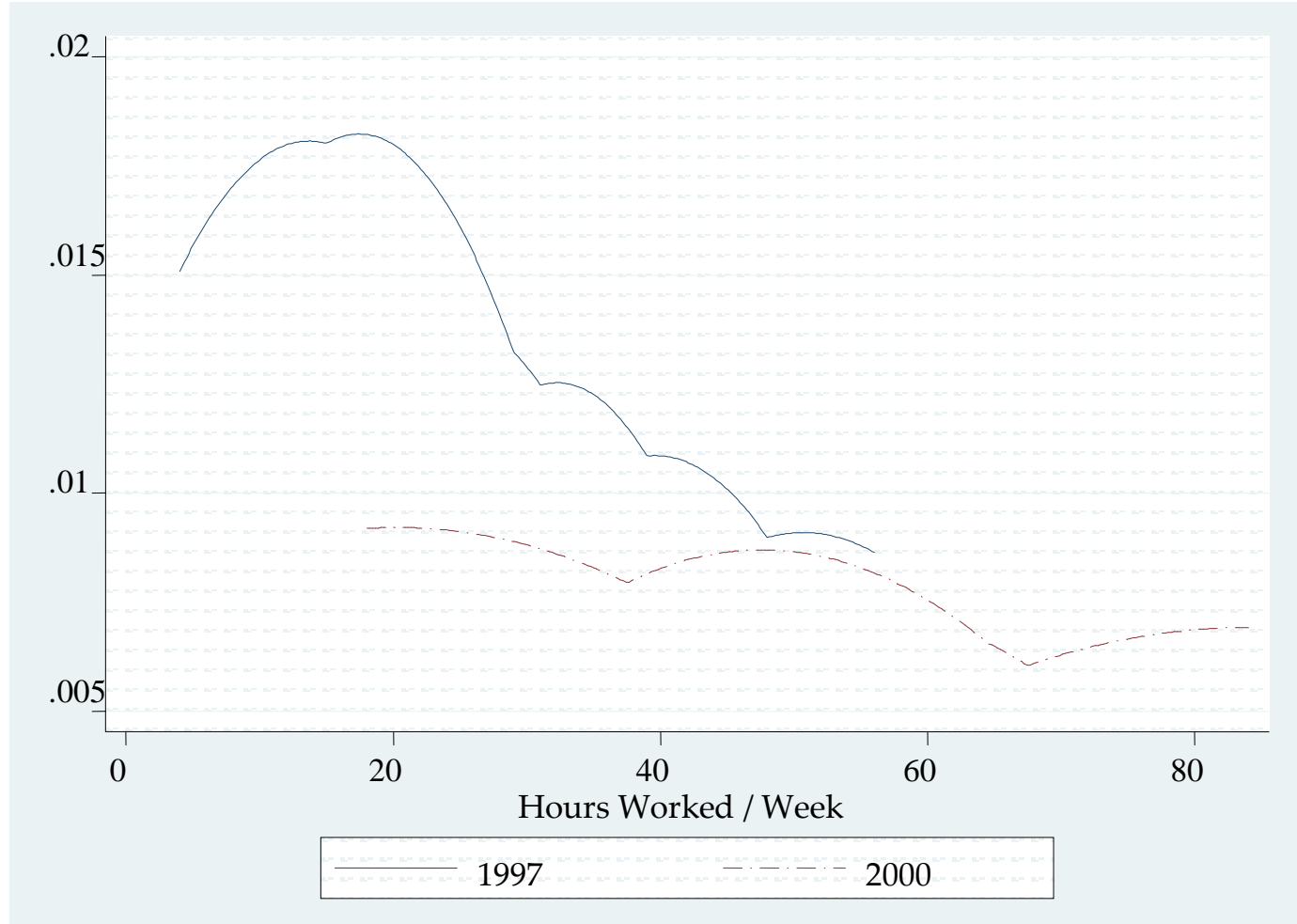


Figure 4.5 Kernel Density for Number of Hours Worked Per Week outside the Household \& Attending Informal School

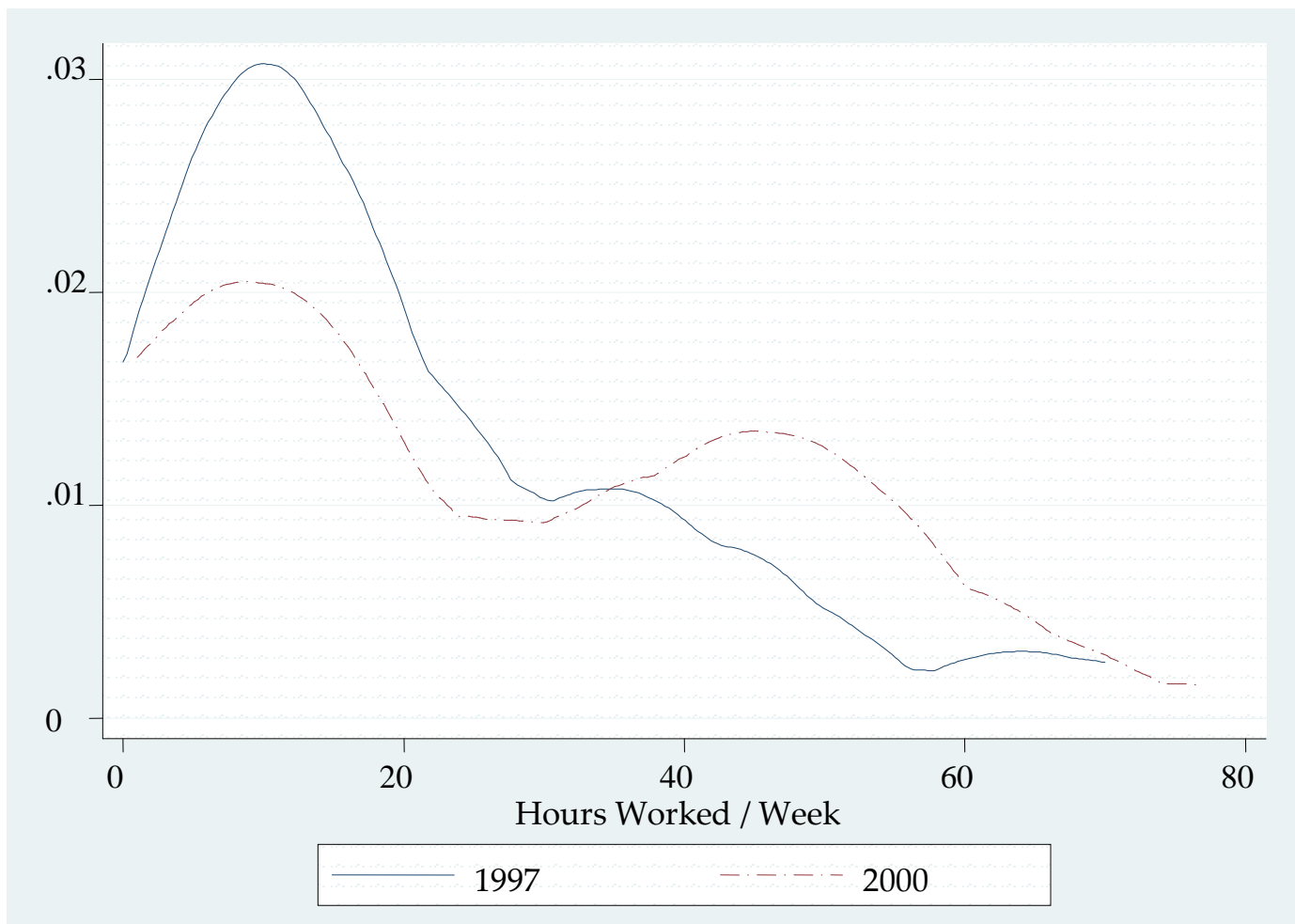

From Figure 4.5, it can be seen that children who work and attend informal school also known as education within the home have similar distributions as the children attending the other two sources of skill formation. However the time allocated for work and the time allocated for skill development cannot be disentangled because it is most likely that both activities are synonymous. Both activities build productive skills as viewed by the family. As can be seen in Figure 4.5, the density in 1997 is in the range of $0-30$ hours and is higher than 2000 . This pattern reverses for the higher range of hours from $30-80$ hours where the density in 2000 is higher than in 1997.

When studying these kernel densities, the caveat is that the distributions only represent children who work outside the household and this understates the full extent of child labor. The substantial increase in the number of hours worked per week in 2000 merits further investigation and this means exploring other dimensions of child labor which I do using the three specifications for child labor. 


\subsubsection{Relationship between Household Income and Simultaneous Work-Schooling}

From Figures 4.3 - 4.5, child workers in 1997 worked a higher number of hours than in 1997. How does this pattern of increased working outside the household and in the household relate to household income? From Figure 4.6, it can be seen that as a result of the Asian Financial Crisis and the extreme inflation levels affecting purchasing power, for this restricted sample household income in 2000 was severely reduced compared to 1997.

Figure 4.6 Household Income Per Capita

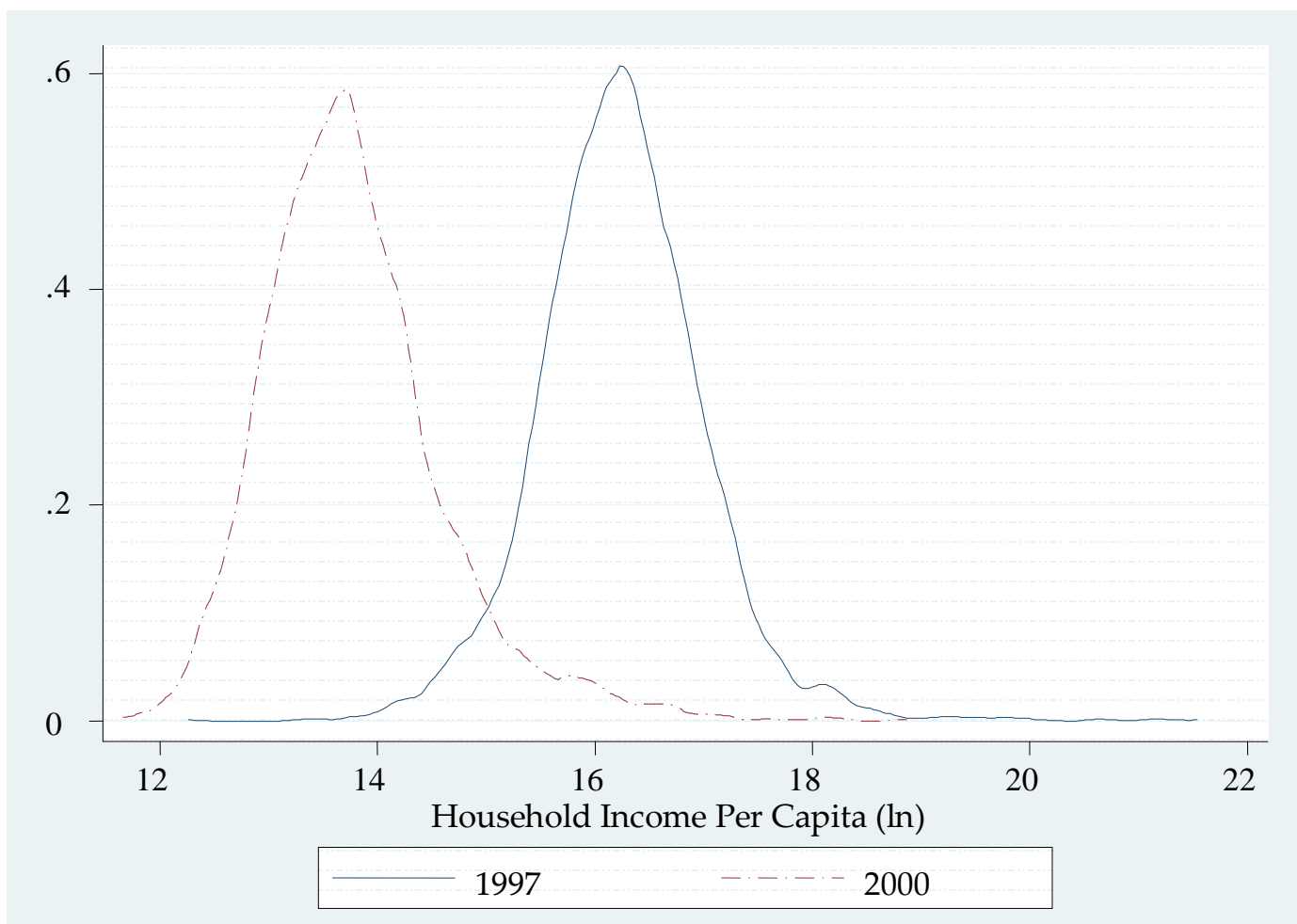

The distribution of household income per capita in log terms shifted left from the range of slightly more than $12 \log$ points $-22 \log$ points to the range of less than 12 $\log$ points $-19 \log$ points. The distributions show that higher income households in 2000 were more negatively affected by the crisis than the lowest income households. Also the spread of the income distribution becomes narrower in 2000 compared to 1997. By comparing Figures $4.3-4.5$ that depict the distribution of simultaneous work-schooling by source of skill formation with Figure 4.6 that 
depicts income, it can be seen that children worked more hours per week when income fell.

Given the kernel densities from Figures 4.3 - 4.5, I pool the observations of child labor and their family's income for 1997 and 2000. Figure 4.7 presents the estimated fit between these two main variables.

Figure 4.7 Relationship between Household Income and Child Labor

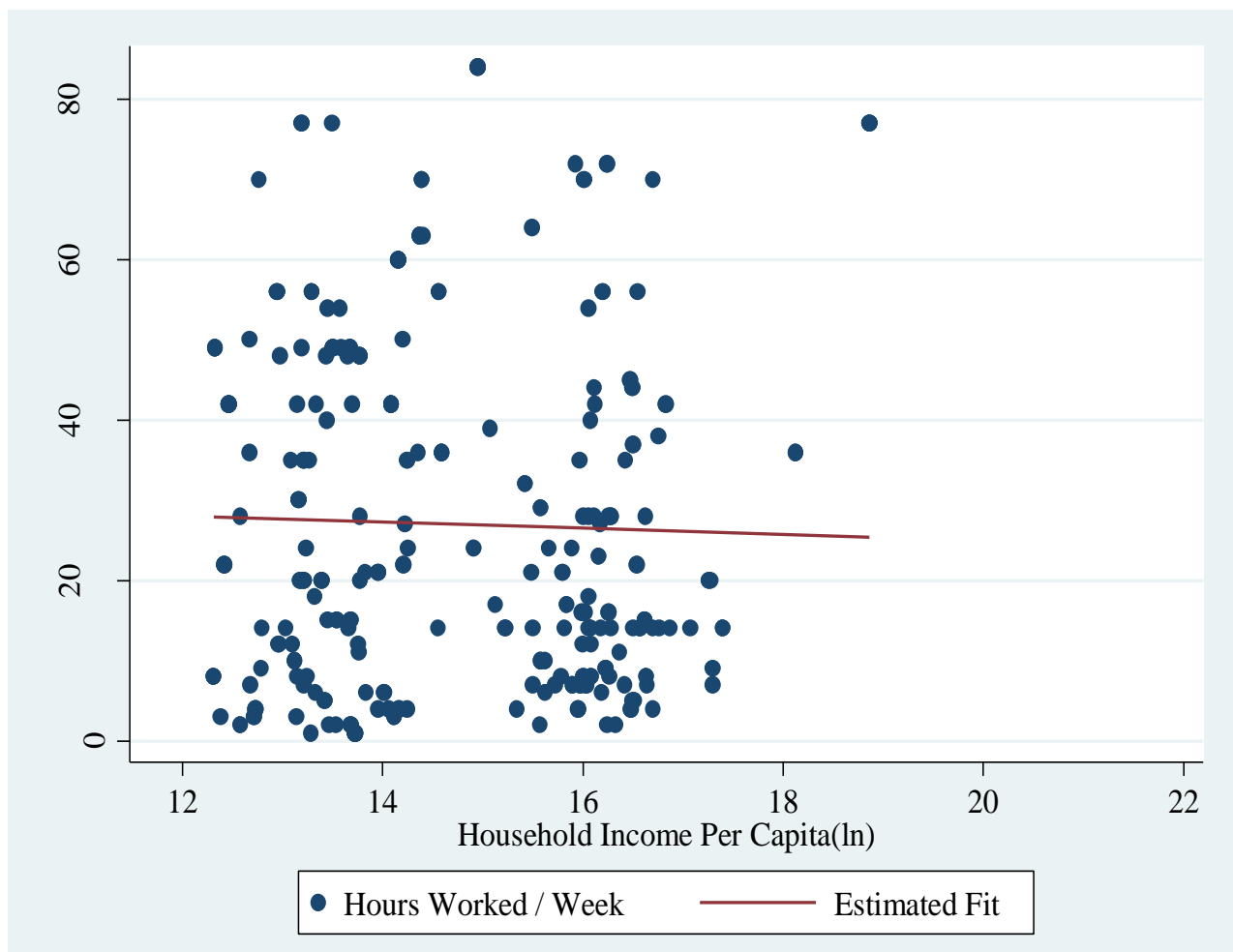

From Figure 4.7 it can be seen that the slope for the estimated fit between child labor and income is nearly flat. This suggests that the contribution of child time for wage work to household income is minimal. Put another way, the supply of child labor may be less than elastic. It appears that a small proportion of child income is endogenous to household income which is generated by working outside the household. This in turn implies that the time value of children working is higher in the household than the market value of working outside the household. This time value working in the household may also be partly reflected in the terms of child work viewed as skill formation. 


\subsubsection{Descriptive Statistics}

Table 4.2 provides information on working children and their sources of skill formation - formal school or alternative school.

Table 4.2 Children Working and Different Sources of Skill Formation

\begin{tabular}{lrrrr}
\hline Source & 1997 & $\%$ & 2000 & $\%$ \\
Formal & 1,638 & 0.20 & 1,616 & 0.22 \\
Non-Formal & 229 & 0.03 & 196 & 0.03 \\
Informal & 6,518 & 0.77 & 5,511 & 0.75 \\
Observations & 8,399 & & 7,323 & \\
\hline
\end{tabular}

Notes: This table provides statistics on all working children - i) children who report working for a wage outside the household and ii) children who report working in the household which includes the family business or farm and home production / domestic production and they do not receive any wages. All children are reported as being registered in one school type / source of skill formation while working.

In both 1997 and 2000 a majority of the children attend informal school to learn independent courses that complement work for the family. The statistic is $77 \%$ in 1997 and $75 \%$ in 2000 which is in similar proportion. 20\% in 1997 and $22 \%$ in 2000 work and attend the formal mainstream education system. 3\% in 1997 as well as in 2000 work and attend non-formal school where the curriculum consists of an equivalency program designed to accommodate child workers who might then return to the mainstream system. These statistics are then disaggregated by the 2 definitions of children working outside the household and in the household.

From Table 4.3, 51\% in 1997 and a reduced 44\% in 2000 who report working outside the household attend informal school. 41\% in 1997 and an increased 51\% in 2000 work and attend formal school. Exploring further this 10 percentage point difference, it is found that a higher proportion of older children in 2000 attend formal junior high. 7\% in 1997 and a slightly smaller 5\% in 2000 outside the household and attend non-formal school.

Table 4.3 Children Working outside the Household and Source of Skill Formation

\begin{tabular}{lrrrr}
\hline Source & 1997 & $\%$ & 2000 & $\%$ \\
Formal & 50 & 0.41 & 85 & 0.51 \\
Non-Formal & 9 & 0.07 & 7 & 0.05 \\
Informal & 63 & 0.52 & 75 & 0.44 \\
Observations & 122 & & 167 & \\
\hline
\end{tabular}

Notes: This table provides statistics on only children in the observed data who report working outside the household and may or may not receive a wage. 
Proceeding to Table 4.4 which provides the statistics for children who work in the household, the pattern of the majority attending informal school is similar to that of children who work outside the household. 78\% in 1997 and a similar proportion of $76 \%$ in 2000 work within the household and simultaneously build their skills within the home. $19 \%$ in 1997 and $21 \%$ in 2000 work in the household and attend the formal, mainstream system. For both periods, $3 \%$ work and attend non-formal school.

Table 4.4 Children Working in the Household \& Source of Skill Formation

\begin{tabular}{lrrrr}
\hline Source & 1997 & $\%$ & 2000 & $\%$ \\
Formal & 1,588 & 0.19 & 1,531 & 0.21 \\
Non-Formal & 220 & 0.03 & 189 & 0.03 \\
Informal & 6,456 & 0.78 & 5,436 & 0.76 \\
Observations & 8,277 & & 7,156 & \\
\hline
\end{tabular}

Notes: This table provides statistics on only children in the observed data who report working in the household which includes the family business or farm and home production / domestic production and they do not receive any wages.

The following Tables 4.5 and 4.6 provide further descriptive statistics for the characteristics of the group of children who work outside the household in 1997 and 2000 and for the characteristics of the group of children who work within the household. 
Table 4.5 Characteristics of Children Working outside the Household

\begin{tabular}{|c|c|c|c|c|c|}
\hline 1997 & & Mean & SD & Min & Max \\
\hline Hours Worked / Week & & 22.19 & 17.68 & 2 & 72 \\
\hline Household Income (ln) & & 16.18 & 0.61 & 14.20 & 18.12 \\
\hline Educational Expenditures (ln) & & 10.28 & 0.84 & 7.71 & 11.98 \\
\hline \multicolumn{6}{|c|}{ Percentage } \\
\hline Girl & \multicolumn{5}{|c|}{0.38} \\
\hline Boy & \multicolumn{5}{|c|}{0.62} \\
\hline Urban & \multicolumn{5}{|c|}{0.30} \\
\hline Rural & \multicolumn{5}{|c|}{0.70} \\
\hline Java and Bali Islands & \multicolumn{5}{|c|}{0.40} \\
\hline Outer Islands & \multicolumn{5}{|c|}{0.60} \\
\hline \multirow[t]{11}{*}{ Distribution by Age } & \multicolumn{3}{|c|}{ Percentage } & & \\
\hline & 6 & 0 & & & \\
\hline & 7 & 0.008 & & & \\
\hline & 8 & 0.04 & & & \\
\hline & 9 & 0.06 & & & \\
\hline & 10 & 0.08 & & & \\
\hline & 11 & 0.09 & & & \\
\hline & 12 & 0.16 & & & \\
\hline & 13 & 0.25 & & & \\
\hline & 14 & 0.31 & & & \\
\hline & 15 & 0 & & & \\
\hline
\end{tabular}


Hours Worked / Week

30.26

23.04

Household Income (ln)

Girl Percentage

Boy

0.58

(1)

0.42

Urban

Rural

Java and Bali Islands

Outer Islands

Distribution by Age

Percentage

6

$\begin{array}{ll}7 & 0.01\end{array}$

$8 \quad 0$

$9 \quad 0.01$

$10 \quad 0.08$

$11 \quad 0.05$

$12 \quad 0.11$

$13 \quad 0.08$

$14 \quad 0.31$

$15 \quad 0.34$

By exploring the characteristics of the child and the household for those who work outside the household, it is observed in the Table 4.5 that the children in 1997 report working an average of 22.19 hours per week. Also it is observed that the minimum number of hours worked per week is 2 hours and a maximum of 72 hours. Average household income per capita is $16.18 \mathrm{log}$ points with a minimum of $14.20 \log$ points and a maximum of 18.12 log points. Parents of children who work outside of the household invest on average $10.28 \mathrm{log}$ points in educational spending. In $1997,62 \%$ of the children are boys and $38 \%$ are girls. The majority at $70 \%$ of children are in rural areas and $60 \%$ are located in the Outer Islands where there is less economic development compared to Java and Bali Islands. The observed data shows that in 1997 children aged 6-9 make up a smaller percentage of child workers. Older children age $12-14$ make up a higher proportion of workers. 
In contrast, for the characteristics of the child and the household in 2000 it can be seen that the mean hours worked per week increased to 30.26 hours per week. Compared to 1997 this is an increase of $36 \%$ of hours worked per week. Also the range of hours worked has a far greater spread in 1997 to 2000. The minimum number of hours worked in 2000 is 1 hour and the maximum if 84 hours which raises the question whether the child workers are allocating more hours for work than what is possibly conceivable given the number of hours available in the day. The child workers in 2000 have on average a household income per capita of 13.69 $\log$ points which is lower than for the child workers in 1997. The reduction in average household income is $2.49 \mathrm{log}$ points. Despite this severe reduction in income, parents in 2000 on average increased educational spending to $10.34 \mathrm{log}$ points compared to 1997 at 10.28 log points (calculated in real terms using a selfconstructed price deflator for education based on teacher wages ${ }^{21}$ ). In 2000, the composition of girl and boy workers has changed compared to 1997. In 2000, girls make up $58 \%$ of workers and boys make up $42 \%$. In terms of the urban / rural split, the majority of child workers in 2000 at $59 \%$ are from rural areas and this is similar in 1997. However like results from the SAKERNAS labor surveys, there is a shift towards child employment in urban centers in 2000 where the percentage of workers in the urban centers is a larger $41 \%$. When looking at the incidence of child labor by islands, in $200063 \%$ of child workers are from Java and Bali. This pattern is the reverse of what is observed in 1997 before the financial crisis when the majority of child workers were in the Outer Islands. As there is more economic development in Java and Bali where there is a higher concentration of the tertiary services sector, the observed data appears to follow the national level trends of child work shifting away from the primary agricultural sector to the tertiary services sector. When looking at the age distribution of child workers in 1997 the pattern is similar to 2000 in terms of younger children ages 6 - 11. The pattern becomes different in 2000 for older children particularly aged 14 and 15 who work more instead of the spread of ages $12-15$ as seen in 1997. The higher incidence of 15 year old children working in 2000 after the financial crisis coincides with the legal minimum age for employment in the country.

${ }^{21}$ Refer to Chapter 2 for the computation of this education price deflator. 
Table 4.6 Characteristics of Children Working in the Household

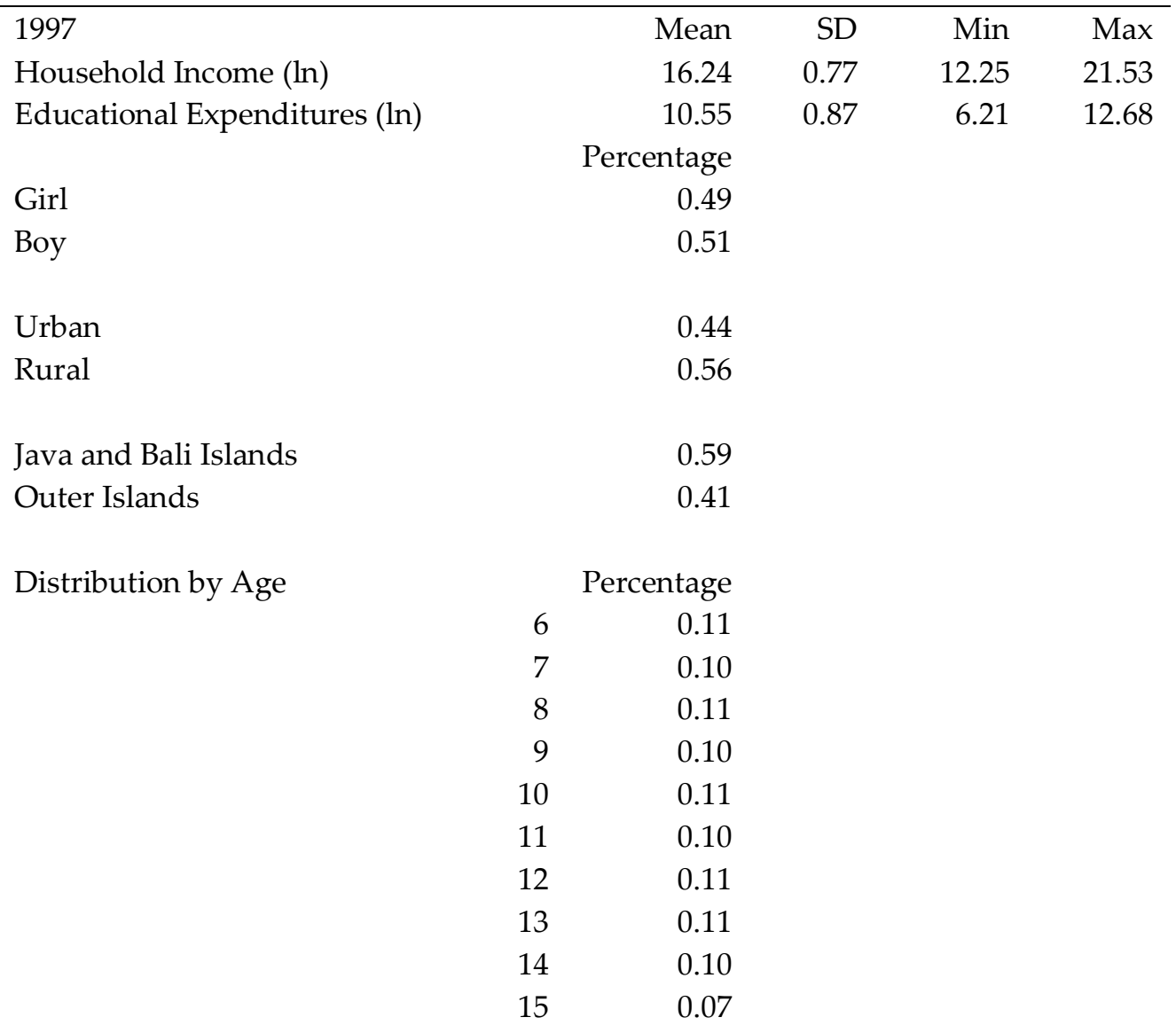


Girl Percentage

Boy

0.50

Boy

0.50

Urban

0.39

Rural

0.61

Java and Bali Islands

0.75

Outer Islands

0.25

Distribution by Age

Percentage

$\begin{array}{rl}6 & 0.08 \\ 7 & 0.11 \\ 8 & 0.11 \\ 9 & 0.10 \\ 10 & 0.11 \\ 11 & 0.11 \\ 12 & 0.10 \\ 13 & 0.11 \\ 14 & 0.10 \\ 15 & 0.05\end{array}$

Notes: Respondents when asked if they work in the household which includes domestic production, the family business or the farm reported either Yes or No but they do not provide the number of hours per week used to carry out these activities in the household. As such this table only reports on children who have the status of working in the household and the household's total annual expenditures and annual educational expenditures.

For Table 4.6 which provides the descriptive statistics for children who work in the household, the children do not report the number of hours worked in IFLS. They only report that they do work and the work is for the family. The non-reporting of hours worked is most likely related to not having the need to recall hours worked because they do not receive hourly wages. In 1997, mean household income per capita is $11.27 \log$ points and the range covers $8.79-16.65 \log$ points. Mean educational expenditures is $10.55 \log$ points with a minimum of 6.21 log points and a maximum of $16.65 \mathrm{log}$ points. Mean household income and mean educational spending is slightly higher for children who work in the household compared to children who work outside the household. There is even split of girl and boy 
workers in 1997. Like children who work outside the household in 1997, the majority who work in the household at $56 \%$ are from rural areas. But $59 \%$ are located in Java and Bali and $41 \%$ are located in the Outer Islands. This is the reverse of children who work outside the household. In terms of the age distribution, the children ages 6-14 are evenly spread out in 1997 where there does not appear to be any difference whether a younger or older child works in the household. The slight exception is that a smaller percentage of 15 year olds work in the household.

As a comparison, in 2000 for children who work in the household, average household income per capita is higher than in 1997. After the crisis, average household income is $11.87 \log$ points with a minimum of $9.86 \log$ points and a maximum of $14.78 \mathrm{log}$ points. However mean educational investments at $10.34 \mathrm{log}$ points are lower in 2000 for children who work in the household compared to 1997. Also the range for educational investments has severely deteriorated after the crisis in terms of the minimum value is at a low of $1.39 \log$ points. However the range has a greater spread compared to 1997 with the maximum value at a high of 13.21 $\log$ points. In terms of gender and the urban / rural split, there is the same pattern in both 1997 and 2000. The incidence of child labor in 2000 shows the same pattern as in 1997 in terms of the majority who work in the household being located in Java and Bali Islands. The age distribution for the children who work for the family in the 2000 remains the same as in 1997 including 15 year old children working less at home compared to the children aged $6-14$.

\subsection{Results}

In Table 4.7, I present the results for the first sample that consists of children who work and attend school and children who do not work and only attend school full time. Full time schooling is in terms of any of the three sources of skill formation. 
Table 4.7 Household Income, Joint Work-Schooling and Fulltime Schooling

$\mathrm{DV}=$ child who combines work with school is 1 ,

Otherwise child has no work and attends school fulltime is 0

(Robust SE is in Parentheses)

(i)

(ii)

(iii)

(iv)

OLS

IV

OLS

IV

Household

Income

$-0.0030$

$-0.0288^{* * *} \quad-0.0013$

$-0.027^{* * *}$

Asian Financial Crisis

(0.0021)

$0.0624^{* * *}$

(0.0015)

(0.5850)

(0.0062)

$0.0628^{* * *}$

(0.0015)

Schooling Expenditures

(0.0066)

$-0.0093^{* * *}$

$-0.0029$

(0.0024)

(0.0024)

Child

Age

$0.0144^{* * *}$

$0.0145^{* * *}$

$0.0122^{* * *}$

$0.0119^{* * *}$

(0.0007)

(0.0007)

(0.0009)

(0.0009)

Boy

0.0012

0.0013

$-0.0001$

0.0003

$(0.0034)$

(0.0034)

(0.0036)

$(0.0036)$

Urban

$-0.0217^{* * *}$

$-0.0124^{* * *}$

$-0.0163^{* * *}$

$-0.0109^{* *}$

Java and Bali

(0.0036)

(0.0034)

(0.0039)

(0.0039)

0.0023

0.0031

0.0057

0.0044

(0.0036)

(0.0036)

(0.0038)

(0.0038)

Schooling Type

Non-Formal School

0.0216

0.0212

(0.0195)

(0.0194)

Informal School

$-0.0242^{* *}$

$-0.0279^{* *}$

(0.0082)

$(0.0082)$

Constant

$-0.0737$

0.3389

0.9635

0.5975

$\mathrm{R}^{2}$

$$
\text { (0.0353) }
$$

$(0.0229)$

(0.0446)

$(0.0354)$

0.06

0.05

0.06

0.06

Observations

14,338

14,338

13,145

13,145

Statistically significant at the ${ }^{* * *} 1 \%, * * 5 \%$ and $* 10 \%$ level

Notes: The instrumental variable for income in (ii), (iv), (vi) and (viii) is the Asian Financial Crisis. In

Table 4.7, the number of observations for children who attend one of the sources of skill formation full time and does not work is smaller than the observations in Table 4.7. In Table 4.8, there are more children observed with joint work-schooling behavior. 
In columns (i) and (ii) the regressions do not include the endogenous explanatory variables, schooling expenditures and schooling type. I find that the OLS estimate in (i) for household income per capita is negative and comparable in magnitude to the IV estimate in (ii). However the IV estimate is statistically significant at the $1 \%$ level and the OLS estimate is not significant. As expected when income is lower, the child combines work with schooling and does not attend school full time. Correspondingly, an increase in schooling related expenditures increases the likelihood that the child will attend school full time. However the effect of schooling expenditures on the child's work - schooling behavior is smaller than the effect of income. In columns (iii) and (iv) the coefficient size for schooling expenditures is smaller than for income. While the OLS estimate for these expenditures is statistically significant it is no longer the case for the IV estimate. In terms of the age effect, I find that across columns (i) to (iv), the older the child is, the higher the propensity for the child to work. This is similar to the national level trend highlighted in Figure 4.1. The OLS and IV estimates for age are similar in magnitude across the four columns and all are statistically significant at the $1 \%$ level. As the OLS and IV estimates are similar, there is little bias. I also find that children who reside in urban centers have the propensity to attend school full time and not work. This is a statistically significant result across (i) to (iv) which is when the endogenous explanatory variables are not included and when included. I do not find any other significant results to explore further in terms of child attributes. This includes the gender of the child which suggests there is minimal bias whether a boy or a girl attends school full time or works full time. When I focus on the three sources of skill formation, I find that the provision of non-formal schooling by nongovernmental organizations including religious schools increases the propensity of joint work-schooling. This is consistent with the design of non-formal schools for accommodating the skill development needs of child workers. However this result is not statistically significant. In contrast, when the source of skill development comes from the family, there is a positive relationship between attending school full time and not working. The OLS and IV estimates have similar coefficients and are statistically significant at the $5 \%$ level.

In Table 4.8, I present the results that use the dependent variable of children who work outside the household combined with attending school and children who work within the household while attending school. 
Table 4.8 Household Income, Joint Work Outside-Schooling and Joint Work in Household-Schooling

DV = child works outside the household and attends school is 1 ,

Otherwise child works in the household and attends school is 0 (Robust SE is in Parentheses)

(i) (ii) (iii) (iv)

OLS IV OLS IV

$\underline{\text { Household }}$

Income

$\begin{array}{llll}-0.0021 & -0.0024^{* *} & -0.0011 & -0.0022^{* *} \\ (0.0015) & (0.0009) & (0.0017) & (0.0009) \\ 0.0009 & & 0.0026 & \\ (0.0042) & & (0.0045) & \\ & & -0.0047^{* * *} & -0.0044^{* *} \\ & & (0.0013) & (0.0013)\end{array}$

Child

Age

$0.0070^{* * *} \quad 0.0070^{* *} \quad 0.0068^{* * *} \quad 0.0068^{* * *}$

Asian Financial Crisis

$(0.0004) \quad(0.0004) \quad(0.0006)$

(0.0006)

Boy

$\begin{array}{llll}0.0006 & 0.0006 & -0.0006 & -0.0006\end{array}$

Urban

$\begin{array}{lll}(0.0021) & (0.0021) \quad(0.0021)\end{array}$

(0.0021)

Urban

$-0.0038^{*} \quad-0.0036$

0.0024

0.0026

Java and Bali

$\begin{array}{lll}(0.0023) & (0.0022) \quad(0.0025)\end{array}$

$(0.0025)$

$\begin{array}{lll}-0.0048^{* *} & -0.0048^{* *} & -0.0047^{*}\end{array}$

$-0.0047^{*}$

(0.0024)

(0.0024)

(0.0026)

(0.0026)

Schooling Type

Non-Formal School

\begin{tabular}{cccl} 
& & -0.0147 & -0.0147 \\
& & $(0.0095)$ & $(0.0095)$ \\
& & -0.0022 & -0.0023 \\
$(0.0050)$ & $(0.0050)$ \\
-0.0173 & -0.0111 & 0.0192 & 0.0342 \\
$(0.0256)$ & $(0.0138)$ & $(0.0290)$ & $(0.0192)$ \\
0.02 & 0.02 & 0.02 & 0.02 \\
15,780 & 15,780 & 14,151 & 14,151 \\
\hline
\end{tabular}

$\mathrm{R}^{2}$

Statistically significant at the ${ }^{* * *} 1 \%,{ }^{* *} 5 \%$ and ${ }^{*} 10 \%$ level

Notes: The instrumental variable for income in (ii), (iv), (vi) and (viii) is the Asian Financial Crisis. In

Table 4.8, the number of observations for children with joint-work schooling behavior is larger than the observations in Table 4.7. In Table 4.7, there are fewer children observed who attend school full time.

The role of income in affecting child labor now changes. With income decreases the incidence of children working outside the household increases. The size of the 
income coefficient as reported by OLS and IV is similar to the size of the income coefficient when the dependent variable is specified as whether a child attends school full time (Table 4.7). However only the IV estimate is statistically significant and this is at the $5 \%$ level. Household investment in schooling as represented by schooling expenditures in columns (iii) and (iv) have the same relationship as income in terms of how it relates to child labor. With a fall in schooling expenditures, the incidence of children working outside the household increases. The OLS and IV estimates for spending are similar in magnitude and statistically significant. More importantly, the size of the coefficients for schooling expenditures is now larger than for household income. The significance of schooling expenditures when child labor is now specified in terms of working outside or within the household suggest that when parents choose to keep their children working in the home, there are likely to be elements of skill formation. As described in Chapter 2, children complement learning in the informal school with individual courses provided by the Ministry of Education. Parents can make these investments in their children when they are in the home enterprise but this may be less likely when the child works outside of the household for an employer.

In comparing the relationship between an income reduction and the incidence of joint work-schooling (Table 4.7) with the relationship between an income reduction and the incidence of working outside of the household (Table 4.8), decreases in income drive the shift towards joint work-schooling. But the reduction in income does not determine if the child will have a higher likelihood of working outside the household or in the household. This can be interpreted as a fall in income causes simultaneous work-schooling decisions but working can just as likely take place outside the household or in the household.

The relationship between the age of the child and the incidence of working is also borne out in Table 4.8 but now specifically in terms of an older child is more likely to work outside the household while attending school. This result is statistically significant at the $1 \%$ level. This finding is consistent with the intuition that when older the child is expected to be better equipped to manage the safety and health risks of working outside without parental supervision. In Table 4.8, Inow have a new result that I did not have from Table 4.8 which is related to the child's residential location. On the one hand residence in Java and Bali Islands does not play a substantial role in determining whether a child is in school or at work full time. But on the other hand, location becomes important for whether a child works outside the household or in the household. From Table 4.8, across columns (i) - (iv) it can be seen a child worker residing in Java and Bali Islands will work outside the household and attend school and this is statistically significant. This strongly suggests that there are more economic opportunities available in Java and Bali compared to the Outer Islands that have lower levels of economic development. As 
such when the child has to work, it is more likely that the child will work outside of the household because the relative returns will likely be higher than what is gained by working for the family in the household. I also find that the source of skill formation that now plays a noticeable role is non-governmental organization run schools for child laborers. This coefficient has a negative relationship with children working outside the household which can be interpreted as non-formal schooling reduces the incidence of working outside the household while attending school. This is consistent with the design and availability of this school type to accommodate the needs of child laborers. Schooling time is structured around the working hours of the child laborers so as not to deprive them of the opportunities for skill development. However the negative relationship between non-formal schooling and working outside the household is not statistically significant. The relationship between informal schooling and working outside the household is also negative and not statistically significant. However the size of the coefficient for informal school is smaller than for non-formal school. This implies that non-formal schools have a more important influence than informal schools in the skill development of children working outside of the household.

Table 4.9 shows the results for the specification of child labor in terms of the number of hours worked per week outside the household while attending school. Given the kernel densities from Figures 4.3 - 4.5, it was found that children in 1997 worked more hours per week while attending school compared to children in 2000. This raises the question of how much time is available for a child to work and to learn while contributing to household income. 


\section{Table 4.9 Household Income and Hours Worked by Child outside the Household}

while Attending School

\begin{tabular}{|c|c|c|c|c|c|c|c|c|}
\hline \multicolumn{9}{|c|}{$\begin{array}{c}\text { DV }=\text { Hours Worked per Week by Child who Works Outside the Household and Attends Scho } \\
\text { (Robust SE is in the Parentheses) }\end{array}$} \\
\hline & (i) & (ii) & (iii) & (iv) & (v) & (vi) & (vii) & (viii) \\
\hline & OLS & IV & OLS & IV & OLS & IV & OLS & IV \\
\hline \multicolumn{9}{|l|}{ Household } \\
\hline Income & $\begin{array}{l}3.8942^{*} \\
(1.4325)\end{array}$ & $\begin{array}{l}-1.1584 \\
(0.9115)\end{array}$ & $\begin{array}{l}4.7490^{* *} \\
(1.6619)\end{array}$ & $\begin{array}{l}-0.7716 \\
(1.0492)\end{array}$ & $\begin{array}{l}4.3767^{* *} \\
(1.4240)\end{array}$ & $\begin{array}{l}-2.8036^{* *} \\
(0.9315)\end{array}$ & $\begin{array}{l}4.3481^{* *} \\
(1.6531)\end{array}$ & $\begin{array}{l}-2.1690^{* *} \\
(1.0133)\end{array}$ \\
\hline Crisis & $\begin{array}{l}13.2350^{*} \\
(4.4960)\end{array}$ & & $\begin{array}{l}14.1238^{* *} \\
(5.1700)\end{array}$ & & $\begin{array}{l}18.4696^{* * *} \\
(4.4740)\end{array}$ & & $\begin{array}{l}16.9530^{* *} \\
(5.1349)\end{array}$ & \\
\hline $\begin{array}{l}\text { Educational } \\
\text { Spending }\end{array}$ & & & $\begin{array}{l}-2.4292 \\
(1.5806)\end{array}$ & $\begin{array}{l}-0.4769 \\
(1.6623)\end{array}$ & & & $\begin{array}{l}-2.0781 \\
(1.7007)\end{array}$ & $\begin{array}{l}0.1734 \\
(1.7359)\end{array}$ \\
\hline \multicolumn{9}{|l|}{ Child } \\
\hline$\overline{\text { Age }}$ & $\begin{array}{l}3.3777^{* * *} \\
(0.5498)\end{array}$ & $\begin{array}{l}3.6226^{* * *} \\
(0.5570)\end{array}$ & $\begin{array}{l}3.8610^{* * *} \\
(0.7066)\end{array}$ & $\begin{array}{l}3.7045^{* * *} \\
(0.7468)\end{array}$ & & & & \\
\hline Urban & $\begin{array}{l}4.5600^{*} \\
(2.4285)\end{array}$ & $\begin{array}{l}5.5944^{* *} \\
(2.5239)\end{array}$ & $\begin{array}{l}4.3567^{*} \\
(2.6236)\end{array}$ & $\begin{array}{l}4.8990^{*} \\
(2.6721)\end{array}$ & & & & \\
\hline Boy & $\begin{array}{l}1.2854 \\
(2.3503)\end{array}$ & $\begin{array}{l}0.1775 \\
(2.3984)\end{array}$ & $\begin{array}{l}3.3175 \\
(2.6302)\end{array}$ & $\begin{array}{l}2.2183 \\
(2.6496)\end{array}$ & $\begin{array}{l}3.1432 \\
(2.4033)\end{array}$ & $\begin{array}{l}1.7303 \\
(2.4812)\end{array}$ & $\begin{array}{l}6.1470^{* *} \\
(2.6569)\end{array}$ & $\begin{array}{l}4.6857^{*} \\
(2.7041)\end{array}$ \\
\hline Java and Bali & $\begin{array}{l}-0.7978 \\
(2.3830)\end{array}$ & $\begin{array}{l}0.2939 \\
(2.4183)\end{array}$ & $\begin{array}{l}2.4529 \\
(2.7960)\end{array}$ & $\begin{array}{l}2.6115 \\
(2.7878)\end{array}$ & $\begin{array}{l}0.2015 \\
(2.4812)\end{array}$ & $\begin{array}{l}1.8755 \\
(2.5524)\end{array}$ & $\begin{array}{l}2.7737 \\
(2.8841)\end{array}$ & $\begin{array}{l}2.9772 \\
(2.8905)\end{array}$ \\
\hline Age_Urban & & & & & $\begin{array}{l}0.4270^{* *} \\
(0.1978)\end{array}$ & $\begin{array}{l}0.5569^{* *} \\
(0.2083)\end{array}$ & $\begin{array}{l}0.4792^{* *} \\
(0.2111)\end{array}$ & $\begin{array}{l}0.5406^{* *} \\
(0.2140)\end{array}$ \\
\hline \multicolumn{9}{|l|}{ Schooling } \\
\hline $\begin{array}{l}\text { Non-Formal } \\
\text { School }\end{array}$ & & & $\begin{array}{l}15.5007 \\
(9.5063)\end{array}$ & $\begin{array}{l}16.1736 \\
(10.4752)\end{array}$ & & & $\begin{array}{l}10.7181 \\
(10.3714)\end{array}$ & $\begin{array}{l}11.6532 \\
(11.4138)\end{array}$ \\
\hline $\begin{array}{l}\text { Informal } \\
\text { School }\end{array}$ & & & $\begin{array}{l}3.2484 \\
(3.1050)\end{array}$ & $\begin{array}{l}1.2770 \\
(3.1981)\end{array}$ & & & $\begin{array}{l}-5.6427^{* *} \\
(2.6598)\end{array}$ & $\begin{array}{l}-7.5099^{* *} \\
(2.6163)\end{array}$ \\
\hline Constant & $\begin{array}{l}-83.6161 \\
(23.9826)\end{array}$ & $\begin{array}{l}-5.1189 \\
(16.7404)\end{array}$ & $\begin{array}{l}-82.7386 \\
(28.4779)\end{array}$ & $\begin{array}{l}-9.8121 \\
(22.9103)\end{array}$ & $\begin{array}{l}-51.9938 \\
(23.0753\end{array}$ & $\begin{array}{l}63.6304 \\
(14.3800)\end{array}$ & $\begin{array}{l}-30.1724 \\
(25.9993)\end{array}$ & $\begin{array}{l}54.0313 \\
(19.4853)\end{array}$ \\
\hline $\mathrm{R}^{2}$ & 0.16 & 0.12 & 0.20 & 0.15 & 0.09 & 0.002 & 0.14 & 0.07 \\
\hline $\mathrm{N}$ & 290 & 290 & 252 & 252 & 290 & 290 & 252 & 252 \\
\hline
\end{tabular}

Statistically significant at the ${ }^{* * *} 1 \%, * * 5 \%$ and $* 10 \%$ level

Notes: Only children who work outside the household report the number of hours worked per week.

The instrumental variable for income in (ii), (iv), (vi) and (viii) is the Asian Financial Crisis. 
From column (i) in Table 4.9, the OLS estimate for income is positive and statistically significant at the $10 \%$ level. When household income decreases by one log point, a child works nearly four hours less per week. The IV estimate in column (ii) negates this relationship where when household income decreases by one log point, the child works one more hour per week. But this result is statistically insignificant. In comparing the OLS and IV estimates, there is selection bias in the observed data where lower income households have children who work fewer hours outside the household. The different directions of the OLS and IV estimates for household income also hold in columns (iii) and (iv) when the endogenous explanatory variables are included. In terms of schooling expenditures, its effect on the number of hours worked outside the household is miniscule. This appears to be consistent with the findings in Table 4.9 when child labor is specified in terms of working outside or within the household. This implies that parents are less inclined to invest in the skill formation process when the child works outside for an employer.

As per the previous two specifications for the dependent variable, the OLS and IV estimates for age reinforce the finding that as the child is older, the incidence and intensity of child labor increases. The results across columns (i) - (iv) show that when the child is older by a year, the child works over three hours more per week. This is statistically significant at the $1 \%$ level. This strongly suggests that it is more the age of the child worker that shifts a child's time more towards work outside the household than variations in household income. In terms of geographical factors, I find that children in urban centers across all the main islands work on average four hours more per week and this is statistically significant at the $1 \%$ level. This result can be seen across columns (i) - (iv). The IV estimates are a half hour to an hour higher than the OLS estimates for each week of work and this is most likely due to attenuation bias.

Because of the statistically significant results from the age and urban center exogenous covariates, I now interact the two covariates and run the regressions from columns (v) - (viii) in Table 4.9. I now have different results for the main relationship of interest which is income and hours worked per week. The OLS estimates for income are positive and larger than for the IV estimates which mean that the OLS estimates are overstating the relationship between income and hours, due to omitted variables. Using the IV estimates from (vi) and (viii) and comparing them with the IV estimates from (ii) and (iv), it can be seen that when income decreases by one log point, the child works two hours more per week controlling for the child's age and urban location. This estimate is statistically significant at the $5 \%$ level. This finding also reflects the selection bias that lower income households have children who work fewer hours outside the household. When I study the interaction between age and urban center, I see that the IV estimates in (vi) and 
(viii) are slightly higher than the OLS estimates in (v) and (vii) which are likely related to attenuation bias. It can be seen that when the child is older by a year and residing in an urban center, the child works 30 minutes more per week and this finding is statistically significant at the $5 \%$ level. This interaction produces coefficient sizes that are noticeably smaller compared to the prior separate estimates on age and urban center in (i) - (iv). Another new finding from this additional specification can be seen in columns (vii) and (viii) where boys tend to spend more time outside the household working compared to girls. The OLS estimate is 6 additional hours of work per week, statistically significant at the $5 \%$ level and the IV estimate is at a lower 4.5 hours of more work per week statistically significant at the $10 \%$ level. This strongly implies that there is a gender bias where boys tend to work outside the household compared to girls and while working outside for a wage or an in-kind transfer, boys increase hours worked more than girls. However if the child worker is combining work outside with gaining skills from informal schooling, hours worked per week fall substantially. When schooling type as endogenous explanatory variables are included into the additional specification of the interaction of age and urban center, accounting for attenuation bias, the child works 7 hours less per week. This finding can be seen in the IV estimate in column (viii) which is statistically significant at the 5\% level. An interpretation for this finding is that the practice of the family enterprise with child apprenticeships downplays the need for the child's market income to complement household income when there is reduced income. The returns to work for the family appear to be higher than the returns to work in the market. In addition, by being an apprentice, the child's skill formation process continues and this is less likely when the child works outside the household.

\subsection{Conclusions}

This chapter has provided evidence on the variations in simultaneous workschooling behavior when income falls. I used different operational definitions for the joint work-schooling decision: joint work and schooling, joint work within the household and schooling, joint work outside the household and schooling; and number of hours worked per week and schooling. A fall in income results in a shift away from full time schooling to joint work-schooling. An income decrease is also found to increase the propensity to shift away from schooling and towards more work for children who demonstrate joint work-schooling behavior. But it is not clear whether the increased incidence of working takes place outside or within the household. When isolating only child work behavior outside the household for wages or in-kind transfers, it is found that an income reduction increases the number of hours worked per week but the increase is small. A one log point decrease in income only increases work by 2 hours in a week which is not likely to conflict with time for schooling. To reconcile these findings, a fall in income does 
increase the propensity of simultaneous work-schooling behavior. However this does not appear to be captured by the child's contribution to household income. Instead the reduction in income may be compensated by a higher relative value of child time used for work. As such, income does not appear to be the main influence for the incidence and intensity of child labor.

The main influence driving joint work-schooling is the age of the child. It is more likely that the child who already demonstrates simultaneous work-schooling behavior from an age as young as 6 is driven to work more when s/he is older. When the child is 12 years old, there is a higher propensity for the child to work outside the household while attending school. In addition this appears to be an urban phenomenon in Indonesia where wage opportunities are higher in areas with more economic development. As the 12 year old child becomes older until $\mathrm{s} /$ he reaches the legal employment age of 15 , the hours worked per week increase and there is a greater shift towards full time work. This strongly implies that if the child is in the formal school system in an urban center, the age range of $12-15$ is where the risk increases that the child will fail to complete junior high. This implies that human capital accumulation will peak at the completion of primary school at age 12 .

This chapter has also provided insight into the schooling choices of child workers formal school, non-formal school or informal school. On the one hand the extent of child labor is arguably overstated if the child is an apprentice in the family enterprise where work and learning activity are occurring simultaneously; both types of activity are the one and the same where work is carried out within the household. As there are productive skills built during the apprenticeship which provide social returns to the household if not private returns in the market, human capital accumulation does not appear to be impaired. The child's health and safety are also more likely to be assured compared to if the child works outside the household unsupervised by the parents. On the other hand the extent of child labor is likely to be understated because in this chapter, a main limitation is that there is no data available on the type of activity that is carried out. Activities in the household that can be physically harmful or do not require any skills such as mundane, repetitive tasks are not observed in the data. As such the child who shifts more towards work and away from learning may be less likely to build human capital.

From the perspective of the national education system, the institutional recognition of both the informal school and non-formal school suggests that the relative value of time working outside or within the household is higher than schooling for some families. This then implies that in certain areas particularly urban centers, parents perceive that the returns to schooling are low. The presence and development of 
the informal school and non-formal school may then be an appropriate educational policy response to ensure that economically active children aged $6-15$ are guaranteed some form of schooling. However another limitation of this chapter is that there is no wage data available to assess this to what extent the returns to schooling are lower than the returns to work outside or within the household. 
5. Dynamic Complementarity of Investment in Education 


\subsection{Introduction}

Education is generally considered as an important investment for economic growth. Optimal investments in human capital depend on the direct and opportunity costs of schooling and the future expected benefits and are thus not determined by parental income. If education is only considered to be a consumption good income would matter. But in Indonesia, monetary constraints together with other high priority expenditures could explain that parents invest less than is optimal in their children's education. This is because parents may have a preference for spending on other urgent issues and perhaps have a preference for their children to work or to help within the household. Alternative explanations for sub-optimal investment would be that poorer parents differ in their characteristics from richer parents and that these characteristics rather than income explain differences in educational investment. These characteristics could include how they vthe future expected benefits from the human capital accumulated by their children. These benefits could be both private and social.

The aims of this chapter are the following. The first aim is to investigate how income has a causal relationship with educational expenditures in Indonesia. The second aim is to determine whether time spent on schooling by Indonesian children is related to income. The third aim is investigate whether Indonesian parents respond to the expected future benefits of education in their current educational expenditures. To identify causality, we use the Asian Financial Crisis in Indonesia as a natural experiment to investigate educational expenditures. In this way, we obtain estimates of the impact of income on educational expenditures and time used for schooling while holding constant parental characteristics. The difference in the parameters between parents of children who have just started junior high and parents of children who have already attained a few years of a junior high education reveals whether parents react to differences in returns. Due to dynamic complementarity in the accumulation of human capital, the loss in returns due to lower investments for children in later grades of junior high is higher. Using repeated cross sections from 1997 and 2000, we find that about 80\% of the cross-sectional link between income and educational expenditures is caused by differences in income. The remaining $20 \%$ is related to unobserved parental characteristics or to unobserved child characteristics. Lower educational expenditures due to less income are highly compensated by time investments. The effect of time investments is $50 \%$ stronger than suggested by cross-sectional evidence. This strongly implies that income related parental characteristics explain a substantial part of these compensating time investments. Finally the reduction in educational expenditures is much lower for children who have already attained a 
few years of junior high education. This implies that parents do take into account the loss in returns related to previous investments on the stock of human capital accumulated. Or put in another way, there is loss aversion. Thus this suggests that the future expected benefits of their children's education do play a role in investment decisions. Taken together these results reveal that monetary constraints do restrict parents in their educational expenditures, that they are concerned with future returns; and that especially parents with favorable characteristics compensate reductions in educational expenditures by letting their higher ability children spend more time in school.

This chapter is related to the literature on educational investments in developing countries. Optimal parental investments based on future expected benefits have tended to be concentrated on potential lost productivity from premature school dropout given credit constraints. Available estimates indicate that schooling in developing countries has a high payoff of a $25-30$ percent real rate of return, especially for lower levels of schooling (e.g. Psacharopoulos 1994; Psacharopoulos and Patrinos 2004). At the same time, school completion rates in developing countries are very low (Lockheed and Verspoor 1991). To reconcile the contradiction between high rates of return with low schooling attainment school quality and quantity of schooling completed may be positively correlated, leading to upward biases in the rates of return estimated by traditional approaches (Behrman and Birdsall 1983; Hanushek, Lavy and Hitomi, 2008). In his review of the literature on education investments comparing developed and developing countries, Hanushek sums up that parents in developing countries may not invest more in education if their children's educational achievement and abilities do not translate into earnings opportunities outside of school $(1995,2008)$.

This chapter is also related to the theory of the technology of skill formation in the child's life cycle (Cunha et al 2004, 2005; Cunha and Heckman, 2007; Caucutt and Lochner, 2008). Cameron \& Heckman (2001), Keane \& Wolpin (2001) and Cameron \& Taber (2004) explore the positive correlation between college enrollment and family income. Using different methodology types, the authors argue that shortrun borrowing constraints do not drive schooling decisions such as staying on at school after the compulsory age. Rather, Cameron \& Heckman (2001) argue that binding lifetime credit constraints alter human capital investment through the entire childhood and drive the stock of human capital at the time schooling decisions are made. We take these arguments into consideration for the Indonesian developing country context where there is no enforced compulsory schooling age, thus credit constraints can drive schooling decisions at any schooling level.

The contributions of this chapter to the literature are threefold. First, optimal education investment does include accounting for the loss in returns from previous 
investments on the stock of human capital that has been accumulated. Put in another way, sunk costs matter. Second, this chapter expands the Cunha and Heckman (2007) technology of skill formation structural equation modeling to instrumental variable estimation. Third, this chapter provides the first piece of evidence on the technology of skill formation in a developing country.

The rest of the chapter is organized in the following way. In Section 5.2, using the theoretical framework of the technology of skill formation, we will build a model to formalize our ideas. In Section 5.3 we outline the empirical strategy, introduce operational definitions related to the technology of skill formation framework; and describe the data we use. This is followed by descriptive statistics and results in Section 5.4. Conclusions are made in Section 5.5. 


\subsection{A Model of the Distribution of Investments over the Child's Life Cycle ${ }^{22}$}

Parental investments are distributed over 2 periods in childhood in the presence of incomplete credit markets and non-compulsory schooling. The child starts in the first period known as the primary school level. If the child passes the standardized test at the end of the first period the child will transition ${ }^{23}$ from this cycle or level of education to the next higher level. The child will go on to the second period known as the junior high level. At age 15, the child enters adulthood and can either continue on to higher education or work. This model follows the Indonesian national education system as described in detail in Chapter 2. The minimum legal age for employment is 15 years old. This model is laid out in Figure 5.1:

\section{Figure 5. 1}

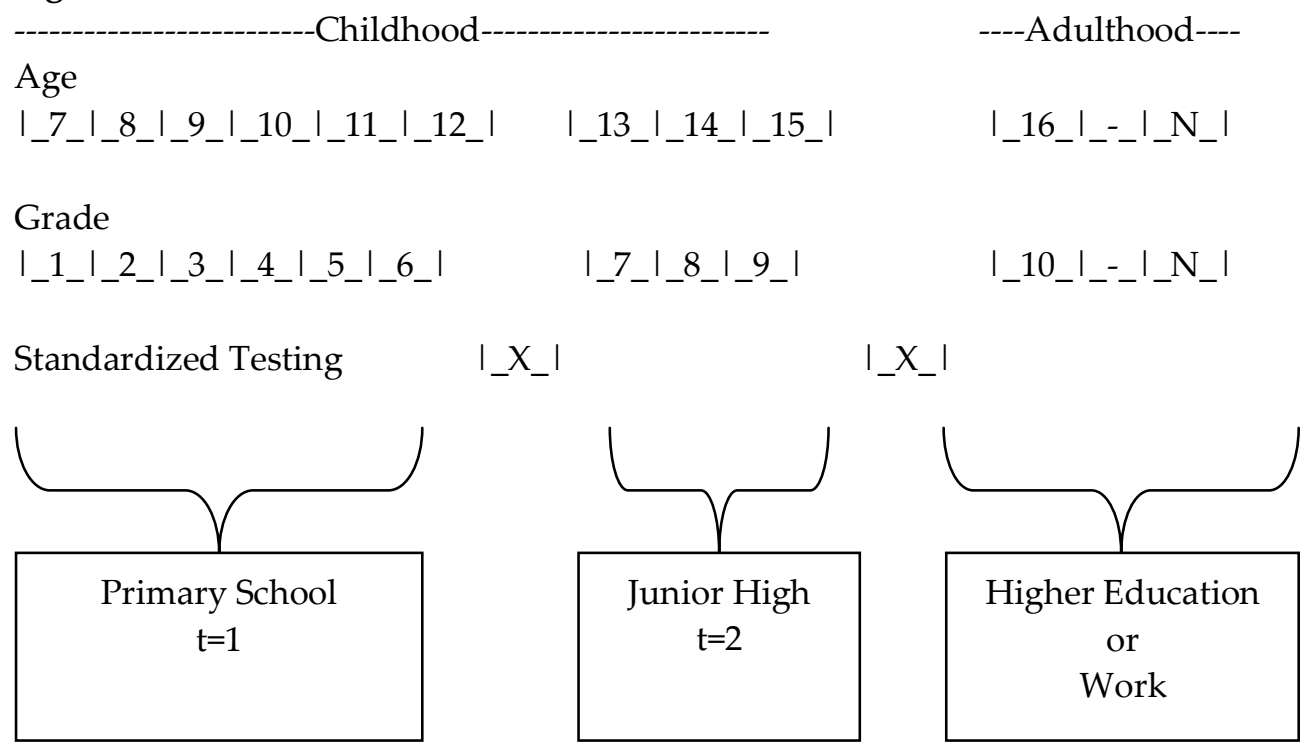

$I_{t}=$ parents financial and time investment in child at time $t$ where $t=1$ and 2 . Time includes a preference that the child attends school instead of going to work or the

\footnotetext{
${ }^{22}$ Adapted from Cunha, Heckman, Lochner and Masterov (2005); Caucutt and Lochner (2008); and Su (2004).

${ }^{23}$ The transition indicator used is from UNESCO education indicators (refer to the publicly available technical guidelines, November 2009). Transition is used to convey information on the degree of access or transition from one cycle or level of education to a higher one. Viewed from the lower cycle or level of education, it is considered as an output indicator, viewed from the higher educational cycle or level, it constitutes an indicator of access. It can also help in assessing the relative selectivity of an education system, which can be due to pedagogical or financial requirements.
} 
child can stay at home. It is a function of household income which consists of per capita consumption $\mathrm{C}_{\mathrm{t}}$ and per capita savings $\Sigma_{\mathrm{t}}$

$$
I_{t}=f_{t}\left(C_{t}, \Sigma_{t}\right)
$$

$\mathrm{C}_{\mathrm{t}}>\Sigma_{\mathrm{t}} ; \Sigma_{t} \neq 0$ because of incomplete credit markets; Parents' utility is increasing and concave.

$S_{\mathrm{t}}$ for $\mathrm{t}=1$ and 2 where $1=$ skills acquired at the primary school level and $2=$ skills acquired at the junior high level. S1 skills consist of Indonesian language literacy, math, science, social studies and moral studies. S2 skills consist of Indonesian and English language literacy, math, science, social studies \& moral studies. Implicitly the stock of skills acquired will depreciate over time as per the Ben-Porath Model $(1967)^{24}$. This depreciation rate is dependent on the child's innate ability.

So are initial skills when the child is born. Assume that the child is born to family with a given occupation and initial skills are correlated with the family occupation $^{25}$. The technology of skill formation can be written as

$$
S_{t+1}=f_{t}\left(S_{t}, I_{t}\right)
$$

where $\mathrm{ft}_{\mathrm{t}}$ is a stage-t function mapping skill (ability) levels and financial investment at stage $t$ into skill(ability) levels at $t+1$. For simplicity we assume that $\mathrm{f}_{\mathrm{t}}$ is twice continuously differentiable in its arguments. Its domain of definition is the same for all inputs that make up the financial investment e.g. books, computers, contributions to the parent-teacher association, etc. The proportion of inputs may be different at different stages in childhood, so that the inputs in It may be different from the inputs at period $\tau$ different from $t$.

Direct complementarity at stage $\mathrm{t}$ is defined by the $\mathrm{L} x \mathrm{~K}$ matrix:

$$
\frac{\partial^{2} S_{t+1}}{\partial S_{t} \partial I_{t}^{\prime}}>0
$$

Higher levels of $\mathrm{I}_{\mathrm{t}}$ raise the productivity of $\mathrm{S}_{\mathrm{t}}$. Or there is the reverse relationship where higher levels of $S_{t}$ raise the productivity of $\mathrm{I}_{t}$

This generalized notation entertains the possibility that some components of skill can only come together and be productive cumulatively at certain critical periods. Period $t$ is critical for skill (ability) $j$ if

\footnotetext{
${ }^{24}$ The implicit assumption of this model with reference to the Ben Porath model

${ }^{25}$ This assumption follows Endogenous Inequality Theory (Mookherjee and Ray, 2003)
} 


$$
\frac{\partial S_{t+1, j}}{\partial I_{t}} \neq 0
$$

But

$$
\frac{\partial S_{t+k+1, j}}{\partial I_{t+k}}=0, \quad \mathrm{k}>0
$$

Crucial or sensitive points in time for investment are those where, at the same level of input $S_{t}, I_{t}$, the $\frac{\partial S_{t+1}}{\partial I_{t}}$ are high. More formally, let $S_{t}=S_{t}, I_{t}=i_{t}, t$ is a sensitive period for skill or ability $\mathrm{j}$ if

$$
\left.\frac{\partial S_{t+k+1, j}}{\partial I_{t+k}}\right|_{S_{t+k}=s_{t}, I_{t+k}=i_{t}}<\left.\frac{\partial S_{t+1, j}}{\partial I_{t}}\right|_{S_{t}=s_{t}, I_{t}=i_{t}}, k \neq 0
$$

The sensitive time in our model is the period of junior high at $t=2$ after the child has completed and transitioned from primary school at $t=1$. This is a sensitive period in terms of maximizing the returns to education in an incomplete credit market.

If there is the dynamic complementarity of investment, current investment should be at a higher level that prior investment. Intuitively, the current level of expenditures for junior high should be higher because the child is older and all educational expenditures should cost more. But it is not only age effects driving expenditures. Our focus is on how much more productivity is gained from having higher later investments on top of early investments. What the child learns in junior high are gains in advanced skills in language and math; and the spillovers these two subjects produce for the other subjects. To illustrate, when in primary school, the child gains a basic skill in literacy using the Indonesian language. This sets the stage for the child in junior high to learn a second language, English which incidentally has similarity in syntax to the Indonesian language. Also the Indonesian language has adopted much of the modern vocabulary of the English language. Put simply, early investments in primary school are not productive if they are not followed up by later investments in junior high.

Proceeding from the theoretical generalized model of the technology of skill formation, we move on to a reduced form specification and we assume a linear model. Considering the dynamic complementarity of investment given income we have the following reduced form: 
Investment $t_{t}=f\left(\right.$ Income $_{t}$ Skills $t-1$, Age $\left.t\right)$ where $t$ covers two periods

Investment at $t$ is for current investment and household income at $t$ is for current income. Skills have been built up over the entire prior period $t-1$ to represent a stock of accumulated human capital. Age represents the current school age of the child and the schooling level. But there is an endogeneity problem. To be able to test this model, we use instrumental variable (IV) analysis as detailed in our empirical strategy in section 4 where the instruments work through the value that parents have for the future expected benefits of their children's skills attained, where the variation in investment at $t$ is owing to parental income at $t$. A comparison of the OLS and IV estimators then enable us to determine the extent to which unobserved parental characteristics influence educational investments. In section 2, we will describe the institutional context for our investigation.

\subsection{Operational Definitions and Empirical Strategy}

Our empirical strategy consists of a natural experiment with instrumental variable (IV-2SLS) estimation. We closely follow the parameters in the theoretical model of the technology of skill formation as can been seen in the applied model in Section 5.2. We proceed to test the causal relationship between income and educational investments in the presence of credit constraints. We exploit the AFC as the source of exogenous variation in income in order to carry out IV-2SLS analysis. Because of the AFC, households incomes are all reduced and it is assumed that there are no incomes moving in the other direction ${ }^{26}$. Heterogeneous responses are then assumed to be with respect to a fall in income. We observe the behavior of rich and poor households across the income distribution and how they adjust their investment decisions before and after the AFC. These investment decisions are with respect to their children transitioning from primary school to junior high. Our identifying assumption is that the AFC affected educational decisions only through income and not through other channels.

The data that we use is the RAND Corporation Indonesia Family Life Surveys (IFLS) Wave 2, 1997 and Wave 3, 2000 repeated cross sections which we view opportunistically as being observations of the same group with the same characteristics in 1997 and 2000. There is no data publicly available for the period between 1997 and 2000 to give us more information about the dynamic relationships occurring during this period of extreme volatility and uncertainty. The unit of analysis is the child with biological parents. To ensure that the group observed in 1997 is the very similar to the group observed in 2000, we carry out a simple pair-wise matching of children with the same school age $11-15$; the same

\footnotetext{
${ }^{26}$ We use this monotonicity assumption for our instrument which is the crisis and so the instrument can only move the endogenous regressor in one direction.
} 
province and the same schooling characteristics - curriculum and standardized tests. The children in 1997 and in 2000 are all currently enrolled in junior high in the period of observation. There is an incidence of 18\% grade repeaters in 1997 and $15 \%$ grade repeaters in $2000^{27}$. The children have all taken their national level standardized qualifying tests at the end of primary school and have entered junior high. As such they all have had the same national academic curriculum as described in Chapter 2, Table 2.2. The children in both observed groups have information on their test scores for EBTANAS; these test scores are a proxy for skills attained in primary school prior to entering junior high. However the sample for each period is not random. There is self-selection from children who either qualified for junior high but did not transition or have qualified for junior high and did transition. In our sample we do not observe the children who qualified but did not transition from primary school to junior high. Also children who failed EBTANAS are unobserved in the samples. This results in positive selection bias in the samples where there are children with higher unobserved ability or children who have parents who are scholastically motivated.

The data consists of children in junior high in each period of observation. With reference to Figure 5.1, the child observed can be 12, 13, 14 or 15 years old. This child has taken the qualifying tests EBTANAS, passed and transitioned which represents prior skills attained. The skills built up represent the amount of financial and time investment that their parents have put into their children in the previous 6 grades of primary school. We do not have more information on income, financial and time investments for grade-to- grade. There is only data on current income and current investment in the period of observation. For the rest of the paper, we consider financial investment in terms of the annual educational expenditures particularly the monthly scheduled fee payments that have to be kept up in each of the grades in junior high. Failure to keep up payments is tantamount to schooling interruptions, i.e. children who are not allowed to attend classes which then negatively affect the skill formation process. Also we use time investment to represent the opportunity cost of time of the child where s / he chooses how to allocate time each day for schooling, work or for staying at home. Failure to keep the optimum number of hours of schooling because of work or staying at home may perhaps negatively affect the skill formation process.

Using the AFC, we exploit changes in income for the whole time period between 1997 and 2000. Children who are exposed to the AFC are in the group in 2000. By this period of observation they will be in junior high and have the school age of 12 , 13,14 or 15 . While junior high starts at the school age of 13 , it is possible that some children will start at age 12 because they started primary school at the school age 6

${ }^{27}$ Grade repetition is only once in both 1997 and 2000. 
instead of school age 7. They will have qualified to start junior high or are already in junior high in 2000 because they have reached age 12 and have their EBTANAS test scores. But before they transitioned in 2000, their parents experienced volatile and unpredictable reductions to income. Primary school investments were correspondingly affected. As graphically represented in Figure 5.2 this occurred when in 1997 the children had starting ages 8, 9, 10, 11 and 12; in 1998 their ages sequentially were 9, 10,11, 12 and 13; in 1999 their ages were sequentially 10, 11, 12, 13, and 14; and in 2000 the ages of the children were sequentially 11, 12, 13, 14 and 15. Consequently, the starting age of the child in 1997 for each sequence determines the length of time the child's investment at junior high is negatively affected by income. A child aged 12 in 1997 receives a depressed investment at age 13 in 1998, age 14 in 1999 and age 15 in 2000. This is different compared to children who turn 12 and enter junior high after 1997 and receive a lower investment for a shorter period of time.

Figure 5.2 School Age when Exposed to the Financial Crisis

\begin{tabular}{|l|l|l|l|l|l|l|}
\hline Year & & & & \multicolumn{2}{|c|}{$\begin{array}{c}\text { Exposure to the } \\
\text { AFC }\end{array}$} & \\
\hline 1994 & 1995 & 1996 & 1997 & 1998 & 1999 & 2000 \\
\hline Age & & & & & & \\
\hline 5 & 6 & 7 & 8 & 9 & 10 & 11 \\
\hline 6 & 7 & 8 & 9 & 10 & 11 & $\mathbf{1 2}$ \\
\hline 7 & 8 & 9 & 10 & 11 & $\mathbf{1 2}$ & 13 \\
\hline 8 & 9 & 10 & 11 & $\mathbf{1 2}$ & 13 & 14 \\
\hline 9 & 10 & 11 & $\mathbf{1 2}$ & 13 & 14 & 15 \\
\hline
\end{tabular}

We exploit this source of variation by estimating the regression in the reduced form of:

$$
I_{i t}=\beta_{0} S_{i}+\beta_{1} Y_{i t}+\beta_{2} S_{i t-1}+\beta_{3} A_{i t}+\beta_{4} A_{i t} Y_{i t}+\mu_{i t}
$$

where $I$ denotes current investment in child $i$ in junior high at $t ; S_{i}$ skills when the child is born; per capita household income $Y$ for child $i$ at $t$; $S_{i t-1}$ skills already attained by child $i$ when in primary school reported as EBTANAS test scores; $A$ age of child $i$ at $t$ and the interaction of $A$ age and $Y$ income which provides a comparison between pure age effects and income effects on investment depending on age of the child.

If equation (1) is estimated by ordinary least squares (OLS), there will be biased and inconsistent estimates. As such IV estimation is used to isolate the relationship between income and investment. The IV approach is used to manage the omitted variable bias problem that is faced from not being able to observe parental 
investment behavior over the period of 1998 and 1999 as well as to enable a discussion of alternative explanations for variations in investment such as unobserved parental characteristics. As the instrument we use is the AFC, this instrument works through the value that parents have for the future benefits of their children's education where the variation in investment is owing to current parental income. This is written as equation (2) where the endogenous explanatory variable income $Y_{i t}$ is a linear function of the exogenous variable the AFC $z_{4}$, a dummy variable and an error term.

$$
\mathrm{Y}_{\mathrm{it}}=\pi_{0}+\pi_{1} \mathrm{z}_{1}+\pi_{2} \mathrm{z}_{2}+\pi_{3} \mathrm{z}_{3}+\pi_{4} \mathrm{z}_{4}+\mathrm{v}_{\mathrm{it}}
$$

Following from the theoretical framework, the critical periods for investment are magnified over the period of the AFC when household incomes are reduced. Parents have to adapt their labor supply, draw down on savings or smooth consumption and they will rearrange their decisions throughout 1998 and 1999. But if their child is very close to completing the junior high level and has attained skills from primary school as measured by EBTANAS, then their decisions over the crisis period may likely condition on the investments already made. By adding this condition, this may possibly show that there are parents who view current investment for their children in junior high as a priority in spite of the financial difficulties faced during the crisis. This may especially be the case if the child is at a school age that is closer to the final grade of junior high (see Figure 5.2 when the child is 15 and at grade 9) compared to a child at a school age that is at the starting grade of junior high (see Figure 5.2 when the child is 13 at grade 7 ). If this prediction is correct then this implies that parents will take into account the loss in previous investments at the primary school level. As such from equation (1), we would like to further investigate coefficient $\beta_{4}$ by decomposing the variable by each age in the observed in the data. This consists of age 12, age 13, age 14 and age 15. The relationship between available income at a given age of the child, is instrumented by the crisis occurring at the point in time when a child is at age 12 completing primary school and then correspondingly when a child is at age 13 starting junior high, then age 14 and age 15 which move closer to the completion of junior high. In so doing there are four instruments for four endogenous explanatory variables for age 12, age 13, age 14 and age $15^{28}$. Equation (1) is then rewritten as:

$$
\begin{aligned}
& I_{i t}=\beta_{0} S_{i}+\beta_{1} Y_{i t}+\beta_{2} S_{i t-1}+\beta_{3} A 12_{i t}+\beta_{4} A 13_{i t}+\beta_{5} A 14_{i t}+\beta_{6} A 15_{i t}+\beta_{7} A 12 y_{i t}+ \\
& \beta_{8} A 13 y_{i t}+\beta_{9} A 14 y_{i t}+\beta_{10} A 15 y_{i t}+\mu_{i t}
\end{aligned}
$$

\footnotetext{
28 There is an additional instrument for children aged 11 in the observed data. However the number of children aged 11 observed is miniscule. While we do use this instrument, we do not report the results in this paper because they do not affect the findings.
} 
Equation (2) is then re-written to represent the multiple instruments used and where the IV estimator then becomes a two stage least squares (2SLS) estimator:

$$
Y_{\text {it }}=\pi_{0}+\pi_{1} z_{1}+\pi_{2} z_{2}+\pi_{3} z_{3}+\pi_{4} z_{4}+\pi_{5} z_{5}+\pi_{6} z_{6}+\pi_{7} z_{7}+\pi_{8} z_{8}+\pi_{9} z_{9}+\pi_{10} z_{10}+v_{\text {it }} \cdots
$$

Because the AFC affected regions across the Indonesian archipelago differently, we account for this by adding controls for the child's residential location where we aggregate Java and Bali Islands and the other islands as the Outer Islands and residency by urban and rural location. We do this because Java and Bali have higher levels of economic development, more waged labor opportunities and more school choice ${ }^{29}$. This is as opposed to the Outer Islands that consist more of subsistence economies, agricultural economies and with lower levels of economic development. Also because the Outer Islands are located further away from the central government in Java and more difficult to access geographically there are fewer education related choices available. We also include further controls that affect schooling investment which are school type and the child's gender. The child's past school type and current school type are included to control for school quality. School type is defined by whether it is a public school funded and run by the government or a private school that is funded privately and unregulated. Public school is a proxy for higher quality education than private school.

\subsection{Findings}

\subsubsection{Descriptive Statistics}

With reference to the following Table 5.1 of descriptive statistics, on average incomes fell by $2.5 \mathrm{log}$ points when comparing 1997 with 2000. Also there are extreme outliers to the right of the income distribution for both groups. Because of the disproportionately high incomes of the richest households in Indonesia, we look at the income distributions for both groups. Starting with the minimum and maximum points in the distribution, in 1997 the range was $14.26-21.05 \log$ points.

${ }^{29}$ Center for Studies in Higher Education, University of California at Berkeley 1991 
Table 5.1 Descriptive Statistics

\begin{tabular}{|c|c|c|c|c|}
\hline 1997 & Mean & SD & Min & $\operatorname{Max}$ \\
\hline Income per Capita (Ln) & 16.47 & .81 & 14.26 & 21.05 \\
\hline Financial Investment (Ln) & 11.69 & .83 & 6.62 & 14.20 \\
\hline Time Investment & 5.88 & .88 & 3 & 12 \\
\hline \multirow[t]{2}{*}{ EBTANAS } & 31.82 & 5.92 & 18.38 & 46.4 \\
\hline & & Perce & & \\
\hline Child is not in school & & .00 & & \\
\hline Child is working & & .005 & & \\
\hline Java and Bali Islands & & .36 & & \\
\hline Outer Islands & & .64 & & \\
\hline Rural & & .46 & & \\
\hline Urban & & .54 & & \\
\hline Junior High - Public & & .61 & & \\
\hline Junior High - Private & & .39 & & \\
\hline Primary School - Public & & .84 & & \\
\hline Primary School - Private & & .16 & & \\
\hline Girl & & .52 & & \\
\hline Boy & & .48 & & \\
\hline $\mathrm{N}$ & & 569 & & \\
\hline 2000 & Mean & SD & Min & Max \\
\hline Income Per Capita (Ln) & 13.99 & .83 & 11.76 & 18.29 \\
\hline Financial Investment (Ln) & 11.28 & 1.03 & 6.40 & 13.84 \\
\hline Time Investment & 5.04 & 2.37 & 0 & 15.81 \\
\hline \multirow[t]{2}{*}{ EBTANAS } & 32.55 & 5.59 & 14.10 & 46.5 \\
\hline & & Freq & & \\
\hline Child is not in school & & .06 & & \\
\hline Child is working & & .16 & & \\
\hline Java and Bali Islands & & .54 & & \\
\hline Outer Islands & & .46 & & \\
\hline Rural & & .51 & & \\
\hline Urban & & .49 & & \\
\hline Junior High - Public & & .68 & & \\
\hline Junior High - Private & & .32 & & \\
\hline Primary School - Public & & .85 & & \\
\hline Primary School - Private & & .15 & & \\
\hline Girl & & .51 & & \\
\hline Boy & & .49 & & \\
\hline $\mathrm{N}$ & & 833 & & \\
\hline
\end{tabular}


In 2000, this became $11.76-18.29$. The shift of the normal income distribution can also be seen in Figure 5.3 where there is a lower peak in 1997 compared to 2000. Arguably due to extremely unpredictable variability in the economy over the period of the crisis, there are far more different incomes levels which further spread out the tails of the normal distribution.

\section{Figure 5.3 Household Income Per Capita}

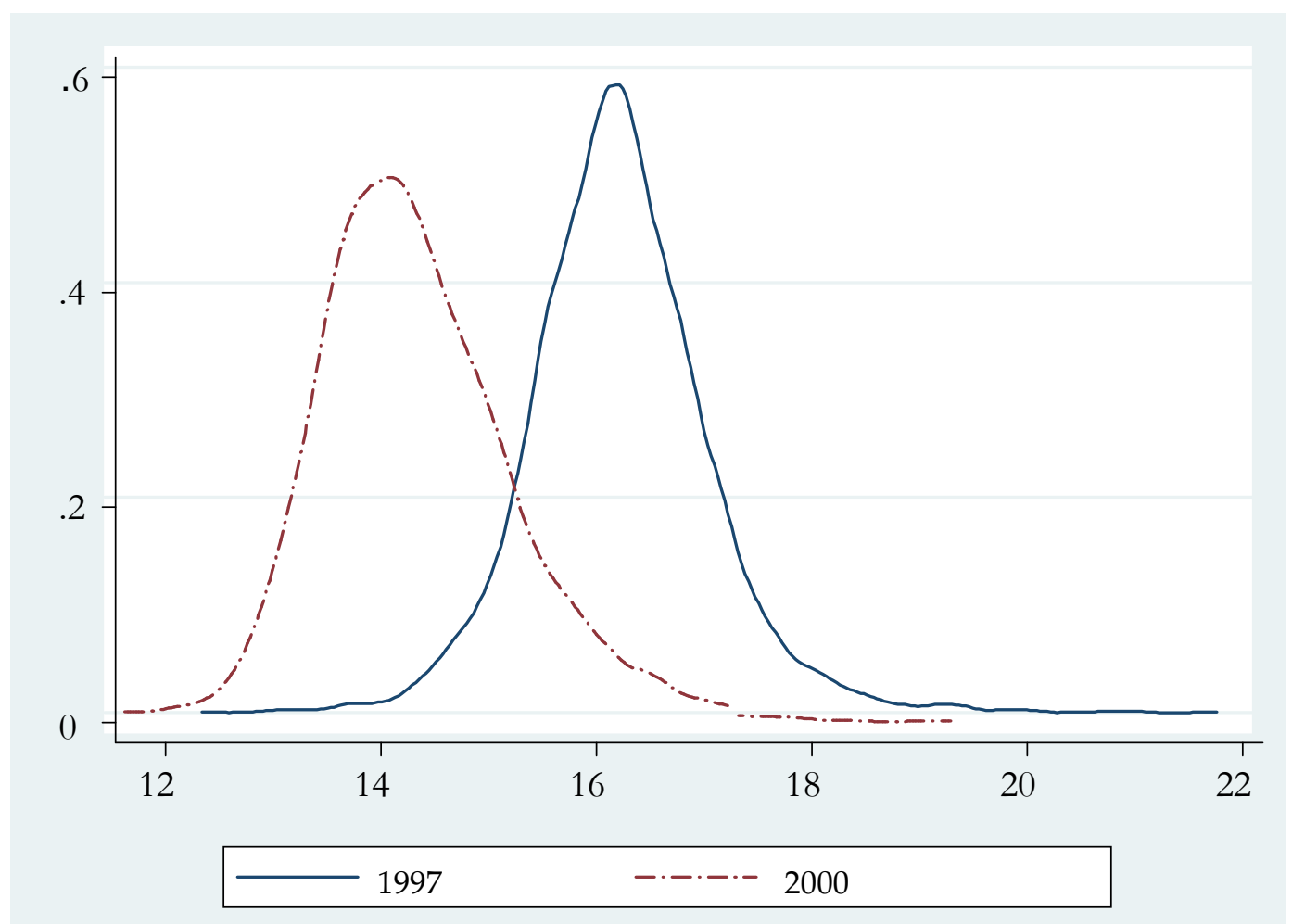

Notes: The proxy used for household income is consumption and savings. To calculate real prices, we follow the Indonesian Census Bureau of Statistics (BPS) convention of the modified Lespeyres deflator. Consumption is measured using the market valued prices of goods and services. This price data is tracked by BPS but has an urban bias because prices come from urban out lets spread across Indonesia. The values of in-kind transfers and own production are not included. Savings is measured using cash on hand, bonds and stocks. It is assumed that this liquidity stems from the year observed and is not accumulated stock over time.

However the bounds for financial investments in education are tighter than for incomes both before and after the crisis. This can be seen in Table 5.1. The range for investments for 1997 is $6.62-14.20 \mathrm{log}$ points and for 2000 they are $6.40-13.84 \mathrm{log}$ points. Investments on average are $11.69 \log$ points in 1997 and $11.28 \log$ points in 2000. There is very little reduction for the lowest end of the investment distribution. 
The fall in investment is primarily coming from the highest $20 \%$ of households of the income distribution.

Looking at the other specification for investment which is the amount of schooling time allocated we also find a reduction in 2000. On average time spent in school each day fell from 5.88 hours in 1997 to 5.04 hours in 2000. For both periods, this average time amount is below the required 7.6 hours based on the national academic curriculum. The range of schooling time in 1997 was $3-12$ hours per day. In contrast, the range for 2000 was spread out to $0-15.81$ hours per day with greater variability compared to 1997.

The schooling time distributions also show that the $6^{\text {th }}$ percentile of children in 1997 reported zero hours allocated for schooling. In addition 0.16 of the 2000 sample reported working. The ages of the 0.16 of this 2000 sample are 14 and 15. In comparison, no children in the 1997 group reported 0 hours of schooling. We interpret this to mean that for the 0.06 not in school, they may either be at home or working; or at home and working. Since the percentage of children reporting working status is higher than the percentage of children with zero hours in school, this suggests that there are children simultaneously working and going to school in $2000^{30}$. We will investigate time investments further in the next section using IV analysis. When we do this, we will transform the variable into log terms to enable ease of comparison.

Despite an income reduction, the children's stock of skill was not severely affected. From the descriptive statistics in Table 5.1, it can be seen that average test scores were higher in 2000. On average test scores in 2000 were 32.55 points in contrast to 31.82 points in 1997. But the minimum for scores in 2000 is an extremely low 14.10 points compared to 18.38 points in 1997. For children in the lower end of the EBTANAS standardized test score distribution, more of them failed almost all of the five subjects tested over the period of the crisis, all of 1998, 1999 and most of 2000. The lowest performance in 2000 versus 1997 came from the science test (this statistic is not reported). The best performance for the children in the lower end of the score distribution in 2000 against 1997 is the Indonesian language literacy test. Looking at the highest end of the test score distribution, there is no change for both groups. Children in the lower end of the EBTANAS distribution are pulling down performance while the achievements of the children from the median to the top $1 \%$ of the distribution remained unchanged. More importantly, the distribution of skills in both periods appears to be a result of selection bias. It seems that the children with test scores higher than the median score in both groups have the same stock of skills. But the children selected into the group in 2000 with lower

${ }^{30}$ I investigate simultaneous work-schooling behavior in Chapter 4 . 
than median scores have a lower stock of skills than children selected into the group in 1997.

To gain a better understanding of the distributional relationship between the main variables of interest in the technology of skill formation, we run kernel regressions. This can be seen in Figures 5.4 and 5.5. The shape and slope of the kernel regressions in both figures are approximately linear given the several bandwidths we have tried using. As such we assume that the relationships are linear which is consistent with our model and the assumption of monotonicity for treatment type effects that are heterogeneous.

Figure 5.4 Kernel Regressions of Financial Investments given Household Income Per Capita

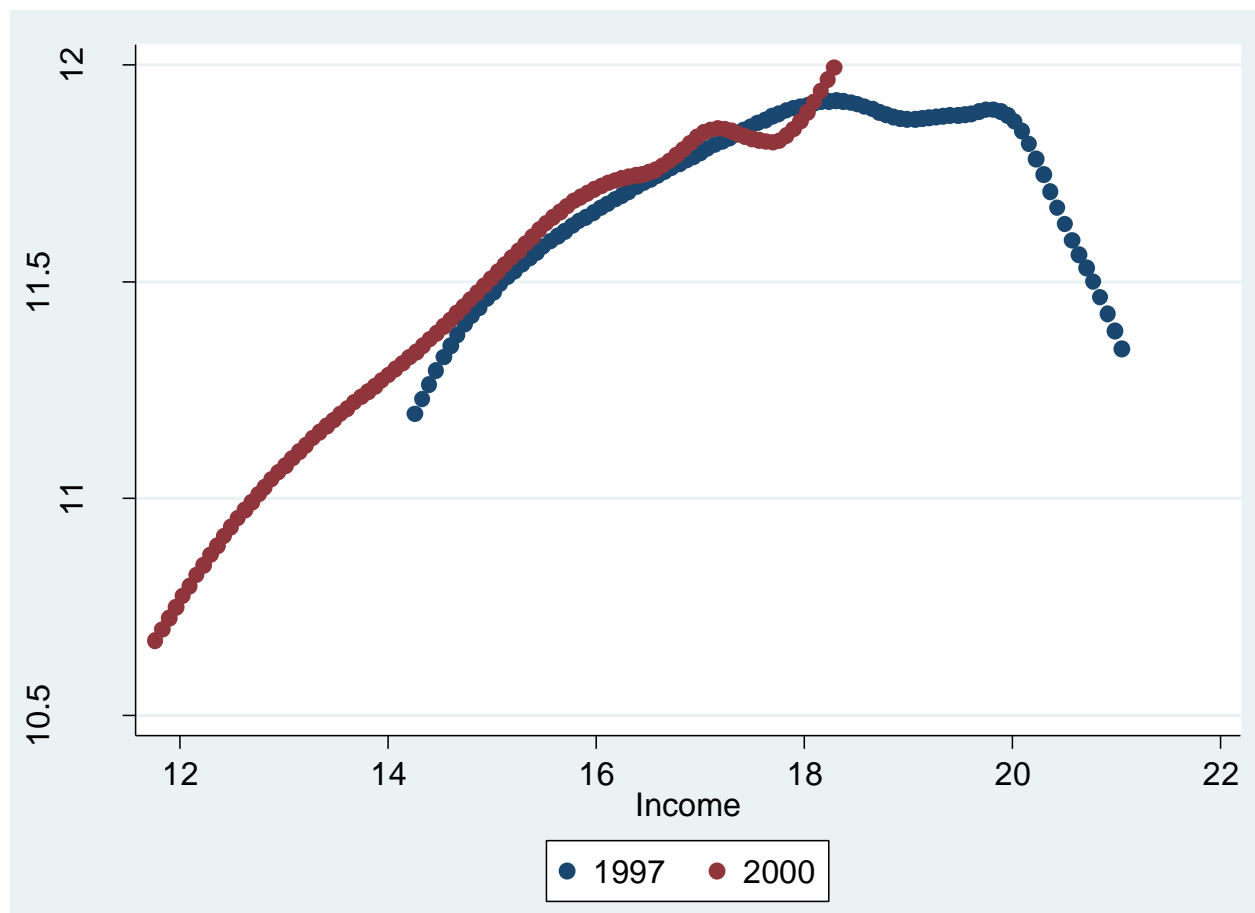

For financial investments given household income in Figure 5.4, the distribution shifts from the right in 1997 to the left in 2000 and in the direction of the origin. Families by and large were not able to keep up investments given how depressed their incomes became. This is especially the case for the poorest of the poor in the first quintile of the income distribution. However households in the fourth and fifth quintiles which include the richest households also failed to maintain investments at pre-crisis levels. Parents in the second and third quintiles were able to not only 
maintain investments but increase the level slightly in 2000. In the following Figure 5.5 we learn more about parents' investment responses to the crisis. We observe that for families with children who have low scores in the $30-35$ test point range, investment in 2000 is higher than investment in 1997. For the rest of the score distribution above the $30-35$ test point range, investment increases as scores increase; the 2000 investment level is higher than the 1997 investment level.

Figure 5.5 Kernel Regressions of Financial Investments in Junior High given Prior EBTANAS Test Scores in Primary School

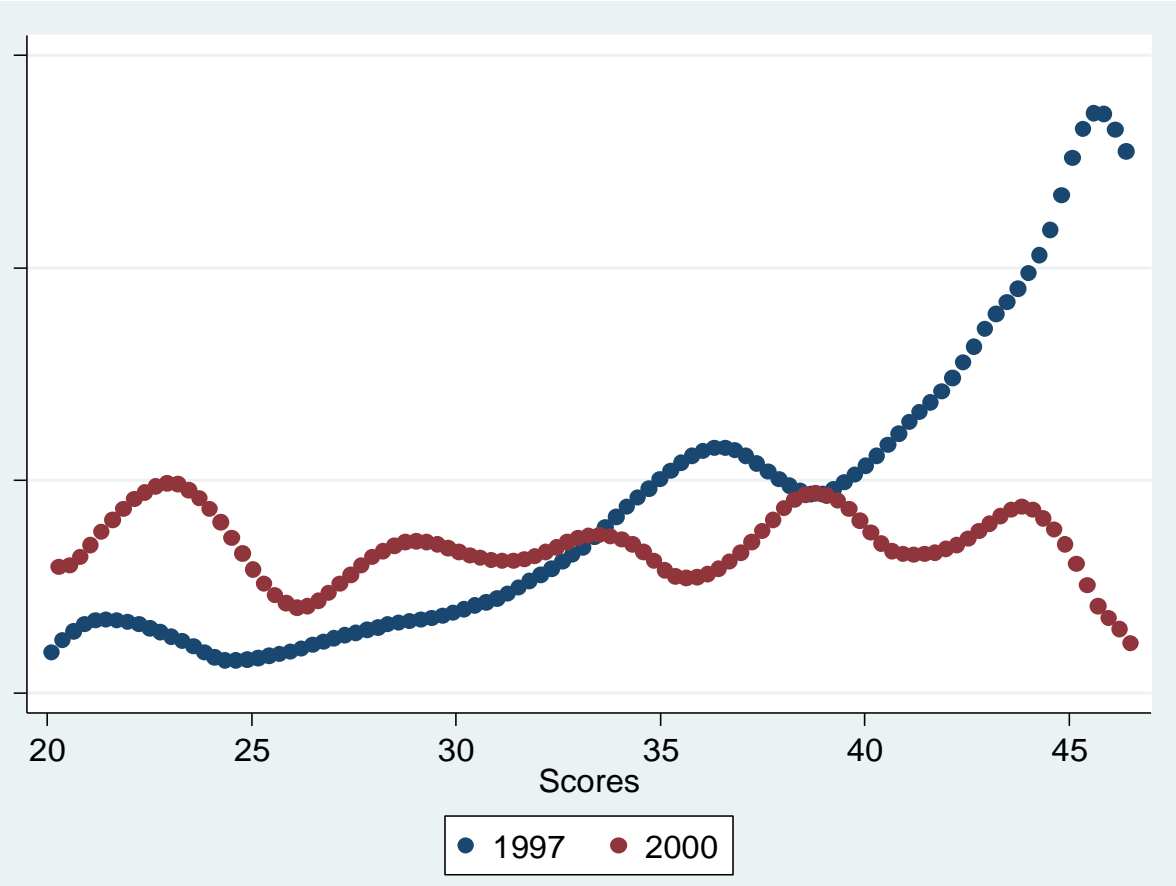

\subsubsection{Results}

\subsubsection{Financial Investments}

We first test the relationship between income and financial investment without factoring in the child's skills attained and without any controls and the results are reported in columns (1) and (2) of Table 5.2. A log point reduction in income causes financial investments in education to fall by $0.17 \log$ points. The OLS coefficient size is $0.22 \log$ points. In contrast IV coefficient size is 0.17 log points which reflects an upwards bias for the OLS estimate. Both results are statistically significant at the $1 \%$ level. When prior skills attained as measured by EBTANAS are added and 
this is seen in specifications (3) - (10), the magnitude of the income coefficient remains at approximately 0.20 for OLS and at 0.17 for IV and is statistically significant at the $1 \%$ level. These estimates remain unaffected by the introduction of control variables. The IV estimates across specifications (1) - (10) indicate that the OLS estimates are biased upwards for unobserved reasons. This finding then strongly implies that in the presence of income constraints, $80 \%$ of the crosssectional link between income and financial investment in education is caused by differences in income. The remaining 20\% of the cross-sectional link between income and educational investment is caused by differences in parental characteristics.

When the stock of skills variable is included as a specification in (3) and (4), we find that prior skills attained have a smaller relationship with investment compared to the causal relationship between income and investment. A one test point increase in EBTANAS increases educational expenditures by $0.02 \log$ points; this is for both the OLS and IV estimates and is statistically significant at the $1 \%$ level. It appears that the differences in the observed human capital accumulated earlier in primary school explain very little for later investment. When the control variables Java and Bali residency, urban residency, school type and gender are added in specifications (5) and (6), the impact of skills attained on investment weakens to 0.01 log points. Statistical significance falls to the $5 \%$ level. This suggests that differences in where the child resides and goes to school and gender differences further weaken the relationship between stock of skills and investment. From these results, we show that 0.8 of the cross-sectional link between income and educational expenditures are caused by differences in income and this result is robust across specifications $(1)-(10)$. 


\section{Table 5.2 OLS \& IV-2SLS Complementarity of Financial Investments in Junior High}

DV = Financial Investment in Junior High given Income in Junior High and Skills from Primary School, 1997 and 2000 (SE for OLS and Robust SE for IV and IV-2SLS are in Parentheses)

\begin{tabular}{|c|c|c|c|c|c|c|c|c|c|c|}
\hline & (1) & (2) & (3) & (4) & (5) & (6) & (7) & (8) & (9) & (10) \\
\hline $\begin{array}{c}\text { Explanatory } \\
\underline{\text { Variables }}\end{array}$ & OLS & IV & OLS & IV & OLS & IV & OLS & IV-2SLS & OLS & IV-2SLS \\
\hline Income & $\begin{array}{l}.2291^{* * *} \\
(.0174)\end{array}$ & $\begin{array}{l}.1784^{* * *} \\
(.0208)\end{array}$ & $\begin{array}{l}.2246^{* * *} \\
(.0177)\end{array}$ & $\begin{array}{l}.1920^{* * *} \\
(.0210)\end{array}$ & $\begin{array}{l}.2059^{* * *} \\
(.0172)\end{array}$ & $\begin{array}{l}.1936^{* * *} \\
(.0209)\end{array}$ & $\begin{array}{l}.2189 * * * \\
(.0178)\end{array}$ & $\begin{array}{l}.1771^{* * *} \\
(.0213)\end{array}$ & $\begin{array}{l}.2002^{* * *} \\
(.0174)\end{array}$ & $\begin{array}{l}.1790^{* * *} \\
(.0210)\end{array}$ \\
\hline Skills & & & $\begin{array}{l}.0235^{* * *} \\
(.0044)\end{array}$ & $\begin{array}{l}.0240^{* * *} \\
(.0044)\end{array}$ & $\begin{array}{l}.0110^{* *} \\
(.0044)\end{array}$ & $\begin{array}{l}.0111^{* *} \\
(.0045)\end{array}$ & $\begin{array}{l}.0233^{* * *} \\
(.0044)\end{array}$ & $\begin{array}{l}.0234^{* * *} \\
(.0044)\end{array}$ & $\begin{array}{l}.0108^{* *} \\
(.0044)\end{array}$ & $\begin{array}{l}.0106^{* *} \\
(.0046)\end{array}$ \\
\hline Age & $\begin{array}{l}.0628^{* *} \\
(.0248)\end{array}$ & $\begin{array}{l}.0479 * \\
(.0253)\end{array}$ & $\begin{array}{l}.0778^{* *} \\
(.0250)\end{array}$ & $\begin{array}{l}.0687^{* *} \\
(.0260)\end{array}$ & $\begin{array}{l}.0713^{* *} \\
(.0244)\end{array}$ & $\begin{array}{l}.0681^{* *} \\
(.0243)\end{array}$ & $\begin{array}{l}.0648^{* *} \\
(.0256) \\
-.0379^{* *} \\
(.0169)\end{array}$ & $\begin{array}{l}.0347 \\
(.0313) \\
-.0995^{* * *} \\
(.0238)\end{array}$ & $\begin{array}{l}.0584^{* *} \\
(.0244) \\
-.0371^{* *} \\
(.0161)\end{array}$ & $\begin{array}{l}.0352 \\
(.0304) \\
-.0943^{* * *} \\
(.0233)\end{array}$ \\
\hline Constant & $\begin{array}{l}7.1630 \\
(.4653)\end{array}$ & $\begin{array}{l}8.1252 \\
(.5325)\end{array}$ & $\begin{array}{l}6.2859 \\
(.0494)\end{array}$ & $\begin{array}{l}6.2859 \\
(.5064)\end{array}$ & $\begin{array}{l}6.8901 \\
(.4886)\end{array}$ & $\begin{array}{l}7.1154 \\
(.5359)\end{array}$ & $\begin{array}{l}6.5411 \\
(.5076)\end{array}$ & $\begin{array}{l}7.5525 \\
(.6236)\end{array}$ & $\begin{array}{l}7.1346 \\
(.4886)\end{array}$ & $\begin{array}{l}7.7386 \\
(.6142)\end{array}$ \\
\hline \multicolumn{11}{|l|}{ Instrumented } \\
\hline $\begin{array}{l}\text { Income by the } \\
\text { Crisis }\end{array}$ & & Yes & & Yes & & Yes & & Yes & & Yes \\
\hline $\begin{array}{l}\text { Age_Income } \\
\text { by Age_Crisis }\end{array}$ & & & & & & & & Yes & & Yes \\
\hline Controls & & & & & Yes & Yes & & & Yes & Yes \\
\hline $\mathrm{R}^{2}$ & .11 & .11 & .13 & .13 & .22 & .22 & .14 & .13 & .22 & .21 \\
\hline Observations & 1,288 & 1,288 & 1,288 & 1,288 & 1,288 & 1,288 & 1,288 & 1,288 & 1,288 & 1,288 \\
\hline
\end{tabular}


Notes: The age range is from $11-15$. For the interaction of age and income, the age variable has been demeaned and the income variable has been de-meaned. The control variables are if the child resides and goes to school in the Java and Bali Islands; if the child is in an urban area; the child's school type at the primary school level and junior high level and if the child is a girl or boy.

In columns (7) and (8) of Table 5.3, we introduce the OLS estimates for comparison with the 2SLS estimates. We instrument income by the crisis and instrument the interaction of age and available income by age and the crisis and without controls. The OLS and 2SLS estimates for income are the same as the prior specifications and are robust. The skill variable is now increased back to 0.02 log points and statistically significant at the $1 \%$ level. But we find that the interaction of age with income has a negative causal relationship with educational expenditures. In response to a reduction in income, parents increase financial investment by $0.03 \mathrm{log}$ points when the child is older by a year. The coefficient size for the 2SLS estimate is a smaller 0.09 which indicates that the OLS estimate is biased downwards for unobserved reasons. This result is statistically significant for the 2SLS estimate at the $1 \%$ level compared to the statistical significance for the OLS estimate at the $5 \%$ level. When controls are re-introduced, the results as can be seen in specifications (9) and (10) remain similar to specifications (7) and (8). The exception is that the size of the skills coefficient is reduced by half again where a one test point increase in EBTANAS only raises investment by $0.01 \log$ points instead of $0.02 \log$ points.

As the sensitive time in our model (Section 5.2) is the period of junior high at $\mathrm{t}=2$ after the child has completed and transitioned from primary school at $t=1$, we proceed to detail which school ages within the junior high level are investment priorities. The relationship between available income at a given age of the child, is instrumented by the crisis occurring at the point in time when a child is at age 12 completing primary school and then correspondingly when a child is at age 13 starting junior high, then age 14 and age 15 which move closer to the completion of junior high and the beginning of the minimum legal employment age. The OLS and 2SLS results are presented in Table 5.3 and the coefficient sizes are similar across all specifications (11) - (14). 
Table 5.3 OLS \& IV-2SLS Complementarity of Financial Investments in Junior High

DV = Complementarity of Financial Investments in Junior High given Income in Junior High and Skills from Primary School, 1997 and 2000

(SE for OLS and Robust SE for IV and IV-2SLS are in Parentheses)

(11) (12) (13)

(14)

Explanatory Variables

Skills

OLS IV-2SLS OLS IV-2SLS

$.0223^{* * *}$

$.0223^{* * *}$

$.0096^{* *}$

$.0095^{* *}$

Age 12

$$
(.0044)
$$

(.0044)

(.0044)

$-.1450$

.0027

$-.2536$

$-.0902$

Age 13

(.2224)

(.2180)

(.2111)

(.2066)

Age 13

$-.0335$

.1504

$-.0880$

.1165

Age 14

(.2141)

(.2005)

(.2035)

(.1893)

Age 15

.0718

.2579

$-.0241$

.1818

(.2133)

(.2003)

(.2028)

(.1896)

$.4917^{* *}$

$.7124^{* * *}$

.3489

(.2442)

(.2028)

(.2324)

$.6512^{* *}$

Age 12_Income

$.4094^{* * *}$

$.4702^{* * *}$

$.4124^{* * *}$

(.1932)

(.0464)

(.0657)

(.0440)

$.4841^{* * *}$

Age 13_Income

$.2707^{* * *}$

$.2446^{* * *}$

$.2464^{* * *}$

(.0631)

Age 14_Income

(.0305)

(.0320)

(.0292)

$.2302^{* * *}$

$.1438^{* * *}$

$.0621^{*}$

(.0304)

(.0272)

(.0339)

$.1350^{* * *}$

$.0824^{* *}$

Age 15_Income

$.3998^{* * *}$

$.4342^{* * *}$

(.0260)

(.0323)

(.0908)

(.0275)

$.3245^{* * *}$

$.4146^{* * *}$

Constant

10.6991

10.5159

(.0865)

(.0361)

(.2518)

(.2405)

11.0174

10.8150

(.2442)

(.2318)

Instrumented

Age 11_Income by Age 11_Crisis

Age 12_Income by Age 12_Crisis

Age 13_Income by Age 13_Crisis

Age 14_Income by Age 14_Crisis

Age 15_Income by Age 15_Crisis

Yes

Yes

Yes

Yes

Yes

Yes

Yes

Yes

Yes

Yes

Controls

Yes Yes

$\mathrm{R}^{2}$

.16

.15

.25

.25

Observations

1,288

1,288

1,288

1,288 
Notes: The age range is from $11-15$. The reference age group is 11 . The results for age 11 (not reported) have a miniscule effect on the coefficient size for financial investments. For the interaction of each age and income, the variable for each age is represented by a dummy and the income variable has been demeaned. The control variables are if the child resides and goes to school in the Java and Bali Islands; if the child is in an urban area; the child's school type at the primary school level and junior high level and if the child is a girl or boy.

When the child is aged 12, has completed EBTANAS for primary school and given an income reduction investment falls by 0.4 . This decrease in investment at age 12 may perhaps be partly explained by government subsidies offsetting parental spending in order to ensure that children complete the final grade of primary school. But when the child is older by a year at age 13, has started junior high at grade 7 and given an income reduction, investment only falls by 0.2 . When the child is aged 14, a year prior to taking EBTANAS for junior high to enter senior high; and a year prior to being old enough to enter the labor force, an income reduction causes investment to decrease by only 0.08 . At age 15 , an income decrease causes a larger decrease in investment of 0.3 for OLS and 0.4 for 2SLS. This implies that the 0.3 of the link between income and investment at age 15 is caused by income and 0.7 by unobserved factors. This substantial decrease in investment at age 15 then implies that investment decision making is influenced by a new set of factors. There is now a fork in the decision path where the child can either take EBTANAS to transition to senior high or take EBTANAS then enter the labor force at the legal minimum age of 15 . The presence of two options - to continue with higher education or to work is consistent with the descriptive statistics where for ages 14 and 15 in the 2000 sample 0.06 of the children reported zero hours allocated for formal schooling and 0.16 reported working. In contrast no children of the same age in the 1997 sample reported zero formal schooling time and 0.005 of the children worked.

The pattern of reduction in educational expenditures is much lower for children who have already attained a few years of junior high education. The reduction is lower for the child aged 14 than for the child aged 13 and both have reductions lower than for the child aged 12 who has only attained a primary school education. This means that junior high investments are a priority despite depressed household incomes. This implies that parents do take into account the loss in returns related to previous investments on the stock of human capital accumulated. But this investment behavior appears to only be partly explained up to 0.8 by differences in household income related characteristics. The remaining 0.2 explanation for this pattern of investment is related to parental characteristics such as scholastically motivated parents. Such parents may view education as a high priority in their children's lifecycle. They allocate more of their children's time for formal schooling and do not consider the possibility of their children working or helping in the 
household. We test this prediction in the next sub-section where investment is specified as schooling time.

\subsubsection{Time Investments}

In our model applying the technology of skill formation, the initial specification for investment was educational expenditures. We proceed to change the specification to investment in schooling time. We investigate whether schooling time compensates for educational expenditures given reduced household incomes. The results in the following Table 5.4 show that in the both groups $50 \%$ of the crosssectional link between income and schooling time investments is caused by differences in income and the remaining $50 \%$ is caused by differences in parental characteristics. In specifications (15) and (16) of Table 5.4, the OLS estimate for one $\log$ point reduction in income increases time investment by $0.4 \log$ points while the IV estimate is $0.6 \log$ points. Both estimates are statistically significant at the $1 \%$ level. The IV estimates indicates that time invested in schooling is higher than the OLS estimate by 0.5 because of unobserved behavioral factors. This result remains unchanged when the skills variable and control variables are included which can be seen across specifications (17) - (24). This infers that when there is an income reduction, resources for schooling is compensated by a time allocation increase. However the compensatory effect of time on expenditures is magnified by the higher ability children with a higher than median EBTANAS test score who are self-selected into junior high. The compensatory effect of time is dampened when factoring in lower ability children who report 0 hours of schooling. 


\section{Table 5.4 OLS \& IV-2SLS Complementarity of Time Investments in Junior High}

DV = Complementarity of Time Investments in Junior High given Income in Junior High and Skills from Primary School, 1997 and 2000 (SE for OLS and Robust SE for IV and IV-2SLS are in Parentheses)

\begin{tabular}{|c|c|c|c|c|c|c|c|c|c|c|}
\hline & (15) & (16) & (17) & (18) & (19) & $(20)$ & $(21)$ & (22) & (23) & (24) \\
\hline$\frac{\text { Explanatory }}{\underline{\text { Variables }}}$ & OLS & IV & OLS & IV & OLS & IV & OLS & IV-2SLS & OLS & IV-2SLS \\
\hline Income & $\begin{array}{l}-.4097^{* * *} \\
(.0121)\end{array}$ & $\begin{array}{l}-.6047^{* * *} \\
(.0147)\end{array}$ & $\begin{array}{l}-.4151^{* * *} \\
(.0124)\end{array}$ & $\begin{array}{l}-.5961^{* * *} \\
(.0147)\end{array}$ & $\begin{array}{l}-.4187^{* * *} \\
(.0127)\end{array}$ & $\begin{array}{l}-.6030^{* * *} \\
(.0152)\end{array}$ & $\begin{array}{l}-.4151^{* * *} \\
(.0124)\end{array}$ & $\begin{array}{l}-.5919^{* * *} \\
(.0144)\end{array}$ & $\begin{array}{l}-.4187^{* * *} \\
(.0127)\end{array}$ & $\begin{array}{l}-.5988^{* * *} \\
(.0150)\end{array}$ \\
\hline Skills & & & $\begin{array}{l}.0249^{* * *} \\
(.0031)\end{array}$ & $\begin{array}{l}.0270^{* * *} \\
(.0033)\end{array}$ & $\begin{array}{l}.0215^{* * *} \\
(.0033)\end{array}$ & $\begin{array}{l}.0231^{* * *} \\
(.0034)\end{array}$ & $\begin{array}{l}.0249^{* * *} \\
(.0031)\end{array}$ & $\begin{array}{l}.0271^{* * *} \\
(.0033)\end{array}$ & $\begin{array}{l}.0215^{* * *} \\
(.0033)\end{array}$ & $\begin{array}{l}.0231^{* * *} \\
(.0034)\end{array}$ \\
\hline Age & $\begin{array}{l}-.0205 \\
(.0173)\end{array}$ & $\begin{array}{l}-.0380^{* *} \\
(.0177)\end{array}$ & $\begin{array}{l}.0345^{*} \\
(.0179)\end{array}$ & $\begin{array}{l}-.0237 \\
(.0203)\end{array}$ & $\begin{array}{l}.0353^{* *} \\
(.0179)\end{array}$ & $\begin{array}{l}-.0210 \\
(.0201)\end{array}$ & $\begin{array}{l}.0345^{*} \\
(.0179)\end{array}$ & $\begin{array}{l}-.0140 \\
(.0184)\end{array}$ & $\begin{array}{l}.0353^{* *} \\
(.0179)\end{array}$ & $\begin{array}{l}-.0111 \\
(.0181)\end{array}$ \\
\hline Age_Income & & & & & & & $\begin{array}{l}-.0011 \\
(.0118)\end{array}$ & $\begin{array}{l}.0040 \\
(.0147)\end{array}$ & $\begin{array}{l}-.0006 \\
(.0118)\end{array}$ & $\begin{array}{l}.0040 \\
(.0145)\end{array}$ \\
\hline Constant & $\begin{array}{l}8.5062 \\
(.3253)\end{array}$ & $\begin{array}{l}12.2261 \\
(.3587)\end{array}$ & $\begin{array}{l}7.6013 \\
(.3565)\end{array}$ & $\begin{array}{l}11.0252 \\
(.4122)\end{array}$ & $\begin{array}{l}76.773 \\
(.3599)\end{array}$ & $\begin{array}{l}11.1474 \\
(.4105)\end{array}$ & $\begin{array}{l}7.6013 \\
(.3565)\end{array}$ & $\begin{array}{l}10.8387 \\
(.3800)\end{array}$ & $\begin{array}{l}7.6773 \\
(.3599)\end{array}$ & $\begin{array}{l}10.9669 \\
(.3790)\end{array}$ \\
\hline \multicolumn{11}{|l|}{ Instrumented } \\
\hline $\begin{array}{l}\text { Income by the } \\
\text { Crisis }\end{array}$ & & Yes & & Yes & & Yes & & Yes & & Yes \\
\hline $\begin{array}{l}\text { Age_Income } \\
\text { by Age_Crisis }\end{array}$ & & & & & & & & Yes & & Yes \\
\hline Controls & & & & & Yes & Yes & & & Yes & Yes \\
\hline $\mathrm{R}^{2}$ & .47 & .39 & .49 & .37 & .50 & .41 & .49 & .41 & .50 & .42 \\
\hline Observations & 1,348 & 1,348 & 1,271 & 1,271 & 1,271 & 1,271 & 1,271 & 1,271 & 1,271 & 1,271 \\
\hline
\end{tabular}


Notes: The age range is from $11-15$. The reference age group is 11 . For the interaction of age and income, the age variable has been de-meaned and the income variable has been de-meaned. The control variables are if the child resides and goes to school in the Java and Bali Islands; if the child is in an urban area; the child's school type at the primary school level and junior high level and if the child is a girl or boy.

When the stock of skills variable is applied in specifications (17) and (24), we find that prior skills attained have the same small relationship with time investment as the relationship with financial investments. The coefficient size of 0.02 for OLS and IV is unchanged and is statistically significant at the $1 \%$ level. This is the same result when the control variables are added. This then strongly implies that the stock of human capital while important for investment decision making drives very little of current educational spending and amount of time allocated for schooling.

When we investigate which school ages within the junior high level are investment priorities in terms of the allocation of schooling time the results in the following Table 5.5 show a different distribution pattern compared to educational expenditures. 
Table 5.5 OLS \& IV-2SLS Complementarity of Time investments in Junior High

DV = Complementarity of Time Investments in Junior High given Income in Junior High and Skills from Primary School, 1997 and 2000 (SE for OLS and Robust SE for IV and IV-2SLS are in Parentheses)
(25)
(26)
(27)

(28)

\begin{tabular}{|c|c|c|c|c|}
\hline Explanatory Variables & OLS & IV-2SLS & OLS & IV-2SLS \\
\hline \multirow[t]{2}{*}{ Skills } & $.0243^{* * *}$ & $.0268^{* * *}$ & $.0213^{* * *}$ & $.0233^{* * *}$ \\
\hline & $(.0031)$ & $(.0033)$ & $(.0033)$ & $(.0034)$ \\
\hline \multirow[t]{2}{*}{ Age 12} & .1828 & .1432 & .1699 & .1165 \\
\hline & $(.1621)$ & $(.2047)$ & $(.1620)$ & $(.2111)$ \\
\hline \multirow[t]{2}{*}{ Age 13} & .1709 & .0196 & .1683 & .0144 \\
\hline & $(.1567)$ & $(.1967)$ & $(.1567)$ & $(.2026)$ \\
\hline \multirow[t]{2}{*}{ Age 14} & .2463 & .0945 & .2384 & .0829 \\
\hline & $(.1561)$ & $(.1967)$ & $(.1562)$ & $(.2031)$ \\
\hline \multirow[t]{2}{*}{ Age 15} & $.5504^{* *}$ & .1205 & .5464 & .1152 \\
\hline & $(.1771)$ & $(.2094)$ & $(.1775)$ & $(.2132)$ \\
\hline \multirow[t]{2}{*}{ Age 12_Income } & $-.4067^{* * *}$ & $-.6231^{* * *}$ & $-.4039^{* * *}$ & $-.6234^{* * *}$ \\
\hline & $(.0323)$ & $(.0448)$ & $(.0323)$ & $(.0445)$ \\
\hline \multirow[t]{2}{*}{ Age 13_Income } & $-.4448^{* * *}$ & $-.5968^{* * *}$ & $-.4472^{* * *}$ & $-.6034^{* * *}$ \\
\hline & $(.0214)$ & $(.0240)$ & $(.0215)$ & $(.0242)$ \\
\hline \multirow[t]{2}{*}{ Age 14_Income } & $-.4171^{* * *}$ & $-.5993^{* * *}$ & $-.4196^{* * *}$ & $-.6050^{* * *}$ \\
\hline & $(.0190)$ & $(.0239)$ & $(.0192)$ & $(.0242)$ \\
\hline \multirow[t]{2}{*}{ Age 15_Income } & $-.2268^{* * *}$ & $-.4726^{* * *}$ & $-.2334^{* * *}$ & $-.4863^{* * *}$ \\
\hline & $(.0628)$ & $(.0620)$ & $(.0631)$ & $(.0564)$ \\
\hline \multirow[t]{2}{*}{ Constant } & 1.6334 & 1.7149 & 1.6653 & 1.772 \\
\hline & $(.1837)$ & $(.2218)$ & $(.1873)$ & $(.2308)$ \\
\hline
\end{tabular}

Instrumented

Age 11_Income by Age 11_Crisis

Yes

Yes

Age 12_Income by Age 12_Crisis

Yes

Yes

Age 13_Income by Age 13_Crisis

Yes

Yes

Age 14_Income by Age 14_Crisis

Yes

Yes

Age 15_Income by Age 15_Crisis

Yes

Yes

Control Variables

Yes Yes

$\begin{array}{lllll}\mathrm{R}^{2} & .50 & .42 & .51 & .43 \\ \text { Observations } & 1,271 & 1,271 & 1,271 & 1,271\end{array}$

Statistically significant at the ${ }^{* *} 1 \%, * * 5 \%$ and $* 10 \%$ level 
Notes: The age range is from $11-15$. The reference age group is 11 . The results for age 11 (not reported) have a miniscule effect on the coefficient size for financial investments. For the interaction of each age and income, the variable for each age is represented by a dummy and the income variable has been demeaned. The control variables are if the child resides and goes to school in the Java and Bali Islands; if the child is in an urban area; the child's school type at the primary school level and junior high level and if the child is a girl or boy.

The interaction of each age 12,13,14 and 15 with income as instrumented by each age with the crisis show that time investment is uniformly increased across age 12, age 13 and 14. For each additional year of the child's age given an income reduction but only up to age 14 , time investment increases by approximately $0.4 \log$ points for OLS and $0.6 \log$ points for 2SLS. This is statistically significant at the $1 \%$ level. These coefficient magnitudes hold with and without control variables as can be seen in specifications (25) - (28) in Table 5.5. Given the difference between 0.4 for the OLS estimate and 0.6 for the 2SLS estimate, it is strongly inferred that $50 \%$ of the cross-sectional link between schooling time investments at age 12, age 13 and 14 and available income are caused by differences in income. The remaining $50 \%$ of the cross-sectional link is caused by differences in parental characteristics or differences in child characteristics. This suggests that there are parents who favor education and are less inclined for their children aged $12-14$ to allocate time for work or helping in the household. Likewise the children may be scholastically motivated and are more likely to spend more time studying. But the inclination to be in school more hours may be limited to high quality and affordable public schools. However there is a threshold at age 15 when time investment decision making changes. The OLS estimate reduces to $0.2 \mathrm{log}$ points and the 2SLS estimate reduces to $0.4 \log$ points and both are statistically significant at the $1 \%$ level. Schooling time compensates less for educational expenditures at age 15 compared to ages $12-14$ but the differences explaining for this remain as half for income and half for unobserved parental characteristics. This is reflected by 0.16 of the 2000 group dividing time between schooling and working. Also this investment behavior may perhaps be attributed to the two choices that a 15 year old has complete junior high and go on to senior high or complete junior high and enter the labor force.

\subsection{Conclusions}

Optimal parental investments in education depend on an evaluation of upfront costs and delayed benefits. If education was only viewed as a consumption good, income would determine optimal investments. In the Indonesian context of incomplete credit markets, we find that there is a causal interpretation between reduced income and financial investments in education. Using repeated cross sections from 1997 and 2000, 80\% of the cross sectional link between income and educational spending is caused by differences in income. The remaining $20 \%$ is 
caused by unobserved parental characteristics or unobserved child characteristics. Our findings also show that the $50 \%$ of cross sectional link between income and time investment in education is caused by differences in income. Financial investments and time investments in education compensate for each other when household income is reduced. But this appears to only be for higher ability children who have completed primary school and selected to enter junior high. This does not appear to be the case for lower ability children in junior high where educational expenditures and schooling time do not compensate each other.

This chapter has also shown that due to the dynamic complementarity of skills attained the reduction in educational expenditures is much lower for children who have already attained a few years of junior high education. This implies that parents do take into account the loss in returns related to previous investments on the stock of human capital accumulated. Put another way, parents do face a loss aversion where sunk costs do matter. But at age 15 the final year of junior high and the minimum legal age for employment, the reduction in expenditures is far greater than for the earlier grades of junior high. This suggests that the child may enter the labor force and have earning opportunities that match the skills accumulated up to junior high. As households bear up to $60 \%$ of the total educational cost, low income households may assess that going on to senior high may entail costs that far outweigh market earning opportunities. As pointed out in the literature on educational investment in developing countries, parents may view the market value of schooling up to a certain school level and in the context of Indonesia this may possibly be at junior high. Hence for low income households, educational investments may then be sub-optimal.

The conclusions that we draw here is that monetary constraints drive schooling decisions for Indonesian children at the junior high level. This is not the case at the primary school level which is heavily subsidized by central and regional government. Parents make sub-optimal investments when they equate the direct and opportunity costs of education with future benefits up to only the junior high level and not at higher levels of education. However, there are parents with children of higher ability who are favorably pre-disposed to higher education where they make investments in both time and money. The parents who are scholastically motivated are then inclined for their children to go on to higher levels of education. But for lower income households with lower ability children, junior high becomes the level at which children may end up working pre-maturely instead of gaining more education. The longer term consequence is then that in adulthood they will have a lower stock of human capital and will be unable to compete in the labor market against others with higher ability and higher education levels. 


\section{Main Findings and Implications}




\subsection{Main Findings}

Education is considered to be very important for economic growth. But family investments in education are much lower in developing countries compared to developed countries. This leads to the question whether families in developing countries have a low preference to invest and whether the market rates of return are very low; or that there are actually constraints to investment.

The aim of this dissertation has been to investigate whether families in developing countries face actual constraints to investing in their children's human capital.

Empirically we have determined two main constraints to educational investment in the Indonesian developing country context: resource constraints on basic facilities we used the access to and use of electricity for studying; and monetary constraints as captured by family income. This empirical work is covered in four chapters. The method that we have used to determine these two main constraints on investment in basic education is the natural experiment or a comparative method focusing on Indonesian families over two periods, 1997 and 2000 where the Asian Financial Crisis occurred in 1998 and 1999.

The main findings in Chapter 2 are that in response to an income reduction, families used various ways to ensure that their children continued their education in primary school and junior high. Parents' adaptive strategies were to shift their children from high quality formal education to low quality non-formal and informal school; maintained a scheduled monthly flow of fees / contributions to keep the school operational or risk their children being withheld from school; trading off timely monthly flow payments by reducing spending on school expenditures at the intensive margin such as school uniforms and sports equipment; and only high ability children on the basis of test scores were selected to transition from formal primary school to formal junior high. An additional finding is that there are regional geographical patterns to the different school types that children attended before and after the Asian Financial Crisis.

In Chapter 3, the main findings stem from investigating the regional patterns in schooling across the Indonesian archipelago. 12 year old children who have more access to electricity have better educational performance. The potential pathway between the availability of electricity and test score performance is via how children use electricity in school and in the household to improve learning efficiency. However given the fixed placement of the national electricity grid which pre-dominates in Java and Bali Islands, children in economically developed areas have higher test score performance than disadvantaged children in 
underdeveloped, lagging behind areas. The regional distribution of electricity is an inherent resource constraint for schooling and learning. The lack of access to electricity is viewed as a non-monetary resource constraint on education as family income has a minimal influence on how the state distributes electricity.

The main findings in Chapter 4 are that there are children who are pre-disposed to working from as young as age 6 and then starting to attend school and they continue to work more as they become older. Work manifests itself in terms of working within the household for the family (e.g. household chores or farm work) or outside of the household for wages or in-kind transfers. Children especially boys work more hours outside the household and for wages when they are older than 12. We find that simultaneous work-schooling behavior does not interrupt schooling and does not impair human capital accumulation as much as would have been expected. However child workers who attend non-formal school with flexible hours that cater to their work patterns; and children who work as family apprentices have lower qualifications than children in the formal education system. This increases the probability of poor formal labor market outcomes later in life. But child apprentices appear to be able to continue the traditional family trade which may be viewed as having a high social return.

In Chapter 5, the main findings are that there exists a relationship between family income and educational investment in Indonesia. A reduction in family income reduces the amount used to finance schooling in junior high but this is compensated by an increase in the amount of time invested in schooling and learning. Despite reduced incomes, the family is not likely to terminate schooling and this is as described in Chapter 2. Optimal education investment does include accounting for the loss in returns from previous investments on the stock of human capital that has been accumulated. Put another way, parents do face a loss aversion where sunk costs do matter. Using repeated cross sections from 1997 and 2000, we find that about $80 \%$ of the cross-sectional link between income and educational expenditures is caused by differences in income. The remaining $20 \%$ is related to unobserved parental characteristics. Strong influences for complementing prior educational investment are when the child is close to completing junior high as opposed to having just started junior high; and when the child has high cognitive ability on the basis of prior primary school test scores.

\subsection{Implications}

The central finding of this dissertation is that families in developing countries do not have a lower preference for education; but rather they are confronted with resource constraints - the lack of school quality; and income constraints. Because 
families are constrained, we will argue that policymakers can look at different ways apart from educational financing and the formal educational system to increase human capital. It is our position that understanding the social and economic status of individual families and the constraints they face plays an important role in educational policymaking.

Developing country governments tend to intervene in the provision of education by building more schools, increasing the number of qualified teachers and providing scholarships to disadvantaged children. Yet in the Indonesian context, since 1997 when the Asian Financial Crisis occurred, the percentage of children who complete a full course of 9 years of primary school and junior high has steadily fallen from $75 \%$ in 1997 to $52.6 \%$ in 2001 . Because of the main constraints to educational investment, we posit that different families by social and economic status have a different calculus of decision making. While in normative terms, parental financing of education is meant to improve the child's labor market outcomes in adulthood, developing country families consider far more factors. The calculus of decision making is most likely not about progressing from one school grade to another. Instead the factors under consideration are concerned with progressing from one school level to another. Given the evidence provided in this dissertation, these factors are regional geographical constraints on school quality; joint work-schooling starting from age 6 until age 15 at the end of junior high when they can legally enter the labor market fulltime; and whether the children have the cognitive skills to merit investment in education in senior high and university.

While near universal primary school education has been achieved, we posit that if there is a clear understanding of the factors and constraints that families face when their children are about to transition from primary school to junior high, there is a higher likelihood that they will achieve all 3 years of schooling at junior high. That is, the battleground to be fought for achieving 9 years of universal basic education is at the junior high level. The battleground is no longer at the primary school level. The school resource constraints and income constraints are likely to be tightest when the child is aged $12-15$. If the child has attended 6 years of primary school in an underdeveloped, lagging behind village with only basic infrastructure, the family may choose for the child to drop out. The school and home environment may not be conducive for continued education at the junior high level. If a child who is accustomed to working since age 6 and has turned 12 after completing primary school, the child may be more likely to work more and attend school less. This is because the child especially a boy working in an urban area may have a higher relative value of time for working rather than attend a low quality school, learning little. But there is evidence that once a child has started a few years of junior high through ages 13 and 14, parents are more likely to continue financing the child's education until junior high is completed. By concentrating on the 
educational choices that families make during this at risk period of three years of junior high, policymakers are likely to be more successful in increasing schooling attainment.

There are various concrete ways to relax these constraints on educational investment. The resource constraint on basic facilities such as electricity access can be relaxed when the state increases the distribution of electricity for school and household use. This will mean redistributing energy capacity away from industrial and transport use. This can be carried out as a part of the country's redistribution program that reduces not just income inequality but schooling inequalities. The family income constraint can be less tight when the state disproportionately increases student scholarships and expenditures for junior high schools when the child is aged 13 in grade 8 and aged 14 in grade 9 . Since there is evidence that families substitute lower educational expenditures with higher time allocated for studying, increasing electricity access in the school and household increases the number of hours that a child can choose to use for learning activity. Hence, it is possible to cogitate that educational investment constraints may interact and that relaxing one loosens the other constraints.

Because of unobserved ability that may perhaps include less scholastic motivation, there will be children who are less likely to complete a full course of 9 years of basic education in the formal education system. These are children who are child workers or apprentices who have gained marketable skills from young by learning on the job. There is evidence of children who self-select out of the formal education system and opt for non-formal and informal schooling. For this group of children, school resource constraints and income constraints may not be the main factors restricting decision making. Their families may view their children's relative value of time to be higher in market work and household production compared to formal schooling. By recognizing these family perspectives, educational policymakers particularly in Indonesia should continue to expand on non-formal and informal schooling choices for this group of children. Based on our knowledge, Indonesia is the only developing country in the world to have a national educational system that provides schooling alternatives for child workers. These schooling alternatives guarantee that economically active children receive some form of schooling regardless of whether they work by choice or because they are forced to. As akin to the Coleman Report and arguments made by Heckman and Lochner (1999), our position is about rethinking how education and training can be used to build socially productive skills and not just marketable skills in the formal sector. For example, a child apprentice from a fishing family in Indonesia may be able to carry on with the family tradition passing skills from one generation to another. This tradition may perhaps be protected when the child receives modern technical skills training to complement existing skills learnt on the job. 
In forthcoming work, we will reconcile the educational choices of children in the formal and alternative schools and examine their longer term educational and labor market outcomes. New available IFLS data in 2007 will enable us to investigate how family decision making over the period of the Asian Financial Crisis affects later outcomes. While the effects of the financial crisis washed away relatively quickly at the macroeconomic level, we would like to investigate if there are longer term consequences in the labor market and within society. 


\section{Bibliography}

Alatas, Vivi (2000) "Evaluating the Left Behind Villages Program in Indonesia: Exploiting Rules to Identify Effects on Employment and Expenditures" Ph. D. thesis, Princeton University

Aguiar, Mark and Hurst, Erik (2005) "Consumption vs. Expenditure" Journal of Political Economy 113:5, pp. 919 - 948

Bacalod, Marigee P. and Tobias, Justin L. "School, School Quality and Achievement Growth: Evidence from the Philippines" Economics of Education Review 25 (2006) pp. $619-632$

Baland, Jean-Marie and Robinson, James A “Is Child Labor Inefficient?" The Journal of Political Economy, Vol. 108, No. 4 (Aug., 2000), pp. 663-679

Basu, Kaushik, Das Sanghamitra and Dutta Bhaskar (2007), “Child Labor and Household Wealth: Theory and Empirical Evidence of an Inverted-U" Working Paper No. 139 (Bureau for Research and Economic Analysis of Development Working Paper, Cambridge MA)

Bayhaqi, Akhmad, 2007 "Education and Economic Growth in Indonesia" PhD Dissertation, National University of Singapore

Bedi, Arjun and Marshall, Jeffrey "Primary School Attendance in Honduras" Journal of Development Economics 69 (2002) pp. 129 - 153

Becker, Gary S. 1964 "Human Capital: A Theoretical and Empirical Analysis with Special Reference to Education" New York: Columbia University Press

Belley, Philippe and Lochner, Lance "The Changing Role of Family Income and Ability in Determining Educational Achievement", Journal of Human Capital, 1(1) winter 2007 pp. 37-89

Behrman, Jere R., and Birdsall, Nancy 1983. "The Quality of Schooling: Quantity Alone is Misleading." American Economic Review 73(5) pp. 928-46

Browning, Martin "Children and Household Economic Behavior" Journal of Economic Literature, Vol. 30, No. 3, (Sep, 1992), pp. 1434 - 1475 
Cameron, Lisa A and Worswick, Christopher, 2001. "Education Expenditure Responses to Crop Loss in Indonesia: A Gender Bias" Economic Development and Cultural Change University of Chicago Press, vol. 49(2), pp. 351-63

Card, David and Krueger, Alan B. (1992) “Does School Quality Matter? Returns to Education and the Characteristics of Public Schools in the United States" Journal of Political Economy, 100(1), pp. 1 - 40

Caucutt, Elizabeth M. and Lochner, Lance J. "Early and Late Human Capital Investments, Borrowing Constraints and the Family" University of Western Ontario, Working Paper 2008

Carneiro, Pedro and Heckman, James J. (2003) “Human Capital Policy” Working Paper 9495, National Bureau of Economic Research

Coleman, James S. "Equality of Educational Opportunity (Coleman) Study (EEOS)" 1966. ICPSR06389-v3. Ann Arbor, MI: Inter-university Consortium for Political and Social Research

Cunha, Flavio and Heckman, James J. "The Economics and Psychology of Inequality and Human Development" Journal of the European Economic Association April-May 2009 7(2-3) pp. 320-364

Cunha, Flavio and Heckman, James J. (2007) "The Technology of Skill Formation" American Economic Review, 97(2), pp. 31 - 47

Cunha, Flavio, Heckman, James J., Lochner, Lance and Masterov, Dimitri V. "Interpreting the Evidence on Life Cycle Skill Formation" National Bureau of Economic Research Working Paper 11331, May 2005

Energy Information Administration, Department of Energy, US Government http://www.eia.doe.gov/emeu/international/contents.html

Daroesman, Ruth "Finance of Education" Bulletin of Indonesian Economic Studies December 1971, Pt. 1, pp. 61 - 95

Deaton, Angus "Understanding Consumption (Clarendon Lectures in Economics)" USA: Oxford University Press, 1993

Deaton, Angus (1989) "Savings in Developing Countries: Theory and Review" Proceedings of the World Bank, Annual Conference on Development Economics, Washington DC 
Department of Education and Culture, Directorate-General of Primary and Secondary Education and Department of Religious Affairs, Directorate of Islamic Institutions (September 1998) "Program Implementation Plan: Scholarship \& Block Grant Program for Primary and Secondary Schools"

Diamond, Jared and Robinson, James A. “Natural Experiments of History” Cambridge: Harvard University Press, 2010

Duflo, Esther (2001) "Schooling and Labor Market Consequences of School Construction in Indonesia: Evidence from an Unusual Policy Experiment" American Economic Review, 91(4), pp. 795 - 813

Edmonds, Eric V. "Child Labor" in Schultz, T. Paul and Strauss, John (eds.) Handbook of Development Economics Volume 4 Elsevier B.V: Amsterdam, 2008

Foster, Andrew and Rosenzweig Mark, "Household Division and Rural Economic Growth". Review of Economic Studies (2002) pp. 839-69

Frankenberg, Elizabeth and Thomas, Duncan "The Indonesia Family Life Survey (IFLS): Study Design and Results from Waves 1 and 2". March, 2000. DRU-2238/1NIA/NICH

Gentzkow, Matthew and Shapiro, Jesse M. "Preschool Television Viewing and Adolescent Test Scores: Historical Evidence from the Coleman Study" The Quarterly Journal of Economics, February 2008

Glewwe, Paul and Kremer, Michael "Schools, Teachers and Education Outcomes in Developing Countries" chapter in Hanushek Eric A. and Welch, Finis (eds) the Handbook of the Economics of Education Volume 2, Elsevier B.V.: Amsterdam (2006)

Glewwe, Paul and Hanan, Jacoby (1994) "Student Achievement and Schooling Choice in Low-Income Countries: Evidence from Ghana," Journal of Human Resources, 29(3) pp. 843-864

Harbinson Ralph.W and Hanushek, Eric A. (1992) "Educational Performance of the Poor: Lessons From Rural Northeast Brazil" Oxford University Press, New York

Hanushek, Eric. A "School Resources" chapter in Hanushek Eric A. and Welch, Finis (eds) the Handbook of the Economics of Education Volume 2, Elsevier B.V.: Amsterdam (2006) 
Hanushek, Eric. A “Interpreting Recent Research on Schooling in Developing Countries." World Bank Research Observer 10 (August, 1995) pp. 227-46

Hanushek, Eric A. and Wößmann, Ludger "Education and Economic Growth" chapter in the International Encyclopedia of Education, 3 ${ }^{\text {rd }}$ Edition (2008)

Hanushek, Eric A., Lavy, Victor and Hitomi, Kohtaro (2008) “Do Students Care about School Quality? Determinants of Dropout Behavior in Developing Countries?" Journal of Human Capital Vol.21 pp. 69 - 105

Heckman, James J. and Lochner, Lance "Rethinking Myths about Education and Training: Understanding the Sources of Skill Formation in a Modern Economy," in S. Danziger and J. Waldfogel (eds.), Securing the Future: Investing in Children from Birth to College, Russell Sage Foundation: New York, 2000

Hill, Hal "Regional Development in a Boom and Bust Petroleum Economy: Indonesia since 1970" Economic and Cultural Change, Vol. 40, No. 2 (Jan 1992), pp. $351-379$

Hill Hal, Resosudarmo Budy P. and Vidyattama Yogi "Indonesia's Changing Economic Geography" Bulletin of Indonesian Economic Studies 2008, Vol. 44 Issue 3, pp. $407-435$

Jalal Fasli et al (2003) “National Plan of Action: Indonesia's Education for All 2003 2015" Jakarta: National Coordination Forum

Jones, Gavin and Hagul, Peter (2001) "Schooling in Indonesia: crisis-related and longer-term issues" Bulletin of Indonesian Economic Studies, Vol. 37, pp. 207-231

Krueger, Alan B. and Lindahl, Mikael "Education for Growth: Why and For Whom" Journal of Economic Literature, Vol. 39, No. 4 (Dec, 2001), pp. 1101 - 1136

Kremer, Michael, Karthik Muraldhiran, Nazmul Chaudhury, Jeffrey Hammer, and F. Hasley Rogers (2005) "Teacher Absence in India: A Snapshot," Journal of the European Economic Association.

Lockheed, Marlaine E., and Adriaan Verspoor. 1991 "Improving Primary Education in Developing Countries" New York: Oxford University Press

Levine, David I. and Minnie Ames (2003) "Gender Bias and the Indonesian Financial Crisis: Were Girls Hit Hardest?" CIDER Working Paper No. C03-130. Berkeley CA: University of California 
Levinsohn, James; Berry, Steven and Friedman, Jed (1999) "Impacts of the Indonesian Economic Crisis: Price Changes for the Poor" Working Paper 7194, National Bureau of Economic Research

Muins, Sutan Makmur "Studi Kondisi Linkungan Tempat Kerja Pekerja Anak di Sektor Perkebunan dan Industri" Ministry of Manpower and Transmigration of the Republic of Indonesia, 2004

Niehof, Anke and Lubis, Firman "Two is Enough: Family Planning in Indonesia under the New Order" Leiden: KITLV Press, 2003

Newhouse, David and Beegle, Kathleen "The Effect of School Type on Academic Achievement: Evidence from Indonesia" World Bank Policy Research Working Paper 3604, May 2005

Olken, Benjamin (2009) “Do TV and Radio Destroy Social Capital? Evidence from Indonesian Villages," American Economic Journal: Applied Economics, American Economic Association, vol. 1(4), pp. 1-33

Perdana, Ari A. and Maxwell, John "Poverty Targeting Indonesia: Programs, Problems and Lessons Learned" Asian Development Bank Institute Working Paper Series 083, 2004

Psacharopoulos, George, and Harry A. Patrinos. 2004. "Returns to Investment in Education: A Further Update." Education Economics 12 (August), pp. 111-34

Psacharopoulos, George. 1994. "Returns to Investment in Education: A Global Update." World Development 22 (September) pp.1325-44

Rosen, Sherwin "Human Capital" chapter in The New Palgrave: Social Economics London and Basingstoke: Macmillan Press, 1989

Sparrow, Robert "Protecting the Education of the Poor in the Time of Crisis" Oxford Bulletin of Economics and Statistics 69, 1 (2007), pp. 99 - 123

Strauss, J., K. Beegle, B. Sikoki, A. Dwiyanto, Y. Herawati and F. Witoelar. "The Third Wave of the Indonesia Family Life Survey (IFLS3): Overview and Field Report". March 2004. WR-144/1-NIA/NICHD

$\mathrm{Su}$, Xuejuan (2004) "The allocation of public funds in a hierarchical educational system" Journal of Economic Dynamics and Control, 28 pp. 2485-2510 
Suryadarma Daniel, Suryahadi Asep and Sumarto Sudarno "Causes of Low Secondary School Enrollment in Indonesia" SMERU Working Paper, August 2006

Suryahadi Asep and Sumarto Sudarno and Pritchett Lant "Targeted Programs in an Economic Crisis: Empirical Findings from the Experience of Indonesia', SMERU Working Paper, October 2002

Witoelar, Firman "Intra-Household Differences in Education and Home Leaving in Indonesia" ASEAN Economic Bulletin Vol.23, No.1 (2006), pp.75 - 97

World Bank Independent Evaluation Group. 2006. "From Schooling Access to Learning Outcomes: An Unfinished Agenda. Washington: World Bank

World Bank Energy and Mining Sector Unit East Asia and Pacific Region (2003) "Project Appraisal Document on a Proposed Loan in the Amount of US\$140 Million to the Republic of Indonesia for a Java-Bali Restructuring and Strengthening Project" 


\section{Summary in Dutch}

\section{Samenvatting}

Onderwijs wordt gezien als erg belangrijk voor economische groei. Maar gezinnen in ontwikkelingslanden investeren veel minder in onderwijs in vergelijking met gezinnen uit ontwikkelde landen. Dit leidt tot de vraag of gezinnen in ontwikkelingslanden een lage prioriteit aan investeringen geven, de opbrengst van de investeringen laag is of dat de mogelijkheid om te investeren beperkt wordt.

Het doel van dit proefschrift is te onderzoeken of gezinnen in ontwikkelingslanden geconfronteerd worden met beperkingen om te investeren in de ontwikkeling van het menselijk kapitaal van hun kinderen. We onderzoeken empirisch twee mogelijke beperkingen van de investering in het onderwijs van Indonesië als ontwikkelingsland. Allereerst de beperking op het gebied van basisfaciliteiten, hiervoor gebruiken we de toegang tot en het gebruik maken van elektriciteit voor onderwijs. Daarnaast kijken we naar de monetaire beperking die tot uitdrukking komt in de hoogte van het gezinsinkomen. Dit empirisch onderzoek beslaat 4 hoofdstukken. Om het effect van inkomen op investeringen in onderwijs te bepalen gebruiken we de Aziatische Financiële Crisis als een natuurlijk experiment dat de inkomens van Indonesische gezinnen beïnvloedde tussen 1997 en 2000, waarbij de crisis in de tussenliggende jaren 1998 en 1999 plaatvond. Om de invloed van toegang tot electriciteit op onderwijsinvesteringen te meten vergelijken we verschillende regio's in Indonesië.

De belangrijkste bevindingen in hoofdstuk twee zijn, dat in een reactie op een inkomensdaling, gezinnen verschillende manieren vinden om er voor te zorgen dat hun kinderen het basisonderwijs en de eerste drie jaar van het middelbaar onderwijs kunnen blijven volgen. Ouders kiezen ervoor om hun kinderen in plaats van officiële scholen van hoge kwaliteit naar kwalitatief mindere informele scholen te sturen naar lage kwaliteit niet formeel onderwijs of naar een informele school; onderhouden een geregelde maandelijkse stroom van vergoedingen en bijdragen om de school te kunnen bekostigen en daarmee te voorkomen dat de kinderen niet naar school kunnen gaan. Om deze maandelijkse contributie te kunnen betalen wordt er minder besteedt aan de eenmalige kosten voor een schooljaar, zoals schooluniformen en sportuitrustingen. Daarnaast krijgen alleen kinderen met goede leercapaciteiten, op basis van behaalde testscores, de mogelijkheid om de overgang te maken van formeel basisonderwijs naar de eerste drie jaar van de formele middelbare school. Een additionele bevinding is dat er regionale 
geografische patronen te herkennen zijn in de verschillende schoolsoorten waar kinderen naar toe gaan, voor en na de Aziatische financiële crisis.

Hoofdstuk drie gaat in op de de regionale patronen in onderwijs in de Indonesische archipel. Kinderen van twaalf jaar, die meer toegang tot elektriciteit hebben, presteren beter op school. Dit verband tussen de beschikbaarheid van elektriciteit en de testscores op school kan mogelijk verklaard worden doordat het gebruik van elektriciteit op school en thuis de efficiëntie van het leren verbetert. Uitgaande van het bestaande elektriciteitsnetwerk, voornamelijk goed ontwikkeld op Java en Bali, blijkt dat kinderen in economisch ontwikkelde gebieden hogere testscores halen op school vergeleken met kinderen in economisch onderontwikkelde gebieden die achter lopen. De regionale distributie van elektriciteit is een inherente beperking voor scholing en leren. Het gebrek aan toegang tot elektriciteit wordt gezien als een niet-monetaire invloed op onderwijs, aangezien het gezinsinkomen een minimaal effect heeft op de verdeling van de elektriciteit door de overheid.

In hoofdstuk vier vinden we dat er kinderen zijn die voorbestemd zijn om al op jonge leeftijd, vanaf zes jaar, te werken en op het moment dat ze naar school gaan, naarmate ze ouder worden steeds meer gaan werken. Bij werk moeten we dan denken aan werken binnen het huishouden (bijvoorbeeld huishoudelijke werk of werk op de boerderij) of buiten het huishouden voor loon of beloning in natura. Kinderen, vooral jongens, werken meer uren buiten het huishouden en voor loon, als ze de leeftijd van twaalf jaar hebben bereikt. We vinden dat de combinatie van school met werken niet zorgt voor een onderbreking van de scholing en minder schadelijk is voor de ontwikkeling van het menselijke potentieel dan gedacht. Echter kinderen die werken en naar een informele school gaan met flexibele uren, die inspelen op hun werktijden en kinderen die het vak leren binnen het gezin, behalen een diploma op een lager niveau dan kinderen in het formele onderwijs systeem. Dit verhoogt de kans om op latere leeftijd een slechte arbeidsmarktpositie in te nemen. Kinderen die het vak van de ouders leren lijken in staat te zijn om de traditionele familiezaak voort te zetten, wat kan worden beschouwd als een vorm van een hoog sociaal rendement.

De belangrijkste bevindingen in hoofdstuk vijf zijn dat er in Indonesië een relatie bestaat tussen het gezinsinkomen en de investeringen in onderwijs. Een verlaging van het gezinsinkomen vermindert de hoeveelheid financiële investering in de eerste drie jaar van de middelbare school, maar dit wordt gecompenseerd door een toename in de hoeveelheid tijd die geïnvesteerd wordt in scholing en leren.

Ondanks een vermindering in inkomen is het niet waarschijnlijk dat het gezin de scholing beëindigt, de reden daarvoor is eerder beschreven in hoofdstuk twee. Met behulp van herhaalde dwarsdoorsneden van 1997 en 2000, vinden we dat ongeveer $80 \%$ van het cross-sectionele verband tussen inkomen en de uitgaven voor 
onderwijs wordt veroorzaakt door verschillen in inkomen. De resterende $20 \%$ is gerelateerd aan de niet waargenomen kenmerken van de ouders. Sterke invloeden om eerdere investeringen in onderwijs ondanks het lagere inkomen aan te vullen, zijn er vooral wanneer het kind dicht bij het afronden van zijn middelbare school is, in tegenstelling tot de tijd wanneer het kind net begint met de middelbare school. En er is sprake van sterke invloed als het kind hoge cognitieve capaciteiten wordt toegedicht op basis van testscores op de basisschool.

\section{Implicaties}

De belangrijkste conclusie van dit proefschrift is dat gezinnen in ontwikkelingslanden niet beschikken over een lagere voorkeur voor het onderwijs; maar zij worden geconfronteerd met beperkte middelen - het gebrek aan kwaliteit van een school; en inkomensbeperkingen. Omdat gezinnen tegen beperkingen aanlopen adviseren we beleidsmakers om naar andere manieren dan financiering van onderwijs en het formele onderwijssysteem te kijken om het menselijk potentieel te vergroten. Het is ons standpunt dat inzicht in de sociale en economische status van individuele gezinnen en de beperkingen waarmee zij worden geconfronteerd een belangrijke rol speelt in de beleidsvorming voor het onderwijs.

Regeringen van ontwikkelingslanden hebben de neiging in te grijpen in het aanbod van onderwijs door het bouwen van meer scholen, uitbreiding van het aantal gekwalificeerde docenten en het verstrekken van studiebeurzen aan kansarme kinderen. Als we kijken naar de Indonesië, sinds 1997 en het begin van de Aziatische financiële crisis, blijkt dat het aantal kinderen dat de volledige 9 jaar van basisschool en drie jaar middelbare school afmaakt gestaag daalt van 75\% in 1997 tot $52,6 \%$ in 2001. Vanwege de belangrijkste belemmeringen voor investeringen op onderwijsgebied, stellen we dat verschillende families door de sociale en economische status een andere manier van besluitvorming hebben. Terwijl in normatieve termen de financiering van onderwijs door de ouders bedoeld is om de arbeidsmarktpositie van het kind op latere volwassen leeftijd te verbeteren, blijken gezinnen in ontwikkelingslanden veel meer factoren in ogenschouw te nemen. De manier van besluitvorming is waarschijnlijk niet gericht op de overgang naar de volgende klas, maar de factoren die een rol spelen zijn gericht op het behalen van het volgende niveau. De verstrekte gegevens in dit proefschrift bewijzen dat deze factoren zijn de regionale geografische beperkingen op de kwaliteit van een school; combinatie van werken en school vanaf de leeftijd van zes jaar tot aan het eind van drie jaar middelbare school wanneer de kinderen met de leeftijd van vijftien jaar legaal fulltime kunnen gaan werken; en of de kinderen voldoende cognitieve vaardigheden hebben om investeringen in onderwijs in de laatste drie jaar middelbare school en universiteit te verantwoorden. 
We stellen dat als bij het bijna voltooien van de basisschool er een duidelijk inzicht is in de factoren en beperkingen waarmee gezinnen te maken krijgen wanneer hun kinderen de overgang maken van basisschool naar middelbare school, er een hogere kans is dat de eerste drie jaar van de middelbare school worden afgemaakt. Het grootste knelpunt om negen jaar basisopleiding te verkrijgen ligt niet op de basisschool maar op de middelbare school. Gedurende de leeftijdsfase van twaalf tot vijftien zijn de beperkingen voor school en inkomen het grootst. Als een kind zes jaar basisschool heeft gehad in een dorp met beperkte infrastructuur in een achtergebleven gebied is de kans het grootst dat de familie zal besluiten om te stoppen met het onderwijs. Zowel de school als de leefomgeving is niet ideaal voor het voortzetten van het onderwijs op de middelbare school. Als een kind gewend is om te werken vanaf zijn zesde en met twaalf jaar zijn basisschool afmaakt, dan is het waarschijnlijker dat het kind meer gaat werken en minder naar school zal gaan. Dat komt omdat een kind, vooral een jongen, in een stadsomgeving een hogere relatieve waarde zal hechten aan tijd voor werk dan aan tijd voor een lagere kwaliteit school, waar hij niet veel zal leren. Er is echter bewijs te vinden voor de veronderstelling dat als een kind een paar jaar middelbare school heeft gevolgd tot de leeftijd van dertien of veertien jaar, het voor ouders steeds logischer is om de opleiding van hun kind te blijven financieren tot het afronden van het derde jaar middelbare school. Door te concentreren op de onderwijskeuzes die gezinnen moeten maken in deze risicovolle periode van de eerste drie jaar van de middelbare school, kunnen beleidsmakers succesvoller zijn in het verbeteren van de leerprestaties. 


\section{Biography}

Treena $\mathrm{Wu}$ was born in Kuala Lumpur, Malaysia on 19 ${ }^{\text {th }}$ August 1971. She graduated from Raffles Junior College, Singapore in 1989.

After completing college in Monash University, Melbourne in 1994, she started working in corporate America at DuPont. Being utterly disillusioned with multinational corporation life, she left DuPont in 1998 and entered international civil service at the United Nations. She worked as a portfolio associate at UNOPS / UN Development Program in the Asia Office. She implemented community development projects in various countries in South Asia and South East Asia.

In January 2002, she started graduate school at New York University (NYU), New York City. At the Wagner School of Public Service, she specialized in public policy and economics. After completing her Masters in 2004, she went on to the PhD program in NYU. She dropped out after getting married and moved to Geneva, Switzerland. In Geneva, she worked for humanitarian aid agencies.

She resumed writing her PhD in September 2006 at Maastricht University where she was awarded a European Commission Marie Curie Fellowship. Her research in labor economics focused on human capital theory and family transfers in Indonesia. She carried out fieldwork and presented at conferences with the support of the Netherlands Organization for Scientific Research (NWO-WOTRO), Agence Française de Développement (the French Development Agency) and the World Bank. In January 2010, she stayed at the Department of Economics, University of California at Berkeley to complete her dissertation.

From September 2010 onwards, Treena is employed as Post-Doctoral Research Fellow at the joint Duke University and National University of Singapore. She is expanding her research on family transfers to intergenerational transfers. 


\section{Maastricht Graduate School of Governance Dissertation Series}

Pascal Beckers

Local space and economic success: The role of spatial segregation of migrants in the Netherlands

MGSOG Dissertation Series, nr. 12 (2011)

Victor Cebotari

Conflicting Demands in Ethnically Diverse Societies

Ethnopolitical Contention and Identity Values in Europe

MGSOG Dissertation Series, nr. 11 (2010)

Dennis Gyllensporre

Competing and Complementary Perspectives on the EU as a Crisis Management Actor: An Examination of the Common Security and Defence Policy through the Lens of Idealism and Realism

MGSOG Dissertation Series, nr. 10 (2010)

Judit Vall Castello

Business Cycle and Policy Effects on Labor Market Transitions of Older and Disabled

Workers in Spain

MGSOG Dissertation Series, nr. 9 (2010)

Keetie Roelen

False Positive or Hidden Dimensions: the definition and measurement of child poverty MGSOG Dissertation Series, nr. 8 (2010)

Denisa Sologon

Earnings Dynamics in Europe

MGSOG Dissertation Series, nr. 7 (2010)

Melissa Siegel

Money and Mobility: Migration and Remittances

MGSOG Dissertation Series, nr. 6 (2010)

Jessica Hagen-Zanker

Modest Expectations: Causes and effects of migration on migrant households in source countries

MGSOG Dissertation Series, nr. 5 (2010) 
Mirtha Muniz Castillo

Human Development and Autonomy in Project Aid: Experienecs from four bilateral projects in Nicaragua and El Salvador

MGSOG Dissertation Series, nr. 4 (2009)

Christiane Arndt

Governance Indicators

MGSOG Dissertation Series, nr. 3 (2009)

Britta Augsburg

Microfinance - Greater Good or Lesser Evil?

MGSOG Dissertation Series, nr. 2 (2009)

Geranda Notten

Measuring and Managing Poverty Risks

MGSOG Dissertation Series, nr. 1 (2008) 